Universidad de Lima

Facultad de Comunicación

Carrera de Comunicación

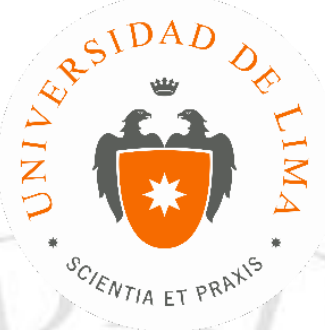

\title{
USOS DE LA COMUNICACIÓN PARA EL FORTALECIMIENTO DE CAPACIDADES EN CONTEXTO DE PREVENCIÓN DE CONFLICTOS SOCIOAMBIENTALES. CASO TARPURISUNCHIS, APURÍMAC
}

Trabajo de investigación para optar el Título Profesional de Licenciado en Comunicación

\section{Nancy Carolina Mayna Flores}

Código 20092428

Asesora

Estela Roeder Carbo

Lima - Perú

Julio de 2017 


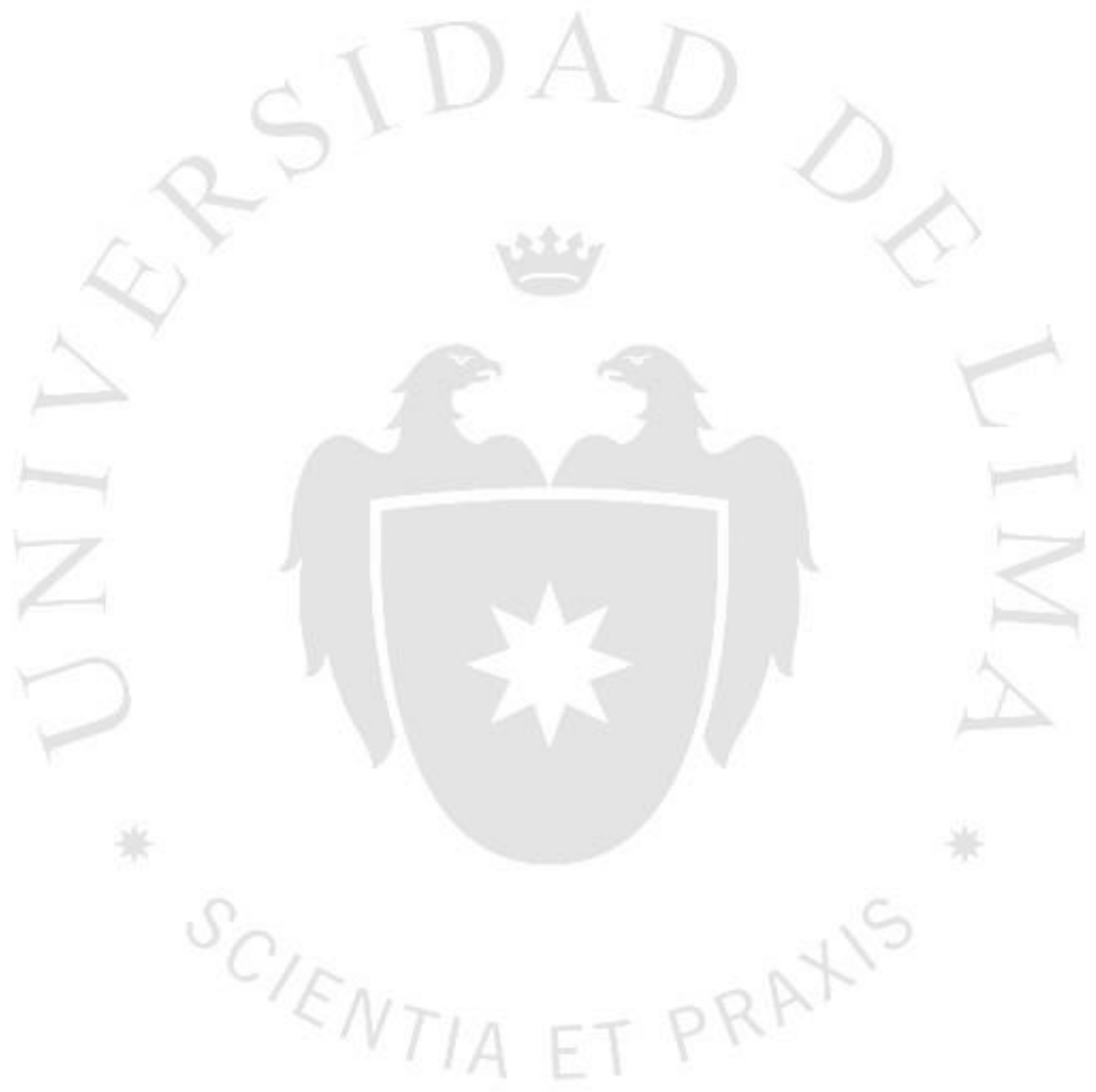


USOS DE LA COMUNICACIÓN PARA EL FORTALECIMIENTO DE CAPACIDADES EN CONTEXTO DE PREVENCIÓN DE CONFLICTOS SOCIOAMBIENTALES. CASO TARPURISUNCHIS, APURÍMAC. 


\section{RESUMEN}

Apurímac, es la región con más inversión y concesión para la explotación minera. Sus proyectos están valorizados en US\$19.713 millones, lo que significa el 33\% de la cartera de proyectos mineros en el país; siendo los principales (aun en etapa de exploración): Haquira (US\$2.800 mlls.), Hierro Apurímac (US\$2.300 mlls.), Cotabambas (US\$1.963 mlls.), Los Chancas (US\$1.560 mlls.), Trapiche (US\$1.000 mlls.) y Anubia (US\$90 mlls.), y el único en etapa de explotación Las Bambas (US\$10.000 mlls.). Pese a que la mayoría de proyectos aun no inicia su etapa extractiva, se han generado 11 conflictos de tipo socioambiental en la región, donde el principal problema es la falta de información oportuna y la ausencia de una estrategia de relacionamiento entre las empresas y los pobladores.

La comunicación es una herramienta básica para la solución de conflictos, por ello, el presente trabajo trata de englobar los usos de la comunicación en la región de Apurímac para tratar de prevenir conflictos a futuro. Los hallazgos permitirán obtener lecciones aprendidas, a partir del trabajo que realiza la institución Tarpurisunchis; a su vez, conocer el rol y opinión de los aliados; así como las expectativas del público al que se dirigen.

\section{PALABRAS CLAVE:}

Perspectivas de desarrollo - Minería - Apurímac - Comunicación - Educación -

Conflictos socioambientales - Gestión social

\section{ABSTRACT}

Apurímac, is the region with the most investment and concession for mining. Its projects are valued at US $\$ 19,713$ million, which means $33 \%$ of the mining portfolio in the country. The main ones (still in exploration stage) were: "Haquira" (US \$ 2,800 m), "Hierro Apurímac" (US \$ 2,300 m), "Cotabambas" (US \$ 1,963 m), "Los Chancas"), "Trapiche" (US \$ 1,000 m.) And "Anubia" (US \$ 90 m.); the only one in the stage of exploitation Las Bambas (US \$ 10,000 mlls.). Although the majority of projects have not yet started their extractive phase, 11 socioenvironmental conflicts have been generated in the region, where the main problem is the lack of timely information and the absence of a strategy of relationship between the companies and the settlers. 
Communication is a basic tool for the solution of conflicts, therefore, the present work tries to include the uses that is given to the communication in the region of Apurímac to try to prevent future conflicts. The research findings will allow us to obtain lessons learned, based on the work carried out by the institution "Tarpurisunchis"; in turn, to know the role and opinion of the allies; as well as the expectations of the target audience.

\section{KEYWORDS}

Development prospects - Mining - Apurimac - Communication - Education Environmental conflicts - Social management 


\section{ÍNDICE GENERAL}

INTRODUCCIÓN.................................................................................1

Antecedentes de la minería y conflictos sociambientales ........................ 1

Antecedentes de comunicación y de las intervenciones de ONGs aplicada a conflictos sociales........................................................................... 3

Tarpurisunchis y "el desarrollo"'........................................................ 7

METODOLOGÍA ............................................................................12

RESULTADOS ..................................................................................14

DISCUSIÓN

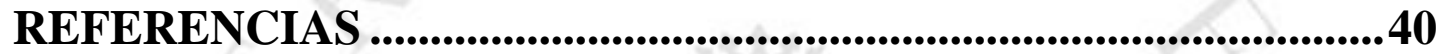

BIBLIOGRAFÍA .....................................................................................42

ANEXOS 


\section{INTRODUCCIÓN}

\section{Antecedentes de la minería y conflictos socioambientales}

El Perú por historia y tradición es un país minero. En la actualidad existen 46 proyectos en el país, que supone una inversión que asciende a US\$ 45,596 millones ${ }^{1}$.

Como resultado de esta actividad, en los últimos veinte años la presencia de conflictos sociales se ha incrementado. Ejemplos como Conga, Tía María, entre otros ${ }^{2}$. Evidencian la falta de diálogo entre los agentes involucrados en los conflictos. Este podría llegar a ser el caso de Apurímac, uno de los departamentos más pobres del país, el cual se ha convertido en foco de la mayor concentración minera, ya que el 57.1\% del departamento ha sido concesionado para este fin $^{3}$.

Para el año 2015, sin haberse iniciado la etapa de extracción de los proyectos mineros de la región, se habían generado 22 conflictos socioambientales vinculados a la actividad minera. Cabe resaltar, que ante el incremento de estos problemas, se ha pretendido dar solución desde el ámbito legal con leyes y normas ${ }^{4}$ que fomenten el diálogo entre los distintos agentes, pero no se han cumplido sus objetivos. Si bien, la actividad económica minera puede generar muchos beneficios para acelerar el crecimiento del país, hasta el momento, resalta más el hecho de la conflictividad que se genera cada vez que se pretende llevar a cabo un proyecto de extracción de minerales en algún territorio aledaño a una población. A esto, se le suma la ausencia del Estado peruano, quien en vez de dar un

\footnotetext{
${ }^{1}$ Según reporte del Ministerio de Energía y Minas (MEM) al mes de setiembre del 2016. Ver en: https://goo.gl/IMVndg

${ }^{2}$ Según el Reporte De Conflictos Sociales N. ${ }^{\circ} 154$ - Diciembre 2016 (último reporte emitido) de los 212 conflictos sociales 146 son de tipo socioambiental (68.9\% del total), de los cuales la mayor cantidad se desarrollan en la región Apurímac (25 casos). (Defensoría del pueblo, 2016)

Cabe resaltar que al inicio de esta investigación, según el reporte $\mathrm{N}^{\circ} 135$ - Mayo 2015, se registraban 211 casos de conflictos, de los cuales 143 eran de tipo sociombiental y que la mayoría de ellos se registraba en la región Apurímac (22 casos). (Defensorio del Pueblo, 2015)

${ }^{3}$ De acuerdo al Séptimo Informe Cartográfico Sobre Concesiones Mineras En El Perú, en el año 2015 se registraba que el $57.1 \%$ del territorio Apurimeño estaba concesionado a la minería, es decir, un equivalente de 1’193,961.8 hectáreas. (Cooperaccion, 2015)

${ }^{4}$ Ley 29785 Consulta Previa aprobada el 7 de setiembre de 2011, que solo aplicaba para el Poder Ejecutivo. El 3 de diciembre del 2014 se aprobó proyecto de Ley de Consulta Previa aplicada al Poder Legislativo. Con este cambio la ley no solo aplicaría a los ministerios, sino también al congreso.
} 
mensaje conciliador, tanto al sector privado como a la población, muchas veces ha sido un detonante más para la disputa ${ }^{5}$.

Las respuestas se complejizan a raíz de este desentendimiento entre los actores y la falta de solución por vías legales y sociales como ${ }^{6}$ :

- Sistema de planificación regional e inversión pública no coordinada.

- Sistema de información y o comunicación entre las instancias y sectores de gobierno insuficientes e ineficientes.

- Deficientes mecanismos y procesos de consulta y participación de la población.

- Políticas discriminatorias o poco claras de desarrollo.

- Vaga orientación o exclusión de políticas ambientales.

- Perspectiva política de manejo de crisis y no de prevención.

Los conflictos socioambientales son procesos complejos en los que distintos sectores de la sociedad, como el Estado y/o las empresas y la población, perciben que sus posiciones, intereses, objetivos, valores, creencias o necesidades son contradictorios con respecto al otro en cuanto al uso y/o acceso al ambiente y sus recursos. Esta situación involucra componentes políticos, económicos, sociales y culturales creándose una situación que podría derivar en violencia. (Defensoría del Pueblo, 2013).

En este contexto, los principales actores que interviene o "actores primarios", son las comunidades o colectividad campesina y la empresa; en cuanto a "actores secundarios", los más cercanos a la población y quienes suelen tener un rol de interlocutores ${ }^{7}$ como las autoridades locales, iglesia, frentes de defensa o movimientos políticos, CONACAMI (Confederación Nacional de Comunidades Impactadas por la Minería), organizaciones no

${ }^{5}$ Ejemplos el del caso Bagua en el año 2009, la protesta de las comunidades amazónicas contra un paquete de decretos legislativos que vulneraban sus derechos y facilitaban la inversión privada en la región.

${ }^{6}$ Un resumen de los desaciertos cometido por la gestión estatal en cuanto a la solución de los conflictos socioambientales. (Huamani Ober, Macassi Lavander, Alegría Galarreta, \& Rojas Alcalde, 2012)

${ }^{7}$ De primer orden, los actores más cercanos a las comunidades o empresas. (Huamani Ober, Macassi Lavander, Alegría Galarreta, \& Rojas Alcalde, 2012) 
gubernamentales (ONGs) y la Sociedad Nacional de Minería, Petróleo y Energía. También interviene instituciones públicas, pero esta suele tener un rol de "actores secundarios de tercer orden". (Huamani Ober, Macassi Lavander, Alegría Galarreta, \& Rojas Alcalde, 2012)

Asimismo, se reconocen principalmente tres tipos de conflictos: a) Naturaleza como recurso natural frente a naturaleza como espacio de vida. Se trata de intereses y necesidades entre dos grupos afectados, por ejemplo, un grupo quiere explotar recursos, pero se contrapone una comunidad la cual vive en este lugar y se verá afectada, suele darse entre personas de una misma comunidad; b) Naturaleza como recurso natural: Conflictos internos. Son conflictos de uso, acceso, explotación, manejos de recursos.

Suele darse entre un grupo que explota un bien natural y otro que se opone; c) Naturaleza como espacio de vida: Conflictos internos. Por uso acceso y manejo de espacios. Alude a conflictos interétnicos e intercomunales. (Orellana, 1999).

En la actualidad, la mayoría de conflictos que se viven en nuestro país han sido representados mediáticamente como el tipo: Naturaleza como espacio de vida. Dadoque la actividad minera no es un recurso renovable, es decir, que su aprovechamiento lleva a la extinción de la fuente productora y estos no se auto-renuevan (Ministerio del Ambiente - MINAM, 2011). Al no ser sostenible en el tiempo y sabiendo que en algún momento estos recursos se acabarán y no se podrán regenerar, se concluye que causarán un daño ambiental irreversible. Sin embargo, también existen casos de minería "responsable", donde no se perjudica los territorios o poblaciones cercanas y se genera una producción y crecimiento perdurable en el tiempo, responsable con los distintos agentes que se ven afectados por esta actividad.

\section{Antecedentes de comunicación y de las intervenciones de ONGs aplicada a conflictos sociales}

Al no lograr soluciones mediante las vías legales, sociales y/o psicológicas, la evidencia apoya la teoría de que la comunicación sería una alternativa en este proceso de diálogo y negociación para disminuir la conflictividad entre los distintos agentes. Lamentablemente, estas estrategias se suelen aplicar una vez que inició el conflicto, mas no como medio de prevención (caso Conga, Tía María, Las Bambas, etc.) Por esta razón, la comunicación para el desarrollo, aplicada en la prevención de los conflictos, reforzará el análisis y la gestión de estrategias que mejoren los procesos de comunicación 
interpersonal que apunten al desarrollo social y entendimiento de los actores. De esta forma, se podría implementar propuestas que promuevan un diálogo abierto y logren crear espacios de debate para prevenir situaciones de crisis.

Ante esta situación, nacen las preguntas: ¿existen estrategias de comunicación definidas para estos casos que puedan contribuir a la solución de conflictos socioambientales? La respuesta a esta pregunta es compleja, ya que, entendiendo las estrategias de comunicación como un proceso estructurado de actividades comunicativas que se desarrolla con el propósito de alcanzar determinados objetivos (Rodríguez, Obregón, \& Vega, 2002), un solo modelo o una sola estrategia definida como una plantilla para aplicarse a todos por igual, no es garantía para que un conflicto se resuelva. Cada estrategia de comunicación responde a un contexto y situaciones determinadas y específicas. Existen diversos acercamientos, modelos, estrategias para abordar la comunicación en una determina situación, como mencionan Rodríguez, Obregón, \& Vega en su libro Estrategias de Comunicación para el Cambio Social, sin embargo, pueden resaltarse ciertos puntos o pasos que son fundamentales para lograr se estratégicos, a continuación, se explican brevemente:

1. Definición del marco estratégico: como su nombre lo dice, un marco que regule el área de intervención y lo que se pretende lograr.

2. Análisis de situación actual: del entorno y el ambiente, asimismo, un análisis interno. Ejemplos: análisis de los factores Políticos, Económicos, Sociales y Tecnológicos; análisis de las fortalezas, debilidades, oportunidades y amenazas (FODA); análisis de la "competencia" en el ámbito social el "costo" un análisis entre el beneficio-valor frente al cambio de comportamiento.

3. Objetivos organizacionales y objetivos de comunicación: los cuales reflejan de forma clara y precisa la visión y objetivos de comunicación en los que se basa la estrategia y los mensajes clave que la organización quiere transmitir ${ }^{8}$.

4. Identificar públicos objetivos: a quien se dirigirá la comunicación.

5. Mensajes: descomponer los objetivos en mensajes relevantes, apropiados y eficientes para el público objetivo.

6. Canales de comunicación: identificar los canales y medios más apropiados para comunicarse con el o los públicos específicos.

\footnotetext{
${ }^{8}$ Ejemplo de esto, la metodología SMART (Specific, Measurable, Achievable, Realistic, Timely) la cual plantea objetivos: Específicos, Medibles, Alcanzables, Realistas, Temporizado.
} 
7. Programación: acciones a realizar, presupuesto, recursos asignados, hitos del proyecto. La planificación del desarrollo del trabajo.

8. Medir y evaluar: una evaluación de las variables en la que se pueda medir el progreso hacia los objetivos finales.

La comunicación, por ende, debe construir su propia identidad y sentido a través de una respuesta específica, concreta y finalmente, efectiva. Se genera una segunda pregunta ¿Hay casos concretos donde se haya llevado a cabo una serie de estrategias comunicativas que ayuden al dialogo entre estos agentes? la respuesta podría dar luces de cómo se podrían aplicar ciertas estrategias en el ámbito peruano.

Melanie Hammond, actual profesora de la Universidad de Lima. Estudió la población aledaña al río Queros para establecer estrategias de comunicación para el desarrollo que permitan un crecimiento sostenible, respetando las necesidades y creencias de la población. Estás estrategias fueron diseñadas para la Asociación para la Conservación de la Cuenca Amazónica - ACCA, la cual presentó al Instituto Nacional de Recurso Naturales (INRENA) una solicitud para gestionar una concesión para la conservación en el departamento de Cusco. Siendo el principal objetivo implementar una estrategia de comunicación y educación ambiental.

Algunos de los principales problemas de comunicación encontrados fueron: la falta de información y conocimientos, prioridad de intereses económicos a corto plazo, rechazo de la población local a las entidades ambientales, desconocimiento de la normativa legal, vínculo entre actividades ilegales sobre uso de recursos naturales y la comunidad, rechazo hacia personas o instituciones foráneas y desarrollo de actividades ilegales.

Las estrategias de comunicación para mejorar esta situación estuvieron basadas en las siguientes recomendaciones: tener un abordaje dialógico y horizontal evitando la prohibición y la restricción de prácticas tradicionales; proponer participativamente un concepto del escenario ideal de desarrollo sostenible a mediano y largo plazo; identificar beneficios concretos a corto plazo a modo de monitorear el avance de las propuestas de conservación y mejora de calidad de vida; fortalecer capacidades internas, institucionales y comunicativas para el trabajo en alianzas estratégicas y concertación (Hammond Cisneros, 2008).

Como respuesta a los antecedentes citados, esta investigación busca indagar formas de afrontar los conflictos socioambientales desde la comunicación, desde una perspectiva 
educativa, participativa y teniendo como visión el desarrollo humano. Ello es abordado mediante el tercer sector el de los Organismos No Gubernamentales - ONGs. Cabe resaltar que los conflictos sociales están presentes intervenga o no una ONG. Existen casos donde este tipo de instituciones han sido utilizadas como medio para defender ciertos intereses personales u obtener beneficios políticos. Pero también, existen escenarios en los que estas organizaciones están orientadas a buscar una solución a los conflictos.

En el grupo de ONGs está ProDiálogo. Esta institución cuenta con un amplio reconocimiento en el sector, así como mecanismos ya establecidos para la prevención, detección ${ }^{9}$ y resolución de conflictos sociales. Dentro de sus proyectos se encuentran los congresos: XI Congreso Mundial de Mediación y I Congreso Nacional para la Construcción de la Paz, donde participaron más 600 personas, entre delegaciones extranjeras y participantes nacionales. Asimismo, otro de sus proyectos es el de "Acción comunicativa por el diálogo y acción no-violenta" el cual cuenta con jornadas de capacitación, publicaciones literarias, informes, etc.

Temáticas de trabajo: Jóvenes, Seguridad Ciudadana y Cultura de Paz Líneas de acción:

- Fortalecimiento de capacidades

- Acción comunicativa por el diálogo y acción no-violenta

Públicos:

- Comunidades y organizaciones de base

- Cooperación Internacional

Otro ejemplo, es la ONG Cooperacción, también reconocida por su participación en la investigación de conflictos socioambientales, y que cuenta con un Observatorio de Conflictos Mineros (OCM), dedicado a sistematizar información de los principales conflictos vinculados a la actividad minera que se desarrollan en el país. Esta organización ha realizado estudios y reportes semestrales, publicaciones y programas para el desarrollo, entre otros.

\footnotetext{
${ }^{9}$ Guía Práctica para el Diseño de Sistemas de Alerta y Respuesta Temprana de Conflictos Sociales (Link descarga: https://goo.gl/emioxV) (ProDiálogo, 2014)
} 
No muy lejana de esta temática se encuentra la ONG Asociación para la Promoción de la Educación y el Desarrollo de Apurímac "Tarpurisunchis", este trabajo intenta definir e identificar las estrategias de comunicación usadas por Tarpurisunchis, quienes previamente han tenido experiencia promoviendo el diálogo en otro tipo de conflictos y problemáticas sociales, por ejemplo la educación, en la que impulsaron el proceso de la Reforma Educativa Regional Autónoma de Apurímac, la cual continua vigente. Actualmente, esta institución, se encuentra realizando distintas estrategias con fines de educar a la población para lograr que las organizaciones sociales, puedan entablar un dialogo con las empresas a cargo de la actividad minera.

El objetivo central es analizar los usos de la comunicación de Tarpurisunchis para comunicarse con las organizaciones sociales de Apurímac para el fortalecimiento del tejido social y su acción empoderada en un contexto de conflictos socioambientales. Los objetivos específicos serán analizar críticamente estos usos de la comunicación que utiliza la ONG; identificar las expectativas de los líderes sociales, es decir, su público objetivo y conocer las motivaciones de las instituciones aliadas con las que trabaja.

\section{Tarpurisunchis y "el desarrollo"}

La Asociación para la Promoción de la Educación y el Desarrollo de Apurímac (Tarpurisunchis), según sus principios institucionales, está comprometida con el desarrollo de las capacidades y la autonomía de la gente, en particular, con los sectores populares. Su meta es lograr una región en la que los hombres, mujeres, jóvenes y niños; vivan en bienestar, decidan con plenitud y responsabilidad sus vidas, recreando formas y prácticas de convivencia sustentadas en la participación, la justicia y la solidaridad. Así mismo, se apoyan en dos ejes fundamentales para mejorar y alcanzar sus objetivos: la educación regional y el desarrollo de las organizaciones comunitarias.

La asociación, fue fundada en el año 2003 en la región Apurímac. Sus miembros fundadores consideraron que era la región con mayor lealtad cultural lingüística, es decir la identidad cultural quechua. Si bien, para algunos fue visto como una debilidad, este grupo lo tomó como una fortaleza que les permitiría progresar con sus objetivos; los cuales eran, permitir sociedades alternativas y viables que fortalezcan la identidad regional y las capacidades de cada individuo. 
Figura 1: Misión y Visión de la ONG Tarpurisunchis.

\begin{tabular}{|l|l|}
\hline \multicolumn{1}{|c|}{ Misión } & \multicolumn{1}{|c|}{ Visión } \\
\hline $\begin{array}{l}\text { Favorecer el desarrollo de un proceso } \\
\text { efectivo de reforma profunda de la } \\
\text { educación regional, en el marco de la } \\
\text { institucionalidad de la región Apurímac. }\end{array}$ & \\
- $\begin{array}{l}\text { Promover el desarrollo de capacidades en } \\
\text { comunidades locales en la perspectiva de la } \\
\text { generación de procesos autónomos y } \\
\text { sostenibles de recreación de formas de vida } \\
\text { alternativa. }\end{array}$ & $\begin{array}{l}\text { Soñamos con una región en la que hombres, } \\
\text { mujeres, jóvenes, niños y niñas viviendo en } \\
\text { bienestar, decidan con plenitud y } \\
\text { responsabilidad sobre sus vidas, recreando } \\
\text { formas y prácticas de convivencia, sustentadas } \\
\text { - } \begin{array}{l}\text { Generar, recrear y/o fortalecer formas de } \\
\text { solidaridad que permitan, la justicia y la solidaridad. }\end{array} \\
\text { cooperación flexibles, efectivas y } \\
\text { enriquecedoras, superando el modelo que } \\
\text { reduce la cooperación a la entrega de bienes. }\end{array}$ \\
\hline
\end{tabular}

Es importante aclarar que esta institución busca fortalecer el tejido social o capital social; entendido como el conjunto de recursos con que cuenta un actor social (por parte de estructuras o redes sociales); además al trabajar dentro del ámbito educativo, resalta el termino capital cultural; entendido como el potencial y la capacidad que hemos adquirido de la cultura intelectual y del medio familiar (Bourdieu, 2001).

En este sentido, el capital social es el vínculo con otros agentes (una cadena interminable) que puede brindar recursos necesarios para satisfacer sus necesidades y cumplir sus objetivos -individuales o colectivos - (Díaz-Albertini Figueras, 2010).

Tarpurisunchis usa el término "Tejido social" para referirse a estos vínculos entre personas y entidades (así como también personas - entidades, entidades - entidades, personas - personas), pero de manera externa a ellos, como una denominación de la población en general, al mismo tiempo reconociendo su vinculación.

Es necesario tomar en cuenta que en la diversidad de nuestro país y su multiculturalidad no existe un consenso único sobre qué es el "desarrollo". A lo largo del trabajo, se usará este término, el cual alude a dos puntos de vista. El primero, es "desarrollo" referido a lo puramente económico, consumista y basado en lo material, un tipo de desarrollo más 
cercano al modelo capitalista, una secuencia de cambios y mutaciones que a partir de las actividades puramente económicas se van extendiendo progresivamente a los restantes ámbitos vitales, desde lo político, hasta lo sociológico, pasando por lo institucional, lo cultural, la demografía, el medio ambiente, etc. (Galraith, 1983). El segundo, que hace referencia a una corriente moderna aplicada mayormente en Latinoamérica, el cual se basa en el desarrollo de capacidades de un grupo y el uso de estas para lograr un crecimiento deseado, ya sea en calidad de vida, variables culturales, comunales, etc. Donde el desarrollo y el crecimiento no son lo mismo y sus objetivos no se centran en el aumento de las variables económicas, sino se enfocan en las personas y el ambiente (RedGE, 2012).

En este camino, Tarpurisunchis ha decido seguir un modelo más similar a la segunda definición, a lo cual adopta el uso del término "Buen Vivir", el cual tiene su origen en las comunidades indígenas y tradicionales de América Latina, junto a un grupo de líderes políticos, ideológicos y universitarios. Sin embargo, este nuevo término no tiene una definición única a nivel mundial ya que el "Buen Vivir" puede variar de sociedad en sociedad refiriéndose exactamente a eso: ¿Qué es el buen vivir para uno? A pesar de ello en sus formas más básicas algunos de sus principales objetivos son: Primero, obtener reconocimiento constitucional de las propias culturas indígena o autóctonas, sus identidades y el derecho al autogobierno y la autodeterminación en las zonas que delimitan como sus territorios para poder incidir en las políticas públicas. Segundo, lograr una economía comunitaria basada en los conceptos de reciprocidad y complementariedad con la naturaleza. Finalmente, propone la educación intercultural bilingüe para integra el conocimiento occidental y la cultura y conceptos fundamentales de la cosmovisión indígena así como la práctica comunitaria y las ceremonias tradicionales (Niel, 2011). En resumen, son concepciones de una buena vida, entendiéndola en un plano personal, pero también comunitario y expandidas a las vinculaciones con la naturaleza. A lo cual Tarpurisunchis tendrá su propia definición de que es el Buen Vivir para ellos.

Este modelo o alternativa al desarrollo se centra en las personas y su visión del mundo, es de ahí que esta institución busque centrarse en el empoderamiento y desarrollo de capacidades de los agentes. Empoderarlos, con un proceso participativo donde el aprendizaje esté basado en la experiencia propia de las personas, una participación orientada a cambiar la realidad (Eizagirre , 2006); ya que en muchos casos la población involucrada necesita reducir su vulnerabilidad en estas situaciones de conflicto, lo cual se 
logra mediante el empoderamiento y la fortaleza de sus capacidades, es decir, desarrollando confianza, visión y protagonizar desde sus propios recursos, estas capacidades podrían ser de diversos tipo como físico-materiales (recursos materiales, conocimientos técnicos, estrategias de afrontamiento), sociales (redes sociales, capital social), o sicológicas (coraje, iniciativa) (Dubois, 2006).

Estas estrategias que ellos ven desde el punto de vista de la educación, también son formas de comunicación. Desde las teorías de la comunicación para el desarrollo, una de ellas la Multiplicidad y Otro desarrollo, alude a las prácticas de esta institución. Esta teoría afirma que no existe un único modelo de desarrollo universal y que este debe ser concebido como un proceso integral, multidimensional y dialéctico (Servaes, 2000) dependiendo de cada sociedad, ya que cada una es única. Dentro de esta independencia se mantienen unos principios generales: necesidades básicas, endógeno, auto confiable, ecología, democracia participativa y cambios estructurales.

Consecuente con esta teoría comunicacional, el modelo de desarrollo participativo se centra en la identidad cultural, democracia y participación. Sostiene que la colaboración recíproca es desde todo los niveles de participación, además de no subestimar la habilidad de las masa para auto desarrollarse; se basa en la capacidad de la gente para discernir "que es lo mejor" para sí mismos y la sociedad (Xavier, 1980). A diferencia de otros modelos que se centran en el medio y sus efectos en el público, el modelo participativo pone en primera instancia a los receptores de la comunicación, ya que de ellos viene la concepción del tipo de desarrollo que necesitan o quieren. Por estos motivos, hay una mayor participación y confianza entre los agentes para entender la diversidad y la colaboración mutua de ambos lados, en muchos casos son la población quien da la iniciativa de lo que se quiere hacer, ya que se busca la participación y empoderamiento para lograr sus objetivos.

Así mismo, existen ciertas estrategias que se podrían acoplar a este contexto de conflictos para lograr procesos de cambio y de transformación social. Por ejemplo, la estrategia de movilización social, la cual se centra en los sectores influyentes en la comunidad, donde se hace un llamado a que se organicen y apoyen determinados procesos. Pueden ser procesos de movilización política, gubernamental, comunitaria, empresarial, beneficiarios. No se centra en un solo individuo sino en los sectores más influyentes. 
A lo largo del trabajo conoceremos si estas actividades que realiza Tarpurisunchis están enfocadas en un contexto comunicacional y de qué forma pueden aportar a la solución de conflictos socioambientales. 


\section{METODOLOGÍA}

El entorno geográfico de trabajo de la institución Tarpurisunchis es la región Apurímac en su totalidad, el cual abarca a las instituciones vinculadas a la temática ambiental y social de la región, nación e organizaciones internacionales. Ante esta muestra, se decidió trabajar en tres grupos que permitan conocer y desarrollar los objetivos de este trabajo. El primero es el de la institución Tarpurisunchis, el segundo será organizaciones aliadas y el tercero la población a quien se dirige el mensaje, su público objetivo.

La recopilación de información se realizó mediante la metodología cualitativa tales como, entrevistas a profundidad y entrevistas a actores clave. Esta metodología permitió identificar características, actitudes, valoraciones, además de desarrollar hipótesis a partir de las respuestas a los entrevistados.

Las entrevistas al primer grupo pretenden conocer más acerca del trabajo de la institución Tarpurisunchis, las estrategias que está utilizando, su trabajo, previo, etc. Se dividió en tres secciones: sobre la línea institucional, sobre el proyecto y sobre las estrategias.

Se realizó una entrevista a profundidad al Director Ejecutivo de Tarpurisunchis, Javier Malpartida, quien también es socio fundador de la institución. En cuanto al segundo grupo, las preguntas estuvieron orientadas a identificar las motivaciones de ser parte del proyecto, por parte de las instituciones aliadas, por lo cual estuvieron divididas en las secciones: línea institucional, sobre sus motivaciones y sobre su aporte al proyecto. Se realizaron entrevistas a los siguientes representantes institucionales de las siguientes instituciones aliadas de Tarpurisunchis pertenecientes al Grupo Apurímac.

- CEPRODER (Centro de Promoción y Desarrollo Rural). Entrevista a Jorge Luis Corcuera, Director Ejecutivo.

- Broederlijk Denle. Entrevista a Raphael Hoetmer, Representante oficial en Perú.

- APRODEH (Asociación Pro Derechos Humanos) Entrevista a Enver Quinteros, Responsable Regional de Apurímac.

- Madre Coraje. Entrevista a Mauro Mazzacani, Representante oficial en Perú de Madre Coraje.

Finalmente se realizarán entrevistas a profundidad con una muestra de la población, seis de veintiséis asistentes al principal evento del proyecto, líderes sociales de Apurímac, 
ellos son el tercer grupo y se buscará conocer sus expectativas. Está sección estará dividida en: Liderazgo, relación con otros agentes y sobre sus expectativas. Para ello se entrevistó a los siguientes líderes sociales, residentes de Abancay y otras zonas.

- Lucy Trujillo, Técnica en Construcción Civil - Abancay.

- Jaime Huaman, Estudiante UNAMBA - Antabamba.

- Alexia Palomino, Estudiante UNAMBA - Abancay.

- Yarid Mogollon. Estudiante UTEA - Abancay.

- Miguel Flores, Agricultor - Abancay.

- Jhon Cordoba Perez, Estudiante - Aymaraes. 


\section{RESULTADOS}

\section{TARPURISUNCHIS}

\section{Línea institucional:}

Desde su fundación TARPURISUNCHIS trabaja con tres grandes motivaciones, también llamados objetivos estratégicos. Primero, construir una experiencia de cambio, de mejora educativa desde las propias fuerzas de la región, es decir una experiencia concreta donde la población mejore su situación y la repercusión en sus vidas como comunidad, desde la participación; a esto le llaman: Reforma educativa regional autónoma y participativa. Segundo, recuperar y potenciar la tradición cultural andina, los valores de solidaridad, la relación con la naturaleza, para construir formas de vida alternativa afrontando el desgaste del modelo clásico capitalista de la economíamundial. Finalmente, buscan replantear la manera en que se entiende la cooperación, basada en la idea de que entregar bienes, dinero o cosas, es la mejor forma de cooperar, porque muchas veces eso es lo que hace más daño. En otras palabras, deslindar con el modelo asistencialista.

Como línea política, en palabras de los directivos de la ONG, proponen el cambio social desde las bases de la población y no pertenecen a ningún partido político. La ONG, se autodefine como una institución de izquierda que busca cambiar desde la raíz las cosas, sin embargo, recalcan tener una posición distante de los partidos o las ideas de vanguardia.

Figura 2: Ciclo de trabajo de las instituciones.
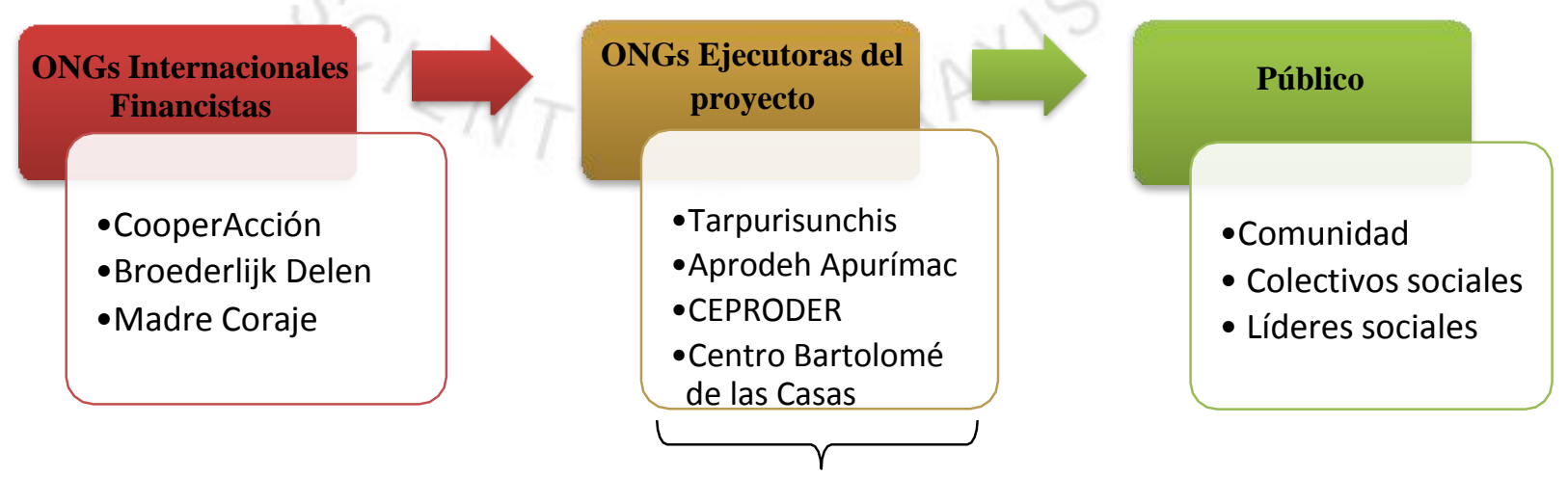

\section{Grupo Apurímac}

En cuanto a aliados institucionales, los más cercanos son el Grupo Apurímac donde se 
encuentran instituciones como Aprodeh Apurímac, CEPRODER, CooperAcción, Broederlijk Delen, Madre Coraje, entre otros. También cuentan con otros aliados que se 
podrían llamar de segundo piso, como son la Red Muqui, el Centro Bartolomé de las Casas y otras instituciones de carácter gubernamental, como la Mesa de Concertación de Lucha contra la Pobreza de Apurímac. En la "Figura 1" se aprecia la organización de las mismas. De igual forma la "Figura 2" se identifica la posición de los actores más relevantes.

Figura 3: cuadro de actores más resaltantes en el ámbito de estudio. Adaptado de (Macassi Lavander, Huamani Ober, Alegría Galarreta, \& Rojas Alcalde, 2012)

\section{CUADRO DE ACTORES}

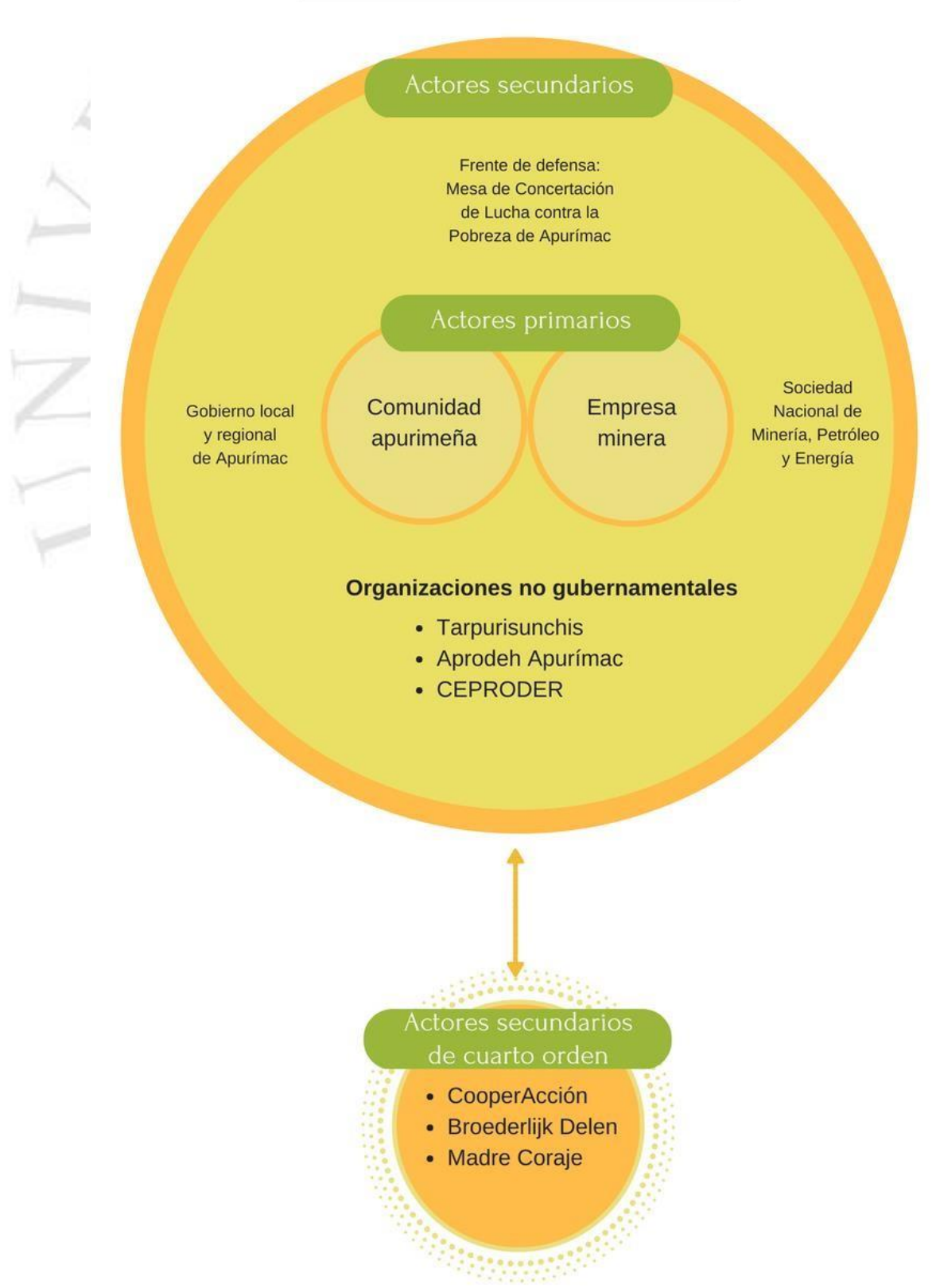


Referente a su relación con instituciones gubernamentales, tratan de mantener una relación armónica mediante la búsqueda del dialogo para lograr cooperación, fortalecerse mutuamente y ayudarse entre ellas. Sin embargo, no dejan de señalar que en algunos casos estas relaciones se complican por la anteposición de intereses personales a los proyectos destinados a la población ya que habría casos de corrupción y acuerdos particulares entre algunos representantes gubernamentales y el sector privado.

Centrándonos en el tema de conflictos socioambientales, la institución los define como situaciones de tensión y/o contradicción, en algunos casos de enfrentamiento, que se da entre la sociedad y las empresas extractivas. Indican, que, por un lado, hay un interés desde lo privado que busca acrecentar sus ganancias y, por otro lado, la población, la naturaleza, el territorio, el pueblo; que, si bien quiere beneficiarse de esas inversiones, tienen tradiciones y formas de relacionarse con la naturaleza y los valores de su comunidad, que al final son incompatibles con los intereses de estas empresas.

En cuanto la labor que realizan para evitar los conflictos sociales, indican que las actividades que aplican son de prevención; ya que no tienen participación directa en los conflictos. Por ello sus programas y proyectos son de capacitación y desarrollo personal por lo que obtendrían resultados a largo plazo. Dentro de estas actividades aspiran a fortalecer las capacidades de las organizaciones sociales, sobre todo de los líderes que representan estas instituciones, tratando de equiparar la información, herramientas técnicas, jurídicas y políticas de las comunidades para que estas mismas, tengan el capital social suficiente y logren establecer un dialogo equitativo con los diversos actores que intervienen en los conflictos. Otro de sus objetivos es animar al dialogo en la sociedad sobre el tipo de desarrollo que se quiere y que se necesita para la región.

Desde estos matices, evalúan la gestión del Estado en los conflictos en general, con un rol deficiente, ya que consideran que actúa de forma parcializada por apoyar principalmente a las empresas mineras, dando facilidades para la inversión y extracción de materias; mas no su apoyo a la población. Así mismo, opinan que no hay un ejercicio pleno de derechos de los ciudadanos, ni respeto o cuidado por el medio ambiente en el afán de continuar con la inversión empresarial. Esto debido a las facilidades que se le da a la inversión privada y en este empeño se rebaja todos los controles y las leyes que causarían el perjuicio de las comunidades. 
Su posición con respecto a la minería no es en contra. Sugieren que el Estado debería de velar por garantizar las condiciones para la inversión, es decir, están de acuerdo con que existan actividades extractivas, pero respetuosas de los derechos de los pueblos, del medio ambiente, además de necesarias, no infinitas o no planificadas.

Finalmente, para concluir el punto uno: Línea institucional; su opinión respecto al tratamiento de los conflictos socioambientales en los medios de comunicación, consideran inapropiado el contenido del medio televisivo y el tratamiento de la noticia con respecto a estos temas. Indican que muchas veces no se trata de informar, sino que buscan dar una opinión sesgada para apoyar a uno de los actores, mayoritariamente al sector minero. En el ámbito local, el tema de conflictos se toca puntualmente y los pocos programas de televisión o radio regional son muy deficientes, debido a que suelen reproducir la programación de los grandes medios. Estos servirían en su mayoría como un medio de rebote más que como un gestor de contenido propio, por ejemplo, se suelen retransmitir noticias de Lima que no aluden a la región o son ajenas a ella. 
2. Sobre el proyecto:

Figura 4: Ficha técnica del proyecto

\section{PROCESO DE \\ PREVENCIÓN DE CONFLICTOS SOCIOAMBIENTALES}

\section{Ámbito de acción}

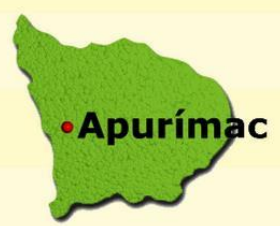

sociales de

\section{Población Directa}

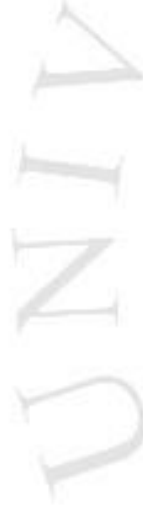

Participación constante

- Ideas consecuentes

- Ganas de aprender

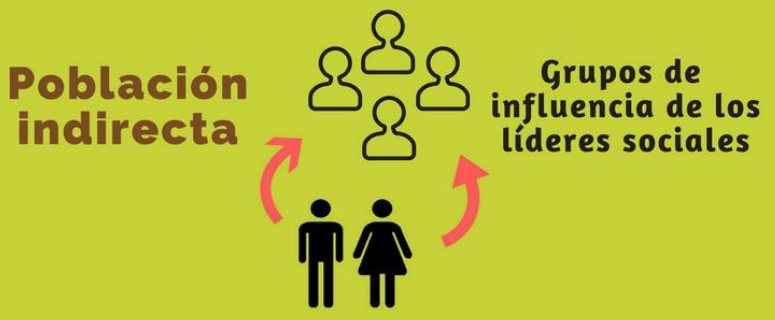

Duración:

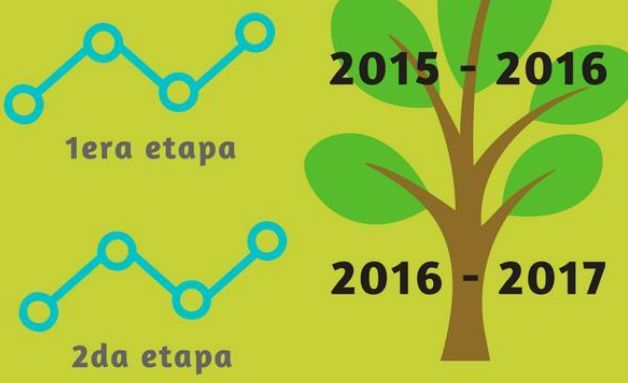

Análisis realizado antes del inicio del proyecto 
En este contexto con sus ideales relatados en el punto línea institucional, Tarpurisunchis ha emprendido un proyecto social, que ellos denominan, de forma más amplia: "proceso de desarrollo" el cual toma un tiempo a largo plazo y entrega varios resultados o productos (sociales), a diferencia de un "proyecto", que consideran tiene un tiempo específico de desarrollo y está destinado a producir un producto (social).

Su público objetivo son los líderes y lideresas de las organizaciones sociales de Apurímac y a su vez, el público de estas organizaciones, a los cuales se llegará de forma indirecta por medio de los primeros. Son veintitrés asistentes y lideresas en toda la región Apurímac, se escogió a esta población porque la institución siempre se ha caracterizado y ha procurado trabajar con todo el territorio Apurimeño en general (las siete provincias). Además de que estos líderes seleccionados, demuestran ser personas activas en las organizaciones sociales a las que representan y han mantenido un comportamiento o una conducta coherente, con respecto al tema de conflictos socio ambientales y se muestran abiertos a querer aprender y capacitarse en el tema.

Cabe resaltar que el proyecto no está centrado directamente en el conflicto ya dado, sino que busca su prevención. Se enfocan en los líderes y lideresas para que puedan incidir, influir, conducir mejor sus organizaciones y poder encarar mejor los distintos retos de la región, además de construir propuestas alternativas. Por ello, como institución, no tienen un mensaje propio que trasmitir, en el sentido de tener un mensaje claro que ellos impongan adoptar o replicar; sino tienen como reto fortalecerlos y ser un factor que potencie y fortifique sus mensajes, para un mejor dialogo, donde se enriquezcan y vayan configurando alternativas y/o propuestas propias.

Una debilidad del proyecto en general es que no cuenta con estudios formales previos. Solo tienen la experiencia de campo con otros procesos que han impulsado y que han servido para sistematizar alguna información, pero no han realizado una investigación a profundidad y no cuentan con indicadores o estudios, recién con este proyecto empezaría a realizar un diagnóstico para comprender mucho mejor la realidad actual.

De esta forma, su proceso busca prevenir los conflictos socioambientales y se basa en dos actividades o proyectos más concretos: 
Figura 5: Proyectos de la ONG Tarpurisunchis, cuadro construido a partir de la información de la institución.

\section{PROCESO: PROCESO DE PREVENCIÓN DE CONFLICTOS SOCIOAMBIENTALES}

\begin{tabular}{|l|l|}
\hline \multicolumn{1}{|c|}{ Proyecto: Fortaleciéndonos } & $\begin{array}{c}\text { Proyecto: ¿Qué tipo de desarrollo } \\
\text { queremos? }\end{array}$ \\
\hline $\begin{array}{l}\text { Busca desarrollar las capacidades de líderes } \\
\text { sociales para un diálogo equilibrado con } \\
\text { actores externos vinculados a conflictos } \\
\text { socioambientales. }\end{array}$ & $\begin{array}{l}\text { Busca promover el debate sobre qué } \\
\text { tipo de desarrollo se quiere en la región. }\end{array}$ \\
\hline \multicolumn{2}{|c|}{ Resultados esperados } \\
\hline $\begin{array}{l}\text { - Fortalecer a los líderes de organizaciones } \\
\text { sociales. }\end{array}$ & $\begin{array}{l}\text { Enriquecer el debate y la reflexión, sobre } \\
\text { el tipo de desarrollo que se desea en la } \\
\text { región. }\end{array}$ \\
$\begin{array}{l}\text { Promover en las organizaciones, } \\
\text { (comunidades, colectivos, etc.) un } \\
\text { comportamiento organizado para lograr una } \\
\text { mayor incidencia en la política regional. }\end{array}$ & $\begin{array}{l}\text { comunicación los componentes } \\
\text { culturales de la región y la problemática } \\
\text { social }\end{array}$ \\
\hline \multicolumn{2}{|c|}{ Indicadores } \\
\hline
\end{tabular}

Este proceso, nace en oposición al modelo de desarrollo extractivista y consumista, el cual consideran se encuentra en crisis a nivel mundial. De esta forma, como reflexión a la experiencia mundial de crisis económica, tratan de aprender de esta y poner en dudasi es que este modelo seguido por muchos años ha sido el correcto y realmente ha conducido al desarrollo de la población. Ante esta reflexión, se alinean a la alternativa del "Buen Vivir" para impulsar formas de desarrollarse desde las propias fuerzas y fuentes de la población, así mismo, proponen repesar y escudriñar en nuestra historia y saberes ancestrales para escoger que se quiere y que no, para ir construyendo una forma de visualizar el futuro, de forma autónoma.

\section{Sobre las estrategias:}

Cabe resaltar que la institución, al no estar especializada en el tema de estrategias de comunicación, no brindó definiciones técnicas, ni enfoques; sin embargo, sí tienen actividades de comunicación en su ejecución. 
Figura 6: Ficha del desarrollo del programa, realizada por

Tarpurisunchis.

\section{Sentido del Programa ${ }^{10}$ ¿Qué vas a aprender?}

El programa ha sido elaborado bajo el enfoque de competencias. Es decir, no solo va a tratar temas para que !@s participantes los aprendan, sino que va a buscar que, al finalizar todos los módulos, I@s participantes sean más competentes y capaces.

Específicamente, se espera que al término de los 2 años de duración del programa I@s participantes van a poder:

- Alentar y orientar la construcción colectiva de un sueño de futuro que articule la modernidad con la tradición y saberes andinos.

- Animar y conducir acciones y procesos sociales que muestren formas de vida alternativas e incidan en decisiones políticas.

- Aprovechar la experiencia cotidiana y convertirla en aprendizaje permanente, tanto en el plano personal como organizacional.

- Incorporar en sus reflexiones y acciones cotidianas, los enfoques de derecho y de justicia. Tanto de justica de género, intercultural como ambiental.

En esa orientación, para que puedan desarrollarse o fortalecerse las capacidades arriba mencionadas, durante el desarrollo de los 2 años del programa van a trabajarse los siguientes módulos:

\section{Desarrollo v Buen Vivir ¿Qué futuro queremos?}

- Enfoques de Desarrollo.

- Política y Contrapoder.

- Buen Vivir.

\section{Módulo \\ Aprendizaje Organizacional \\ ¿Cómo seguimos creciendo?}

- Saberes y Aprendizaje.

- Enfoque Constructivista.

- Inteligencia Emocional

\section{Gestión de Procesos Sociales ¿Cómo avanzamos hacia él?}

- Liderazgo y Participación.

- Construcción de Políticas Públicas.

- Conflictos Sociales y Concertación.

\section{Módulo \\ Enfoques Transversales \\ ¿Con qué valores?}

- Enfoque de Derechos.

- Justicia Intercultural y Ambiental.

- Justicia de Género 
10 Para ver la ficha completa de: Sentido del programa y metodología, archivo Tarpurisunchis; revisar anexo 7. 
Figura 7: Estrategia matriz, esquema creado a partir de la recopilación de información de la ONG.

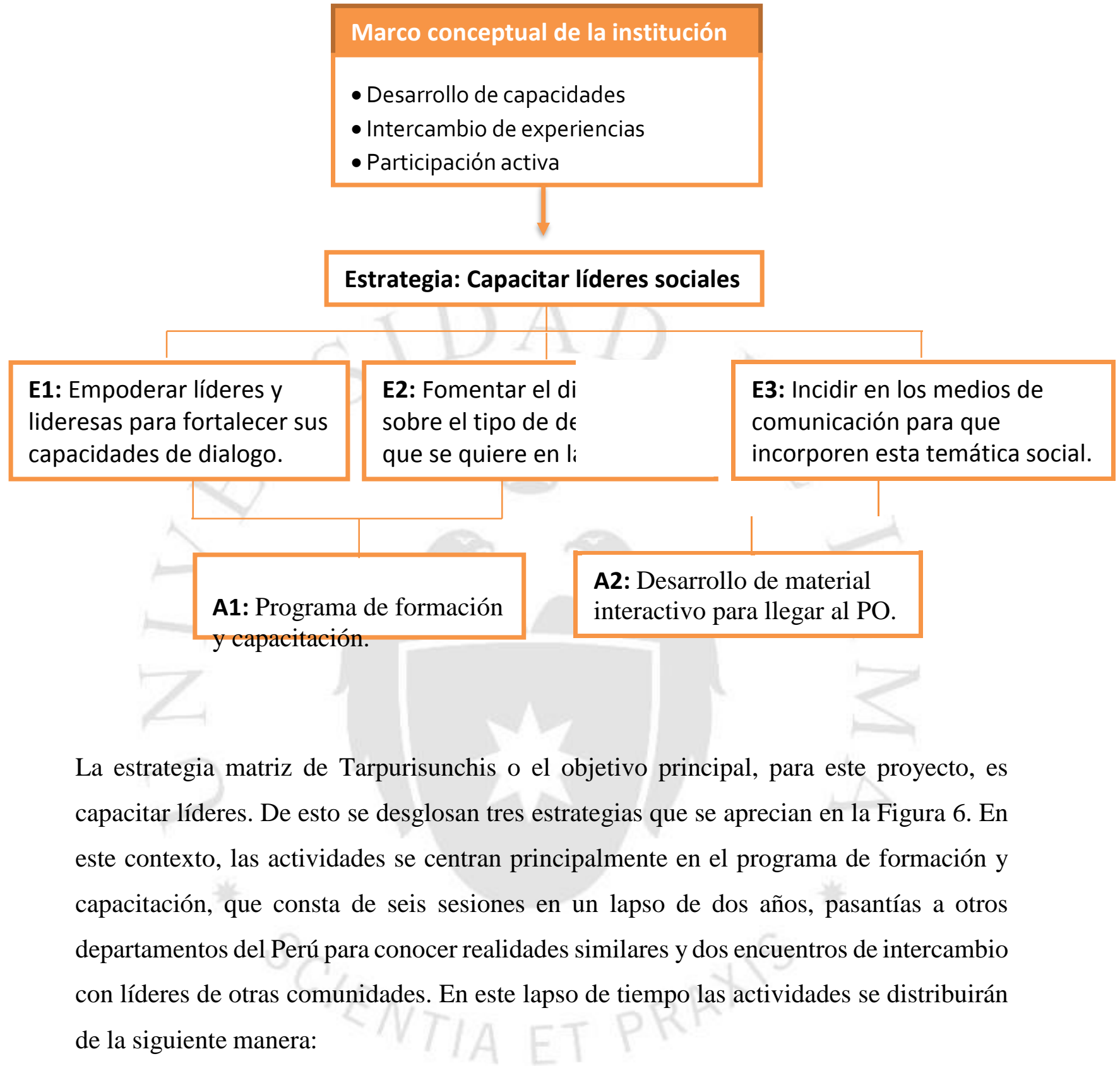


Figura 8: Línea de tiempo de desarrollo del programa.

\section{Programa de Actividades}

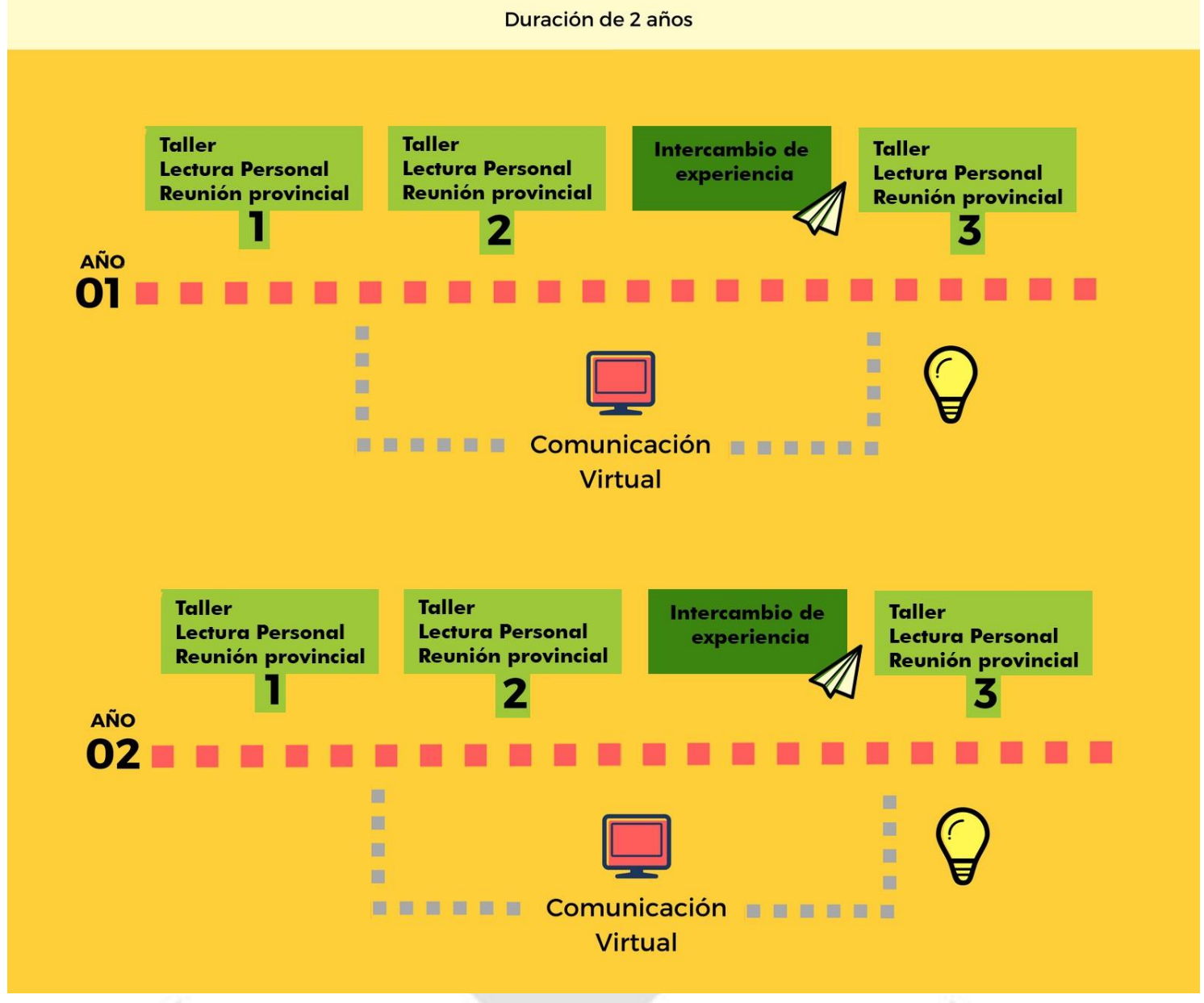

Dentro de estas actividades, para el primer año (2015) se programaron 3 talleres y un viaje. Consideran que su herramienta principal será el fortalecimiento y la capacitación; en cuanto a medios de comunicación, se busca influir en estos para que incorporen la temática social, saberes, conocimientos y la lengua quechua en su programación. En la siguiente figura, se puede observar el desarrollo de las actividades a lo largo de los dos años que dura el proyecto.

En cuanto al Desarrollo de material interactivo para llegar al público objetivo dentro del material comunicacional que han producido, existen diversos videos como spots y una serie de documentales de saberes ancestrales, materiales interactivos en DVDs, etc. Estos se toman como herramientas frecuentes para iniciar el debate. Por ejemplo, en el año 2014 en las elecciones municipales, se lanzaron una serie de spots por internet para promover 
el debate sobre un voto responsable ${ }^{11}$. En el año $\left(2015^{12}\right)$ se programó lanzar una revista virtual audiovisual de nombre Llaqtanchispaq (Por nuestro pueblo, en quechua), la cual propone publicar noticias en una página web en formato audiovisual, que a su vez se repartirá vía correo electrónico. Según sus expectativas, esto permitirá tener una mayor acogida del público por el uso de un lenguaje sencillo y muy conciso. Una desventaja que ellos consideran en cuanto a este medio es que el acceso a internet aún puede ser limitado para la población en general ${ }^{13}$. Por ello, en los talleres del proyecto enfocado a líderes y lideresas, se dispondrán sesiones de capacitación en el uso de las nuevas Tecnologías.

\section{INSTITUCIONES ALIADAS}

Presentados detalladamente en la figura comparativa (Figura 4). Los principales hallazgos en la sección central (sobre sus motivaciones) son los siguientes:

CEPRODER, se centra en un enfoque de desarrollo territorial basado en la participación plena, en la opinión de los pobladores, la calidad de productos sanos, en un buen vivir, con enfoque de derechos. Su enfoque lo definen como el buen vivir, buen comer, buen producir. Desde el punto de vista del desarrollo, pretenden rescatar los saberes locales, para lograr sus objetivos. Están centrados en aspectos más humanos y sociales que económicos. Sus motivaciones para participar en este proyecto, nacen del olvido y falta de acciones por parte de la población en general con respecto a los problemas sociales en la región. En sus estudios previos, descubrieron que solo tres provincias de Apurímac recibían mayor atención y concentración de proyectos públicos y privados, sin embargo, el resto de provincias estaban rezagadas u olvidadas. En consecuencia, decidieron trabajar en la provincia de Grau, ya que observaron se encontraba en una situación olvido. Todo esto con el fin de lograr en el tiempo procesos de desarrollo que reviertan estos fenómenos.

Frente a esto, decidieron formar líderes con mayor capacidad de diálogo, familias capacitas para gestionar, dirigir y proponer una revolución productiva en su entorno. En resumen, consideran que sus motivaciones son aportar a la región de una forma social y

\footnotetext{
${ }^{11}$ Ver en: https://goo.gl/KuWMLb

${ }^{12}$ Fue lanzada en el año 2015. Enlace: www.revistallaqtanchispaq.com

${ }^{13}$ No tienen indicadores o investigación del acceso a internet de su PO.
} 
humanitaria, no ven un fin de beneficio económico para ellos, sino un crecimiento en la región.

Por parte Broederlijk Delen, consideran que el enfoque de desarrollo que se pretende lograr en la región lo debe dar Tarpurisunchis en conjunto con las organizaciones que trabaja, pero la noción de Buen Vivir, para ellos, no es un enfoque de desarrollo, sino una alternativa al desarrollo que aún no se encuentra totalmente acabado, ya que continúa reformulándose de sociedad en sociedad. Por ello, el mensaje al que quieren contribuir es a que exista más debate público en Apurímac, sobre el modelo de desarrollo, la identidad y la cultura. Por otro lado, sus motivaciones se basan en considerarse una organización de solidaridad internacional, pues argumentan que la justicia, la solidaridad y la igualdad, son valores que deberían de dirigir las sociedades mundiales.

Creen en el derecho de los pueblos de crear y definir su propio destino y la obligación del Estado de organizar los derechos de la población, como de colaborar con esos procesos de construcción para fomentar una vida digna en las comunidades rurales. Este punto de vista, nace de la opinión en que vivimos en un mundo donde el nivel de desigualdad, insostenibilidad e injusticia, que genera el modelo de desarrollo actual, nos debe llevar a plantear una trasformación de la organización económica y política en nuestros países y el mundo en general.

Con respecto al tema minero, en sus palabras, consideran que el Perú necesita esta actividad como parte de su modelo económico, pero que no se debe pensar que únicamente este recurso servirá de sustento para la economía del país. Indican que ellos buscan colaborar con las poblaciones campesinas porque en el mundo actual hay procesos de urbanización muy fuertes que llevan a que la gran mayoría de la población viva en ciudades, cuando en realidad también se necesita mucho al campo. De esta forma apoyan la condición agrícola, el trabajo de las comunidades y de las poblaciones rurales que hacen pequeña y mediana agricultura.

En cuanto a la ONG Madre Coraje, se basan en un enfoque transversal de desarrollo humano, de derechos y de género. De igual forma, para ellos el Buen Vivir, más que un enfoque, es un concepto en construcción que debe ser creado por cada población en base a lo que ellos consideren necesario e importante para su comunidad 
Figura 9: Resumen de respuestas de las instituciones aliadas.

\begin{tabular}{|c|c|c|c|c|c|c|c|c|c|c|c|c|}
\hline & \multicolumn{5}{|c|}{ Sobre linea institucional } & \multicolumn{4}{|c|}{ Sobre sus motivaciones } & \multicolumn{3}{|c|}{ Sobre su aporte al proyecto } \\
\hline Dimensión Aliados & 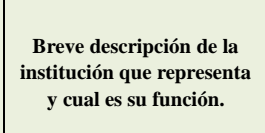 & $\begin{array}{l}\text { ¿Qué linea politica tiene la } \\
\text { institución? }\end{array}$ & $\begin{array}{l}\text { ¿CĆmo define usted a los } \\
\text { conflictos socioambientales? }\end{array}$ & $\begin{array}{l}\text { ¿Qué actividades realizan en } \\
\text { relación a los conflictos? }\end{array}$ & $\begin{array}{l}\text { ¿Cree que los medios de } \\
\text { comunicación inflyen en en } \\
\text { desarroollo del conflicto? } \\
\text { ¿Cómo? }\end{array}$ & $\begin{array}{l}\text { ¿Qué enfoque de desarrollo los } \\
\text { guua? }\end{array}$ & $\begin{array}{c}\text { ¿Cuále se el principal mensaje } \\
\text { que quieren trasmititr? }\end{array}$ & 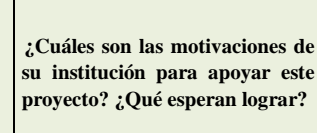 & $\begin{array}{c}\text { ¿Cuále s sa posicíńn del proyecto } \\
\text { respecto a la mineria? }\end{array}$ & $\begin{array}{l}\text { ¿Cuálessu aporte como } \\
\text { institución al proyecto? }\end{array}$ & $\begin{array}{l}\text { ¿Qué actividades realizaran } \\
\text { para lograr sus objetivos? }\end{array}$ & $\begin{array}{l}\text { 3. iEste process promueven la } \\
\text { organización social? }\end{array}$ \\
\hline $\begin{array}{l}\text { CEPRODER } \\
\text { (Centro de } \\
\text { Promoción y } \\
\text { Desarrollo Rural) } \\
\text { Entrevista Jorge } \\
\text { Luis Corcuera, } \\
\text { Director Ejecutivo. }\end{array}$ & \begin{tabular}{|c} 
ONG especializada en \\
potenciar aa actividades \\
productiva de as \\
comunidades y la gestión \\
del manejo ambieintal.
\end{tabular} & \begin{tabular}{|c|} 
Politica no partidaria. Una \\
politica de total transparencia, \\
de educación horizontal, del \\
cuidado del medioambiente.
\end{tabular} & 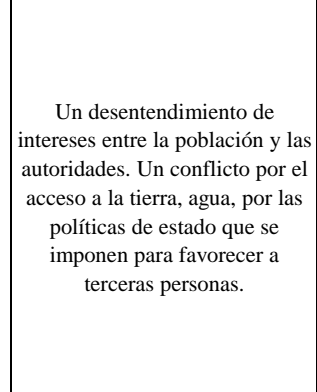 & 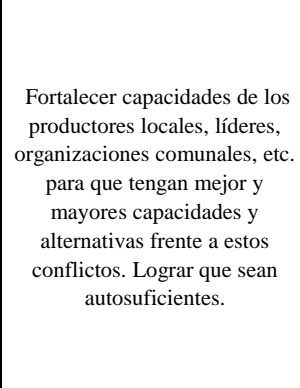 & 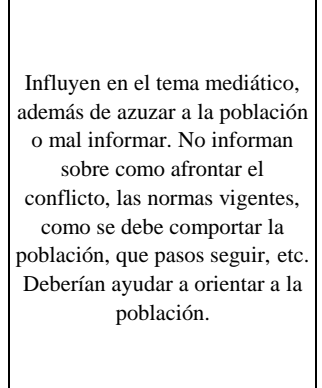 & 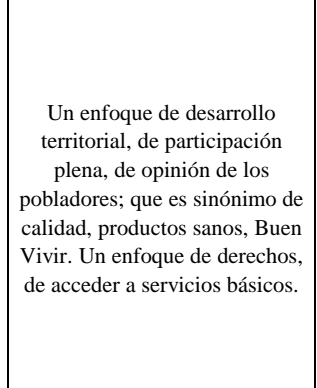 & 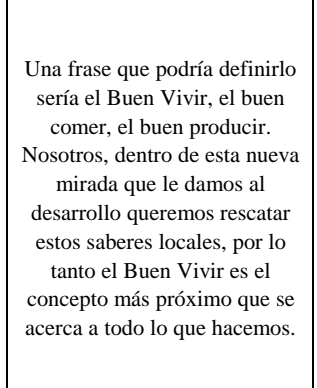 & 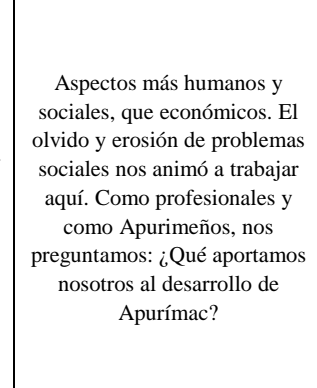 & 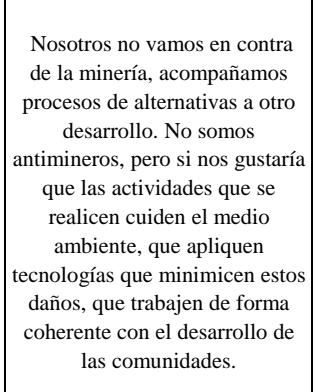 & \begin{tabular}{|c|c} 
Promovery y trabar la \\
heramainta del \\
ordenamimento teritiorial.
\end{tabular} & 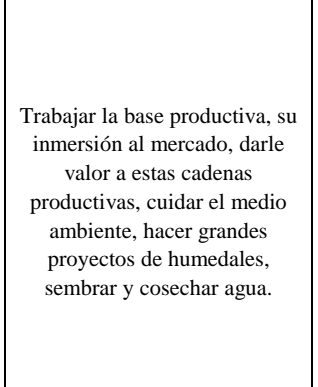 & 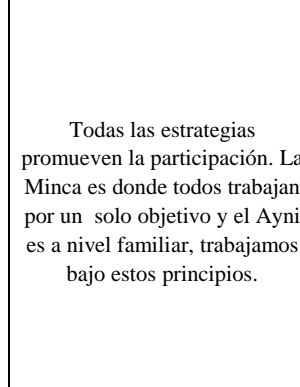 \\
\hline $\begin{array}{c}\text { Broederliji Denle } \\
\text { Entrevista Raphael } \\
\text { Heomer, } \\
\text { Representantere } \\
\text { oficial en Perui. }\end{array}$ & 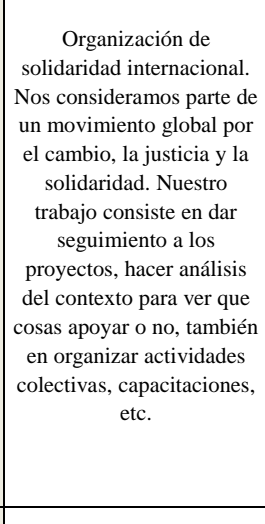 & 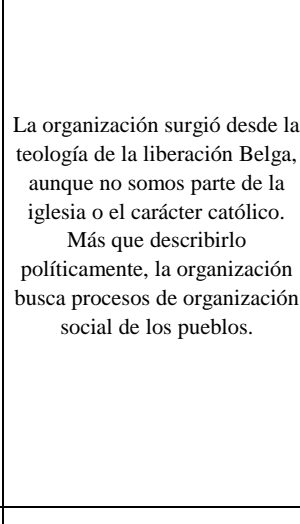 & 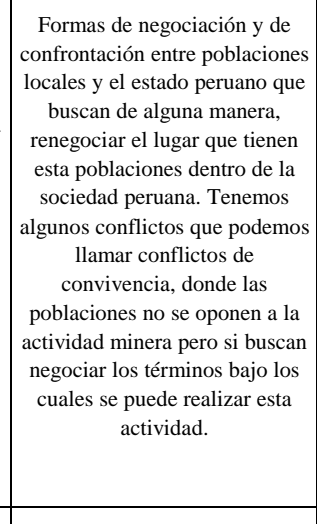 & 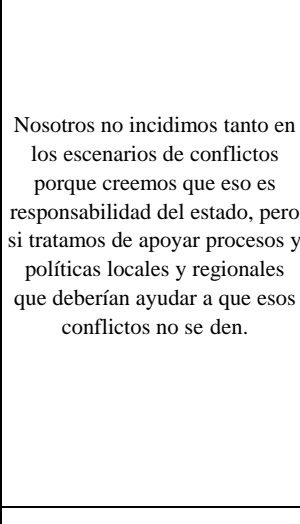 & 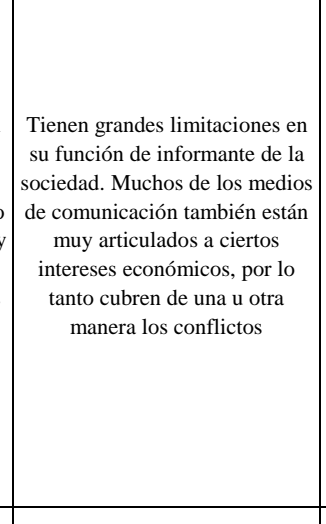 & 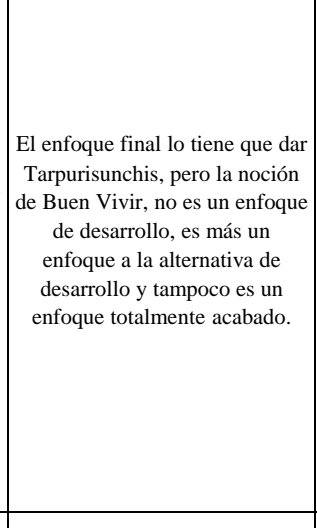 & 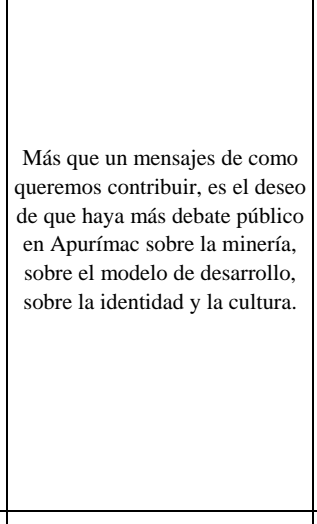 & 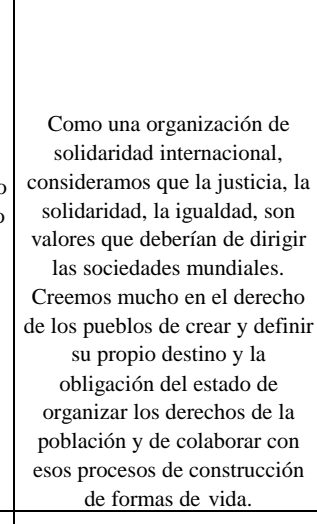 & 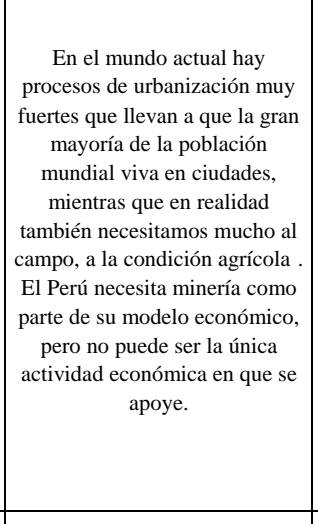 & \begin{tabular}{|c|} 
Una estrategia pedagogica \\
de etenáticas atrabajar. $Y$ \\
financiamiento.
\end{tabular} & 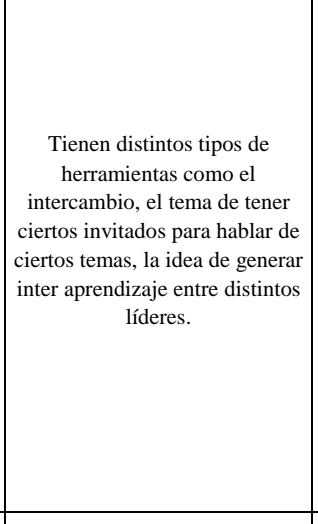 & $\begin{array}{l}\text { Si, es uno de los objetivos, } \\
\text { reanudar la organización social }\end{array}$ \\
\hline 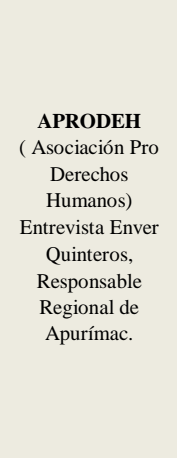 & 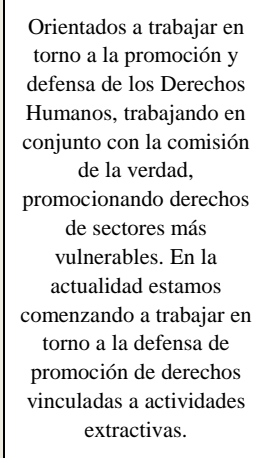 & 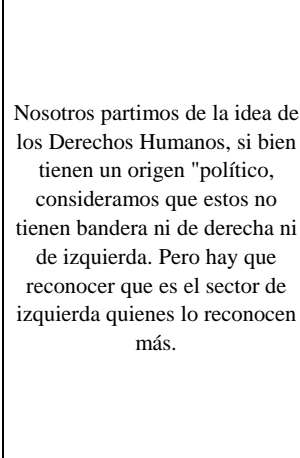 & 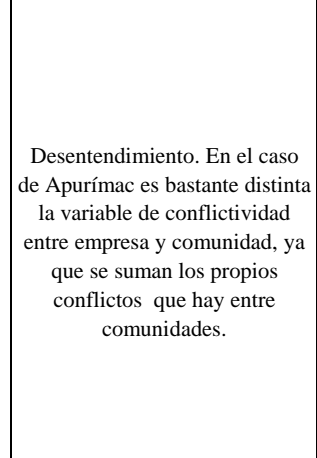 & 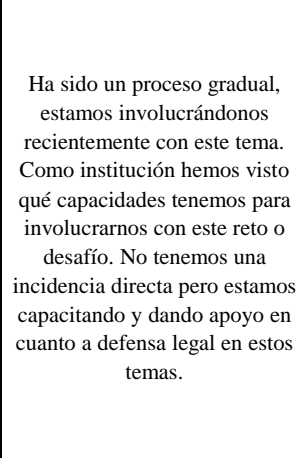 & 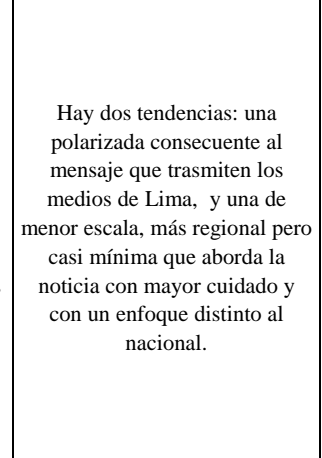 & \begin{tabular}{|c|} 
Al buen vivir como una idea, \\
pero falta desarrollar su \\
contenidid. Se tiene que \\
aterrizar en la práctica.
\end{tabular} & $\begin{array}{l}\text { La posibilidadd de trabajar } \\
\text { modelos alternativos de } \\
\text { desarrollo. }\end{array}$ & 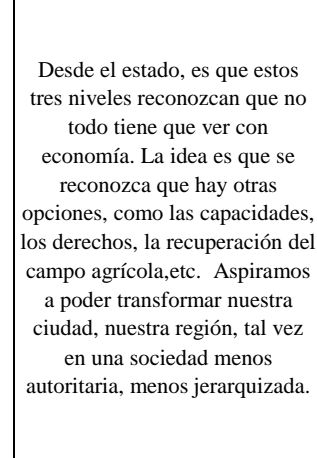 & 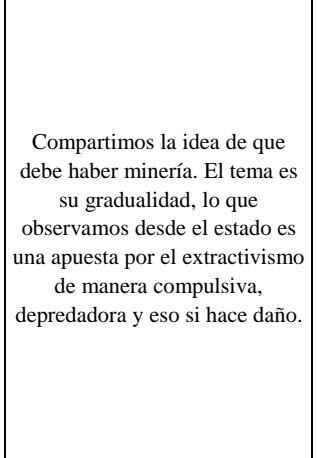 & $\begin{array}{c}\text { Mas cercando a la defensa } \\
\text { de derechos humanos, } \\
\text { apoyo legall capacitación en } \\
\text { estos temas. }\end{array}$ & $\begin{array}{l}\text { Un programa de formací́n, que } \\
\text { serána suerte de escuela. Va a } \\
\text { tener tres o c caurom módulos de } \\
\text { trabajo. }\end{array}$ & 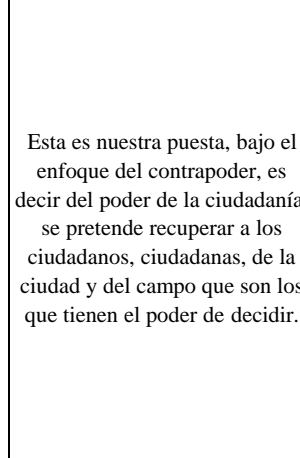 \\
\hline 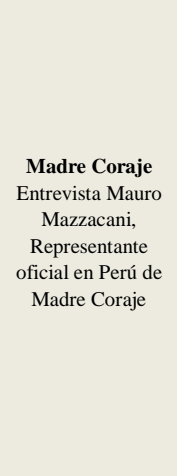 & $\begin{array}{l}\text { Madre Coraje proviene del } \\
\text { sur de Espaná, es una } \\
\text { Organización No } \\
\text { Gubernamental Extranjera } \\
\text { que trabajaj en el Perú } \\
\text { ejecutando o financiando } \\
\text { proyectos de desarrollo. }\end{array}$ & 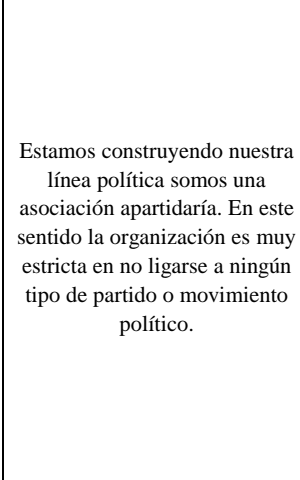 & 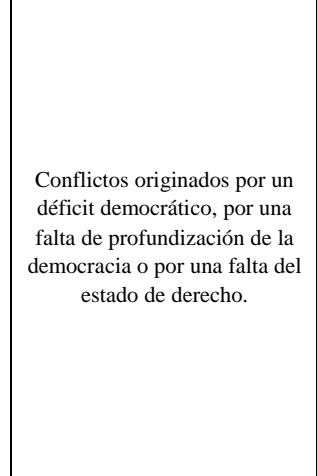 & 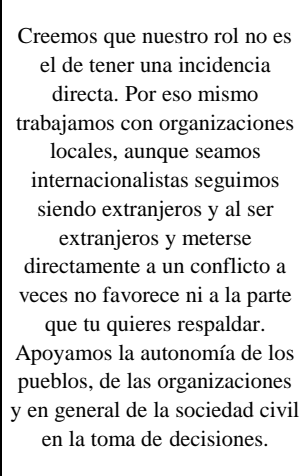 & 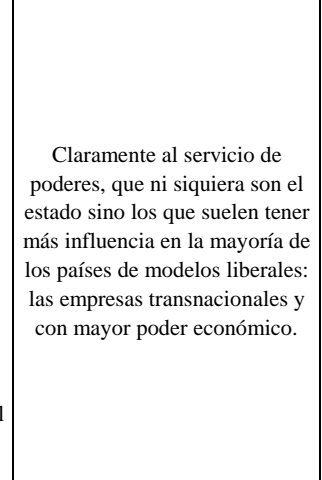 & $\begin{array}{l}\text { El enfoque de desarrollo } \\
\text { humano, de derechos, de genero } \\
\text { transuersal. El Buen Vivir, mas } \\
\text { que un enfoque es un concepto } \\
\text { en construcción. }\end{array}$ & 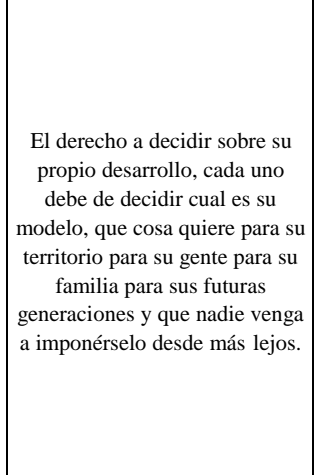 & 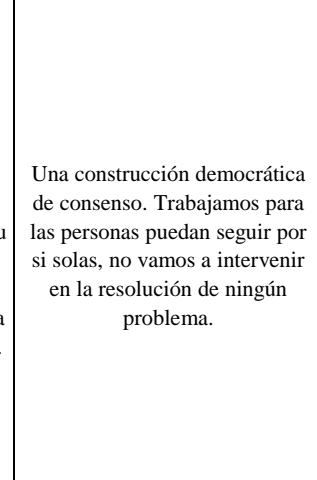 & 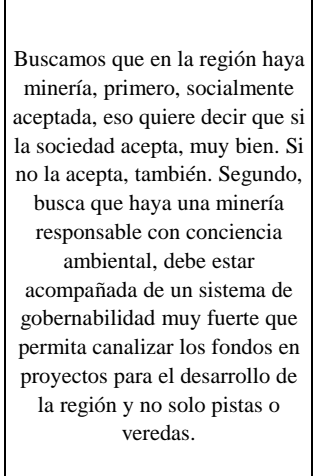 & 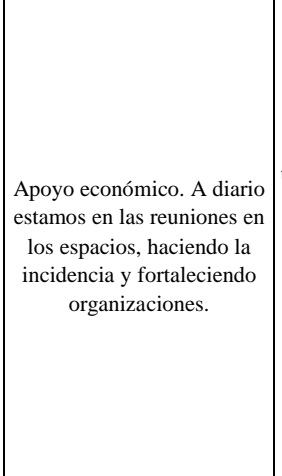 & 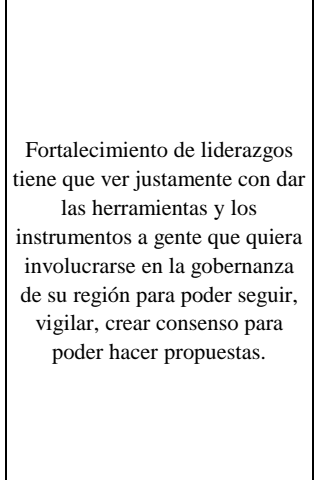 & $\begin{array}{l}\text { Es el objetivo central, buscara } 1 \\
\text { reorganización de la población } \\
\text { para la toma de decisiones e } \\
\text { incidencia en su comunidad. }\end{array}$ \\
\hline
\end{tabular}


Por otro lado, quieren recordar a las personas su derecho a decidir sobre su entorno.Para ellos cada población debe decidir cuál es su modelo de desarrollo, qué cosa quiere para su territorio, su gente, su familia, sus futuras generaciones y que nadie debe de imponérselo. Con su trabajo buscan apoyar estos procesos para que luego las poblaciones puedan seguir por si solos, ya que ellos, como institución no buscan resolver ningún problema. En cuanto a la minería, concuerdan con que en la región se desarrolle esta actividad; primero, socialmente aceptada; segundo, busca que haya una minería responsable con conciencia ambiental que debe estar acompañada de un sistema de gobernabilidad muy fuerte que permita canalizar los fondos en proyectos para el desarrollo de la región y no solo en pistas o veredas. Su misión es colaborar con los pueblos empobrecidos y en riesgo de exclusión del mundo. Comentan que su relación con Perú es histórica (relación Perú - España) y Madre Coraje tiene como principio la gratuidad, la reciprocidad, la solidaridad internacional y el perseguir la justicia social.

Finalmente, por el lado de APRODEH, consideran al Buen Vivir como una idea a la que le falta desarrollar un contenido, ya que indican se debe crear según los ideales o necesidades de la población; basado en sus anhelos de lo que quieren lograr a futuro. Por ello, el principal mensaje que buscan transmitir, es la variedad de opciones o posibilidades que hay para trabajar modelos alternativos al desarrollo convencional (capitalismo), pretenden dar a conocer ideas más amplias y diversas de como crecer, desarrollarse, sin solo centrarse en un camino o forma; por ello quisieran que la población tenga la posibilidad de crear su propio significado del Buen Vivir.

Sus principales motivaciones nacen desde un punto de vista en el que el Estado (en sus tres niveles: municipal, regional, nacional), se comprometa a reconocer que no todo lo concerniente al desarrollo tiene que ver con economía; sino que hay otros aspectos importantes como las capacidades, los derechos, la recuperación del campo, la agricultura, etc. Aspiran a poder transformar la sociedad una menos autoritaria, menos jerarquizada. Finalmente, comparten la idea de que debe haber minería, pero se debe debatir su gradualidad, ya que lo que se observa actualmente es una apuesta por el extractivismo de manera compulsiva, depredadora.

\section{LÍDERES SOCIALES}

Uno de los objetivos específicos era conocer las expectativas de los líderes sociales asistentes a los talleres o programas de formación. En la Figura 5, se 
Figura 10: Resumen de respuestas de los líderes sociales

\begin{tabular}{|c|c|c|c|c|c|c|c|c|c|c|c|c|c|c|}
\hline Dimasian Liarers & 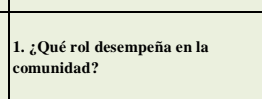 & 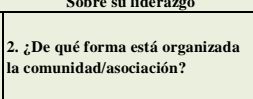 & 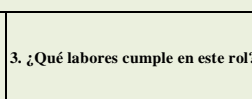 & 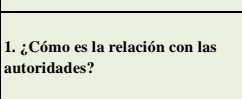 & 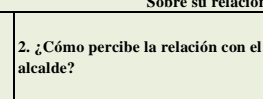 & 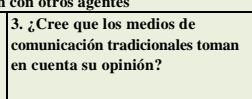 & 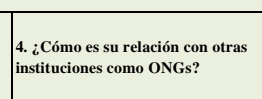 & 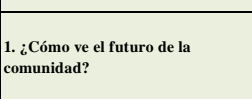 & 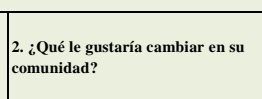 & 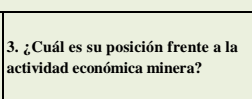 & 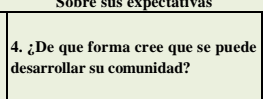 & 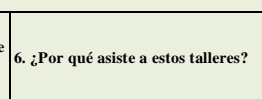 & acalde & 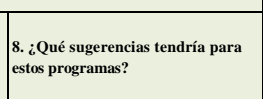 \\
\hline 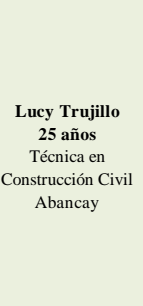 & 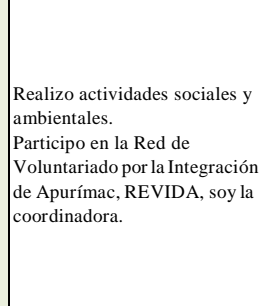 & 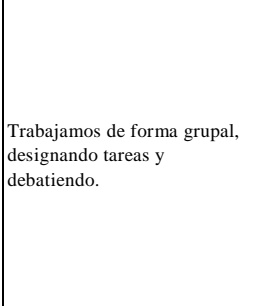 & 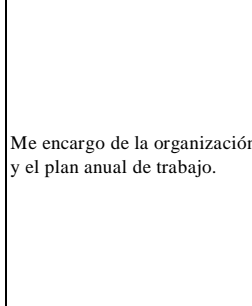 & 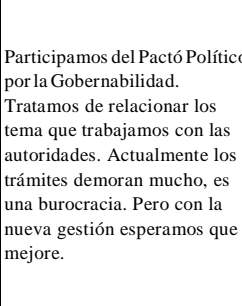 & 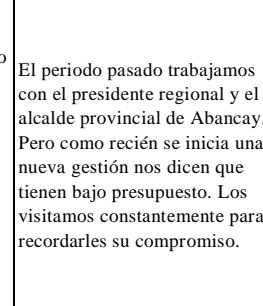 & 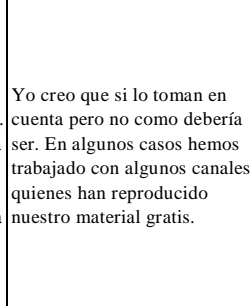 & 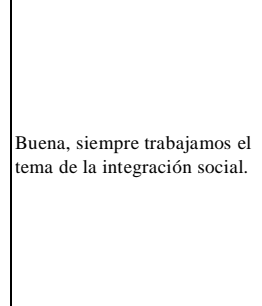 & 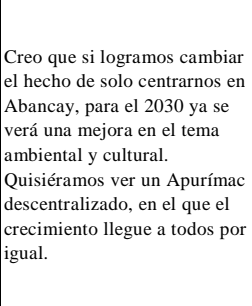 & 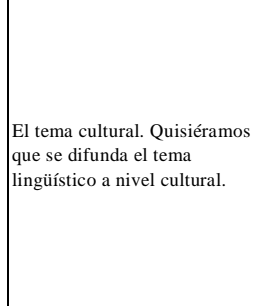 & 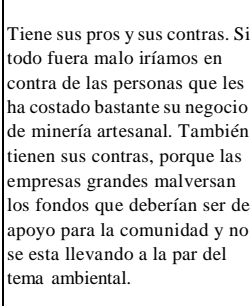 & 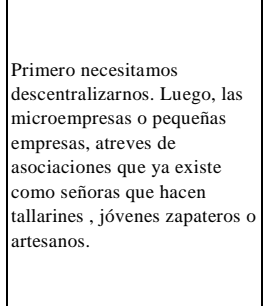 & 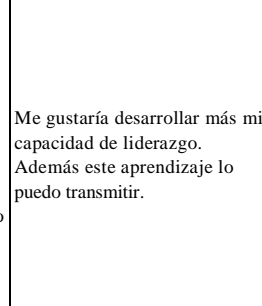 & 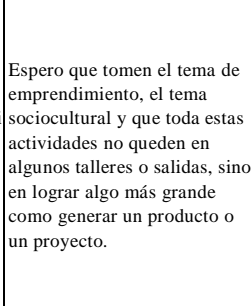 & 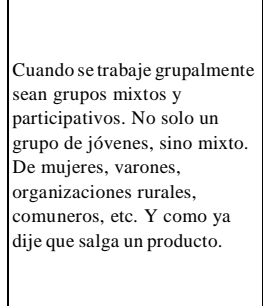 \\
\hline 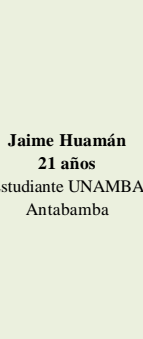 & 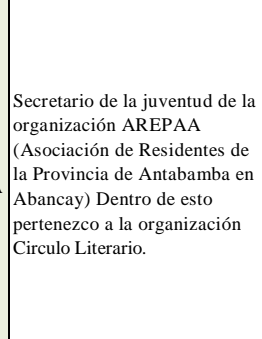 & 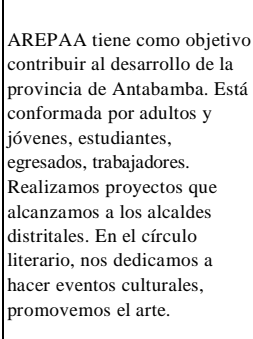 & 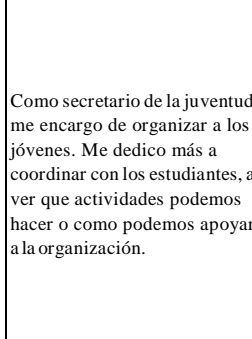 & 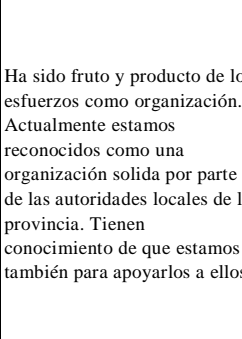 & 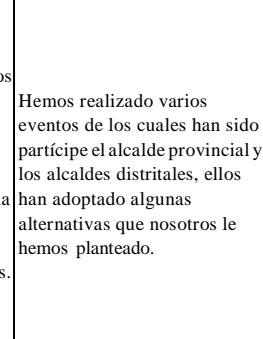 & 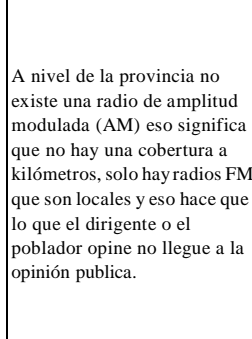 & 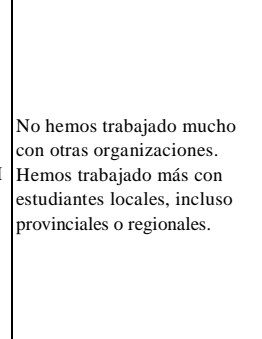 & 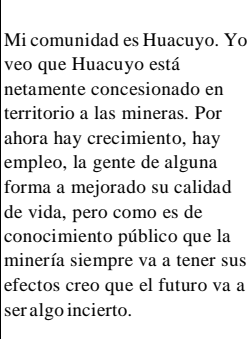 & 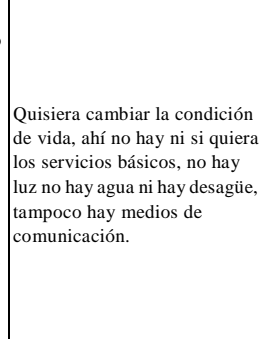 & 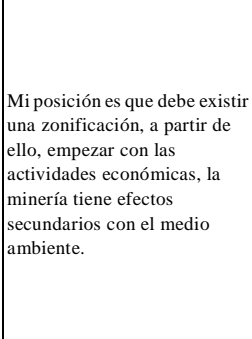 & 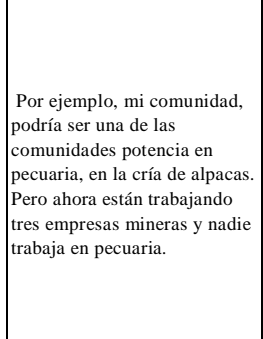 & 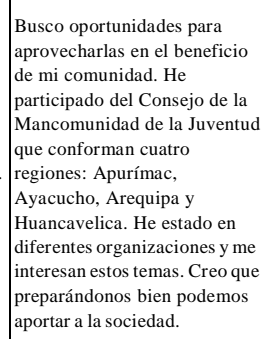 & 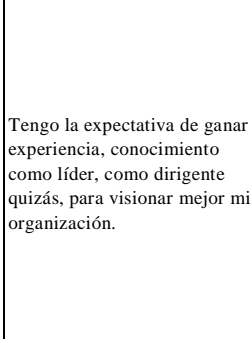 & 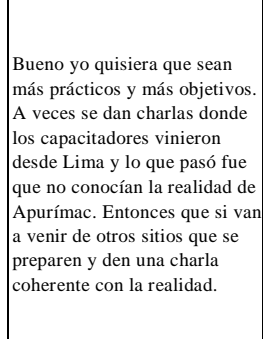 \\
\hline 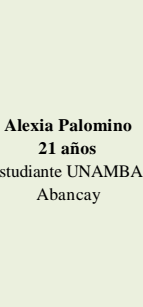 & 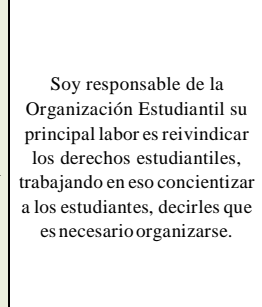 & 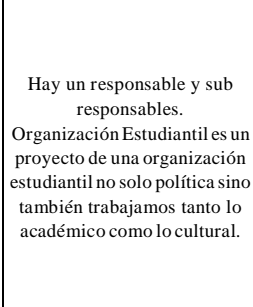 & 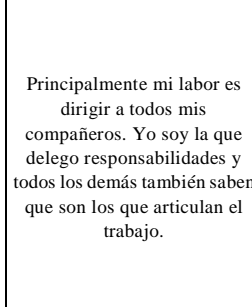 & 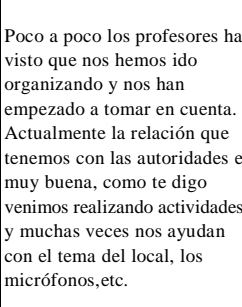 & 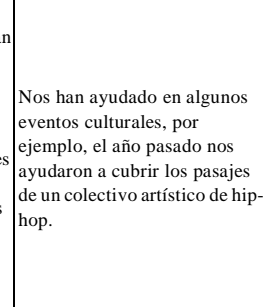 & $\begin{array}{l}\text { Solol henom rabat } \\
\text { APRODEH }\end{array}$ & 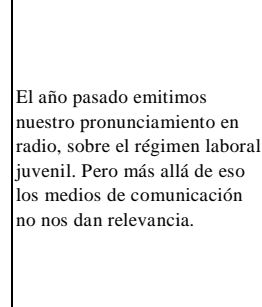 & 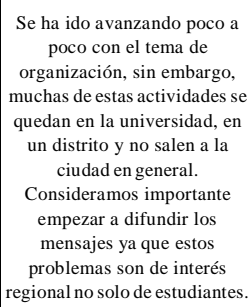 & 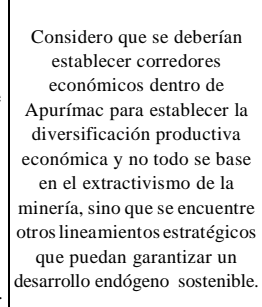 & 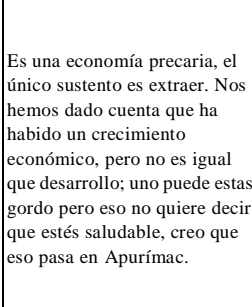 & 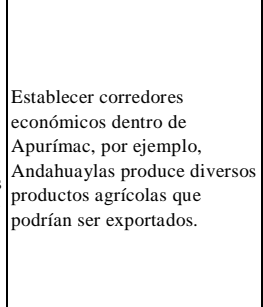 & 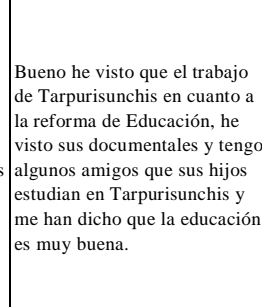 & 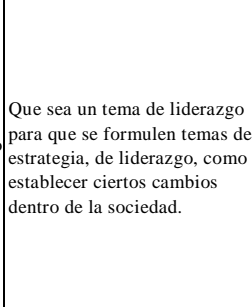 & creo quen no. \\
\hline 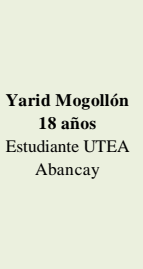 & 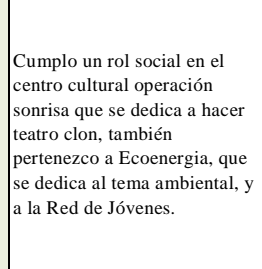 & 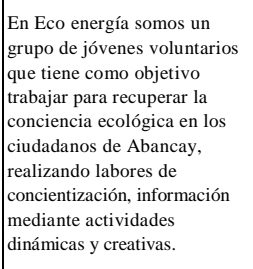 & 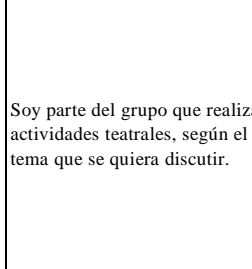 & 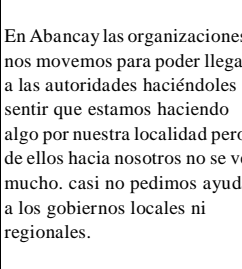 & 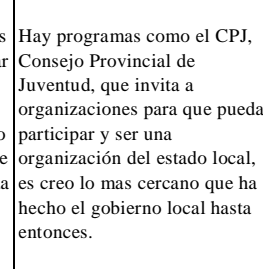 & 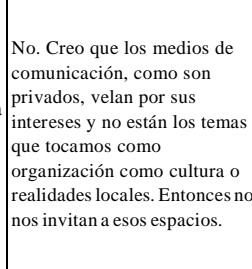 & 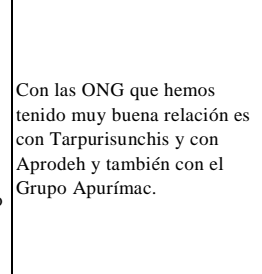 & 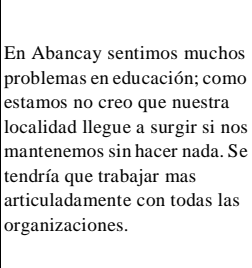 & & 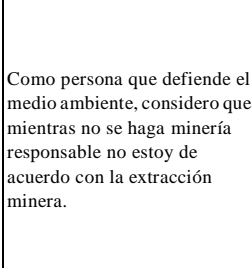 & 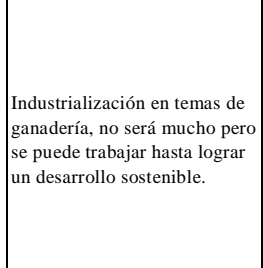 & & 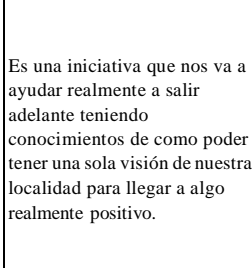 & 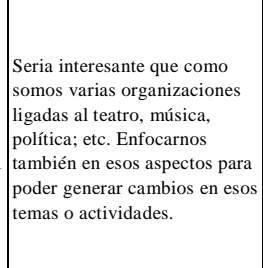 \\
\hline 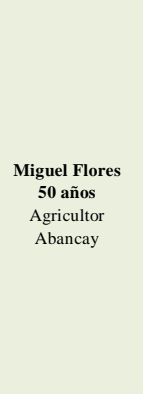 & 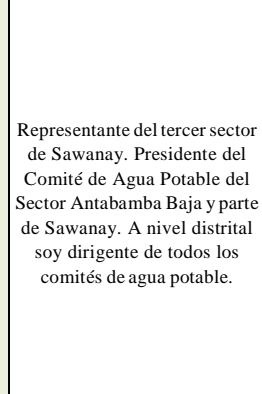 & 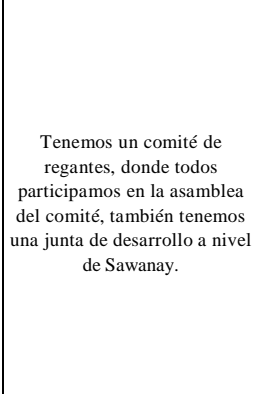 & 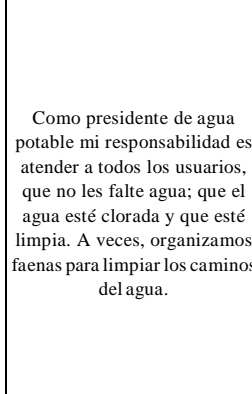 & 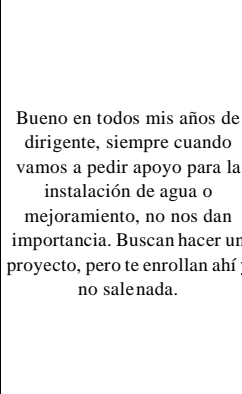 & 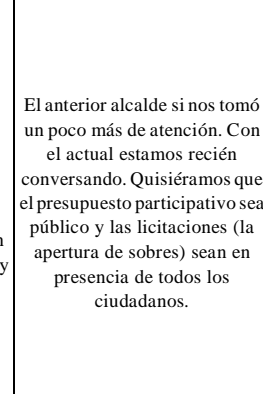 & $\begin{array}{l}\text { No. No tienen nada que ver } \\
\text { con onosoros. }\end{array}$ & 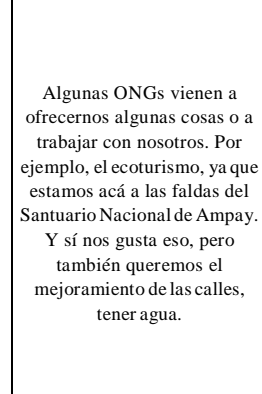 & 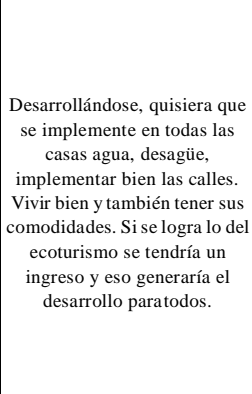 & 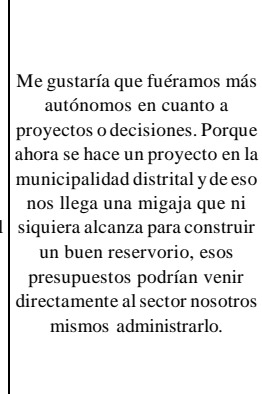 & 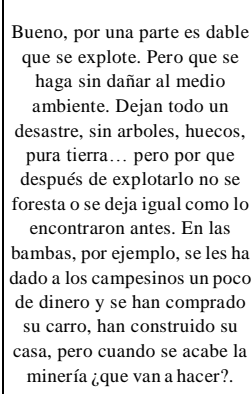 & 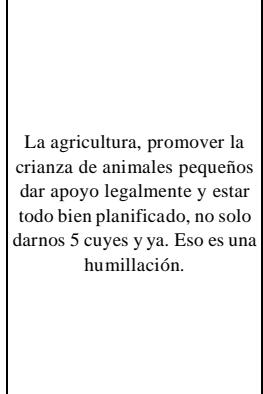 & 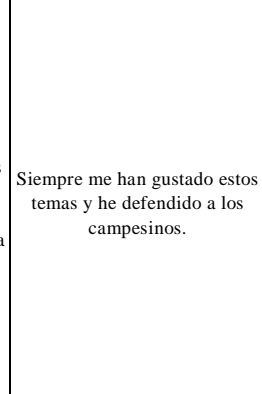 & Aprender para compartir. & 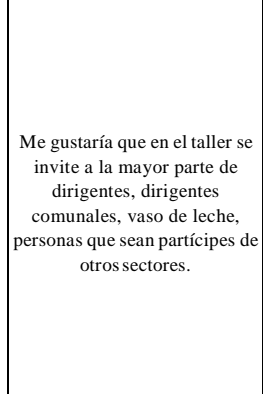 \\
\hline 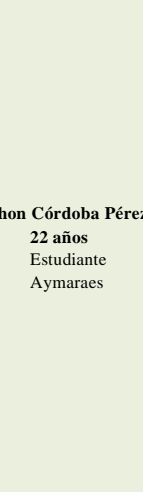 & 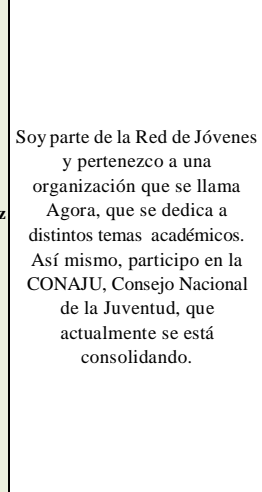 & 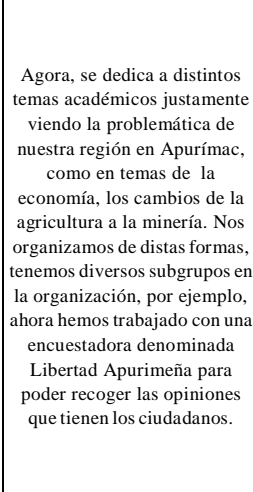 & 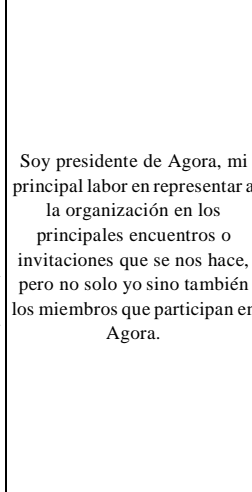 & 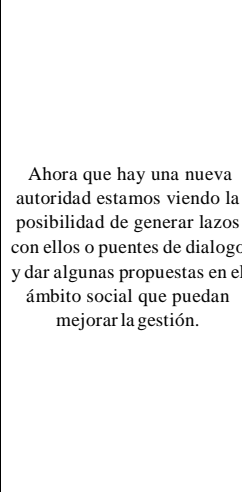 & 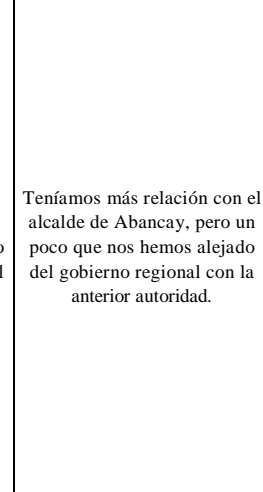 & 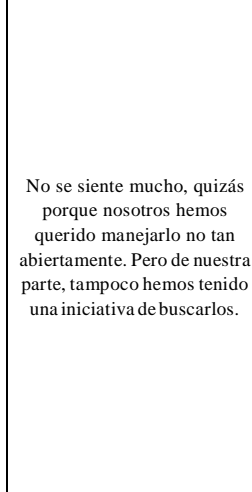 & $\begin{array}{l}\text { atabald con } \\
\text { Apurinac. }\end{array}$ & 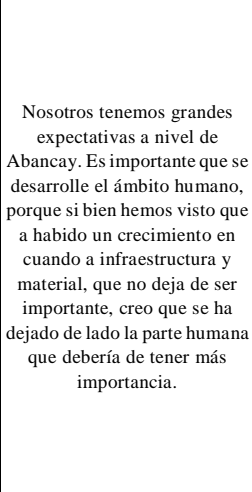 & 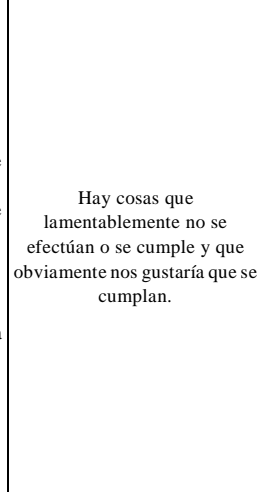 & 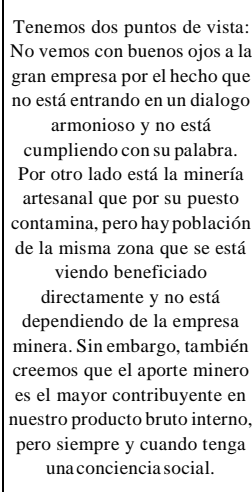 & 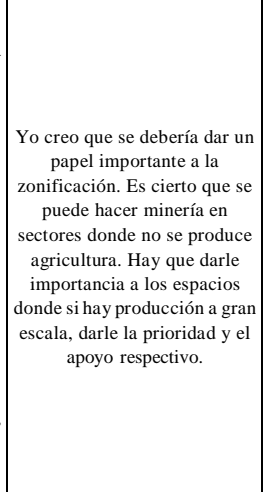 & 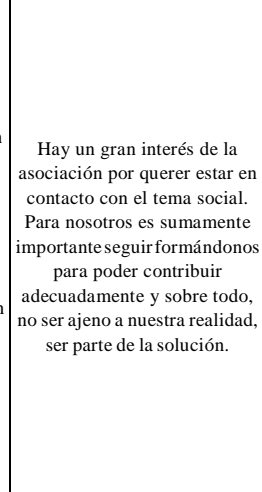 & 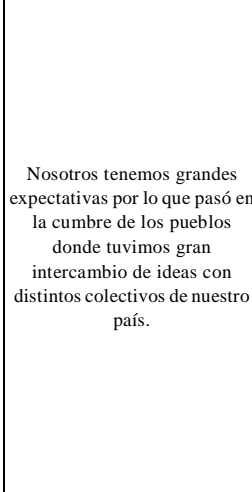 & 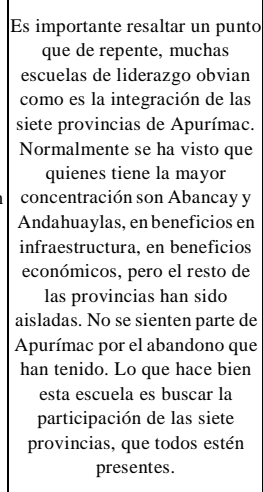 \\
\hline
\end{tabular}


resumen de las respuestas sobre en cuanto a los temas de liderazgo y la relación con su entorno.

En cuanto a sus expectativas sobre el futuro de su comunidad, la mayoría resalta que se ha visto un crecimiento o una mejora poco a poco, sin embargo, está no continuará si no se empieza a realizar un trabajo global en la región, dejando de trabajar solo en las universidades distritos o ciudades, sino realizar un trabajo regional que promueva proyectos para el desarrollo, la cultura, la educación y también servicios básicos de vida, ya que mencionan el desinterés por algunas localidades (provincias) frente a la constante mención de otras como Andahuaylas y Abancay, esto genera un crecimiento centralizado. Así mismo mencionan que se ha visto un incremento del empleo, calidad de vida, economía e infraestructura, pero que sigue siendo muy centralizado en los lugares donde se ha instalado la minería, donde a su vez se deja de lado el crecimiento humano, el cual debería ser el más importante. Por ello, dudan del desarrollo a futuro con la actividad minera y están alerta a los efectos nocivos sobre la población y el ambiente.

Frente a esta situación, quisieran realizar cambios en su comunidad en distintos ámbitos como: nivel de servicios básicos implementando a toda la población luz, agua, desagüe, etc. A nivel cultural, con la implementación del quechua a la vida diaria de la ciudadanía. A nivel económico, estableciendo corredores económicos dentro de Apurímac para establecer la diversificación productiva económica y que no todo sea minería. Y en cuanto a educación ciudadana, para concientizar a la gente de los temas de interés regional y el cumplimiento de sus deberes y derechos.

Referente al crecimiento económico mediante la minería, la mayoría coincide en que tiene su lado positivo y negativo, lo positivo para ellos es el ingreso económico del canon minero para gestionar nuevo proyecto, sin embargo, rápidamente descartan este beneficio mencionando la corrupción y mal manejo de estos recursos, así como con la analogía de que crecimiento económico no es igual a desarrollo. En cuanto al lado negativo, los principales temas mencionados son la contaminación, el crecimiento de desigualdad en la población, la concentración e incremento de esta actividad sin límites y su falta de sostenibilidad en el tiempo.

Cabe resaltar que la mayoría a pesar de tener dudas sobre la minería a gran escala, resaltan el hecho de que la minería artesanal podría ser una buena alternativa económica (aunque son conscientes de que este tipo de minería también contamina pero minimizan el daño), 
ya que afirman que en la región, solo se extrae el mineral en bruto y no se transforma o procesa en las localidades, también porque hay población que se ve beneficiada directamente y no dependen de la gran empresa, así mismo sugieren se pueda dar facilidades para formalizar esta actividad.

Por otro lado, al conversar sobre las alternativas de desarrollo desvinculadas de la minería resaltan su deseo de que se fomente la creación de microempresas o pequeñas empresas, a través de asociaciones entre distintos grupos de productores como artesanos, zapateros, gastronomía, etc. En Abancay, sugieren mayoritariamente las actividades pecuarias de cría de animales que las actividades agrícolas, por problemas de riqueza de suelos, a diferencia de Andahuaylas donde si hay una mayor productividad agrícola ${ }^{14}$. Así mismo mencionan la creación de corredores económicos en la región que faciliten el comercio de las actividades antes mencionada. Finalmente, proponen una zonificación adecuada en la región para que puedan trabajar al mismo tiempo la minería y las otras actividades económicas sin que los efectos negativos de la primera, lleguen a la segunda.

${ }^{14}$ Ver Figura 7 con explicación detallada de productividad de la región. Según el Plan Estratégico Regional del Sector Agrario de Apurímac 2009-2015, en general la productividad (rendimiento) de la actividad agrícola regional es más baja que la de nivel nacional; ello debido a los factores como el uso de tecnología tradicional, la falta de crédito, capacitación y asistencia técnica, etc. Dichos factores negativos son compensados, en parte, por el clima benigno de algunos valles como el de Abancay y Curahuasi y por la laboriosidad de la pequeña agricultura campesina. (Ministerio de Agricultura y Riego, 2009). 
Figura 11: Situación de las actividades económicas en Apurímac (Ministerio de Agricultura y Riego, 2009)

Áreas Diferenciadas por Su Dinamismo - Actividades Económicas Apurímac

Zona Dinámica. - Constituida por las provincias localizadas mayormente en la zona de alto y meso andino: Abancay, Andahuaylas y Chincheros, que han logrado un mayor desarrollo relativo que las restantes provincias de la Región.

Zonas Estancadas. - Esta tipificación corresponde básicamente a las provincias de, Antabamba y Aymaraes, caracterizado por su producción de base agropecuaria de tecnología tradicional, producción destinada mayormente al consumo local, de bajos rendimientos, esta zona a través de la red vial que posee está articulada con la capital de la Región y Lima.

Zonas marginales (aisladas).- En la Región se distinguen como zonas marginales las provincias de Grau y Cotabambas, sustentado en el bajo nivel de comercialización, su difícil accesibilidad, territorios sub ocupados y economías de subsistencia, población predominantemente rural, considerados en extrema pobreza.

\begin{tabular}{|l|l|l|l|l|}
\hline Zona & Provincia & $\begin{array}{l}\text { Área de } \\
\text { Influencia }\end{array}$ & $\begin{array}{l}\text { Actividades } \\
\text { Económicas }\end{array}$ & $\begin{array}{l}\text { Centros de apoyo } \\
\text { a la producción }\end{array}$ \\
\hline Dinámica & $\begin{array}{l}\text { Abancay, } \\
\text { Andahuaylas, } \\
\text { Chincheros }\end{array}$ & $\begin{array}{l}\text { Nacional, } \\
\text { Regional, Local }\end{array}$ & $\begin{array}{l}\text { Agrícola } \\
\text { Pecuaria } \\
\text { Industria } \\
\text { Turismo }\end{array}$ & $\begin{array}{l}\text { Abancay, } \\
\text { Curahuasi, } \\
\text { Andahuaylas, } \\
\text { Chincheros }\end{array}$ \\
\hline Estancada & $\begin{array}{l}\text { Antabamba, } \\
\text { Aymaraes }\end{array}$ & Local, regional & $\begin{array}{l}\text { Agrícola } \\
\text { Pecuaria } \\
\text { Minería } \\
\text { Turismo }\end{array}$ & $\begin{array}{l}\text { Antabamba, } \\
\text { Chalhuanca, } \\
\text { Haquira }\end{array}$ \\
\hline Marginal & Grau, \\
Cotabambas & Local, regional & $\begin{array}{l}\text { Agrícola } \\
\text { Pecuaria } \\
\text { Minería } \\
\text { Turismo }\end{array}$ & $\begin{array}{l}\text { Chuquibambilla, } \\
\text { Tambobamba, } \\
\text { Ccoyllurqui }\end{array}$ \\
\hline
\end{tabular}

Frente a esta problemática, estas personas deciden asistir a los talleres o programas de formación que brinda Tarpurisunchis porque quisieran aprender y capacitarse sobre el tema social y poder compartir lo aprendido con su comunidad o colectivos. Así mismo, desean desarrollar sus capacidades de liderazgo y conocer más sobre la realidad regional e interactuar con otras personas interesadas en los mismos temas para debatir y poder iniciar proyectos juntos. Sus expectativas giran en torno a los mismos temas de emprendimiento, gestión social, obtener experiencia, lograr cambios en las sociedades, etc. 
Finalmente, sus sugerencias están dirigidas primero, hacia la forma de trabajo en los talleres. Comentan que se debería tener grupos mixtos para generar la participación, mezclar jóvenes, hombres, mujeres, dirigente, etc. Así mismo, tener una preparación previa si es que los ponentes serán de otras ciudades fuera del territorio apurimeño, ya que no habría un vínculo o conocimiento de la realidad local. Segundo, consideran que se debe integrar a las siete provincias teniendo participantes de todas las ciudades. Y finalmente, que el trabajo no culmine solo en un taller, sino que se genere un producto o proyecto que se pueda desarrollar en conjunto y tenga evaluación constantemente, es decir, lograr compromiso con los involucrados. 


\section{DISCUSIÓN}

El objetivo central de esta investigación fue analizar el uso de la comunicación de Tarpurisunchis para el fortalecimiento del tejido social y su acción empoderada en un contexto de prevención de conflictos socioambientales con el objetivo secundario de desarrollar competencias y capacidades decomunicación con las organizaciones sociales de Apurímac. De esta forma, se concluye que su plan de acción en capacitar líderes sociales para que ellos puedan generar un debate con la población sobre el tipo de desarrollo que se quiere para la región y la vigilancia del cumplimiento de esta.

Mediante este proceso, se trabaja el capital social de la población además de un aporte al capital cultural por parte de Tarpurisuchis con información que ayude a equiparar el conocimiento de la población con respecto a la de los agentes involucrados en los conflictos socioambientales. Así mismo, según lo planteado por la institución, se basan en un modelo de desarrollo alternativo, ligado a un Buen Vivir ya que orientan sus objetivos a la concientización del reconocimiento de las culturas indígenas, la implementación de la educación bilingüe (idiomas originarios), el autogobierno por parte de las comunidades, el incentivo de la economía comunitaria y todo esto vinculado a aspectos no tangibles como situación psicológica, cosmovisión indígena, respeto a la naturaleza, etc. De esta forma, se separan del modelo de desarrollo clásico; cabe resaltar que este enfoque de Buen Vivir aún se encuentra en definición por la población apurimeña, ya que lo que busca la institución es que la sociedad misma lo cree y valide. Por otro lado, según sus estrategias y actividades a realizar tomarán en cuenta el refuerzo de capacidades y el empoderamiento según la definición de Eizagirre ${ }^{15}$ aplicado a su propio contexto. La institución busca que se aplique un modelo de desarrollo participativo y contrario al modelo de "un solo desarrollo universal".

En cuanto a sus aliados, las organizaciones participantes (Grupo Apurímac), tienen una línea institucional similar a la de Tarpurisunchis; ya que todas ellas comparten la idea de que la minería primero, deber ser aceptada por la población; segundo, respetar los estándares de seguridad y cuidado ambiental; tercero, generar proyectos que ayuden a crecer a las comunidades no solo en infraestructura sino en proyectos para el desarrollo. De esta forma, respondiendo al primer objetivo específico sobre cuáles son sus

\footnotetext{
${ }^{15}$ Un proceso participativo donde el aprendizaje esté basado en la experiencia propia de las personas, una participación orientada a cambiar la realidad. (Eizagirre, 2006).
} 
motivaciones (de las cuatro instituciones aliadas), la respuesta a esta interrogante supondría que se basan en el refuerzo y aporte a la sociedad orientada según sus propios objetivos institucionales: mejorar su entorno social centrándose en las personas, realizando proyectos de capacitación e instrucción, deslindando del asistencialismo.

De acuerdo a esta conclusión, se puede resaltar la concordancia entre los agentes involucrados: Tarpurisunchis - Instituciones aliadas - Líderes sociales. Sin embargo, por parte del último agente: líderes sociales, se aprecia una idea contradictoria con respecto a la explotación minera. Por un lado, ven todos los aspectos negativos de la gran minería o minería transnacional, aceptando su aplicación con las precauciones del cuidado del medio ambiente y sociedad. Sin embargo, por otro lado, la mayoría de líderes considera a la actividad minera como una actividad económica que es mejor desarrollar en pequeña escala y de forma artesanal, incluso algunos sugieren que se debe dar facilidades para la formalización de los mineros informales, alegando que en su mayoría se dedican a la extracción y no transformación del material por lo que sí contaminarían, pero de forma leve.

Como bien se sabe la minería artesanal realiza operaciones mineras de pequeña escala, en las que se utiliza tecnologías rudimentarias e intensivas en mano de obra y con poca exigencia sanitaria, de seguridad y cuidado ambiental. A pesar del beneficio y la independencia de la población al manejar esta actividad extractiva, el uso intensivo de mercurio, la emanación de gases y la dispersión de partículas de mercurio durante su quema hacen que esta actividad sea sumamente contaminante y que tenga grandes impactos sobre la salud pública. Asimismo, su escasa formalización da paso a operaciones mineras muy inseguras, propensas a la sobreexplotación de mano de obra. Esta contradicción respecto a sus ideales podría ser un factor clave para entender la conflictividad en esta zona, ya que, si bien hay un discurso y posición, de parte de los líderes sociales, de cuidado del medio ambiente, por falta de información o beneficio económico de la población, se acepta esta actividad en su forma artesanal.

Es principalmente por este punto de contradicción y discordancia, donde se encuentra una de las principales debilidades del proyecto, ya que no cuentan con estudios previos para identificar los principales problemas, fortalezas, oportunidades, debilidades, amenazas que interferían con el plan a desarrollar y permitirían obtener puntos clave y resultados medibles del proyecto, un ejemplo de esto es la situación de contradicción de discursos 
frente a la minería de gran escala versus la minería de pequeña escala. A esto se suma la falta de un plan estratégico definido en el ámbito comunicacional.

Si bien, como se mencionó previamente, Tarpurisunchis no se basa en estrategias de comunicación sino que tienen un enfoque pedagógico, fácilmente su estrategia y acciones podrían encajar en la estrategia comunicacional de "movilización social"16, la cual propone un enfoque global sin centrarse en individuos específicos. Esta estrategia, busca llegar a todos los sectores sociales con objeto de que la sociedad se movilice y apoye determinados procesos. En este caso específico se aborda desde la "movilización comunitaria"17, y dirigida a "re-editores", es decir, a personas que tienen público propio, buscando: primero, formular un horizonte atractivo y deseable (un imaginario, en este caso del tipo de desarrollo que se quiere para la región); segundo, definir adecuadamente el campo de actuación del re-editor, a quienes otros llegará el conocimiento obtenido; y tercero, colectivizar la acción. (Bernardo Toro \& Rodríguez, 2001). Esto se reflejaría en las alianzas que hace con distintas organizaciones y sobre todo con los líderes sociales que influenciaran a sus propios grupos y el trabajo a nivel regional.

De esta forma, al centrarnos en lo que es "ser estratégicos", la investigación concluye, desde el punto de vista de la comunicación estratégica, que la ONG estaría realizandoun trabajo implícito de comunicación, más no un desarrollo claro de estrategias que permitan cumplir el objetivo. En la Figura 11, se aprecia un análisis FODA que define los puntos clave que evidencian la situación del proyecto.

\footnotetext{
${ }^{16}$ Entendida como: "la convocación de voluntades para actuar en la búsqueda de un propósito común bajo una interpretación y un sentido compartidos” (Bernardo Toro \& Rodríguez, 2001).

${ }^{17}$ Orientada a lograr el compromiso de los líderes sociales tradicionales como organizaciones no gubernamentales y grupos de base, a los cuales se busca capacitar y que estos a su vez difundan a sus organizaciones. (Rodríguez, Obregón, \& Vega, 2002).
} 


\begin{tabular}{|c|c|}
\hline AMENAZAS & FORTALEZAS \\
\hline $\begin{array}{l}\text { - Ideas contradictorias del público objetivo } \\
\text { respecto a la minería formal e informal. } \\
\text { Minería informal (pequeña escala) = no } \\
\text { contaminación / minería formal (gran } \\
\text { escala)= contaminación. } \\
\text { - Bajo porcentaje de acceso a internet en la } \\
\text { región, por lo que el material enviado por } \\
\text { este medio no sería recibido. } \\
\text { - Poco apoyo recibido de los organismos } \\
\text { estatales y medios tradicionales de } \\
\text { comunicación. }\end{array}$ & $\begin{array}{l}\text { - Cuentan con experiencias previas de } \\
\text { gestión social en la región. } \\
\text { - Personal capacitado en el tema de } \\
\text { fortalecimiento y empoderamiento de } \\
\text { poblaciones. } \\
\text { - Cuentan con aliados de otras } \\
\text { organizaciones nacionales e } \\
\text { internacionales. }\end{array}$ \\
\hline DEBILIDADES & OPORTUNIDADES \\
\hline $\begin{array}{l}\text { - Falta de estudios formales previos de la } \\
\text { eficacia y eficiencia de proyectos anteriores. } \\
\text { - Falta de estudios situacionales de la } \\
\text { población, como uso de internet y medios } \\
\text { digitales. } \\
\text { - Escaso presupuesto } \\
\text { - Ausencia de un área de comunicación para } \\
\text { el desarrollo con profesionales calificados } \\
\text { en comunicación estratégica. }\end{array}$ & $\begin{array}{l}\text { - El tema de conflictos socioambientales } \\
\text { se ha vuelto más presente debido a lo } \\
\text { coyuntura nacional, por lo que se podría } \\
\text { aprovechar para obtener más apoyo } \\
\text { financiero y logístico y poder realizar } \\
\text { estudios previos y situacionales. } \\
\text { - Encontrar nuevos aliados (instituciones) } \\
\text { especialistas en el tema, que aporten } \\
\text { desde el punto de vista comunicacional. }\end{array}$ \\
\hline
\end{tabular}

Asimismo, en base a la definición y pasos básicos, antes presentada ${ }^{18}$, sobre comunicación estratégica se puede concluir lo siguiente: Sí se realiza una definición del marco estratégico, siendo los líderes sociales el público objetivo directo y a su vez, las organizaciones en las que participan estos líderes sociales su público indirecto. En cuanto al análisis de la situación actual, Tarpurisunchis se basa en experiencias pasadas de proyectos desarrollados en la región, mas no cuenta con estudios o indicadores clave que permitan un correcto análisis de las variables externas como factores políticos, económicos, sociales y tecnológicos, asimismo, al no ser especialistas en comunicación faltaría profundizar en el análisis social del costo-beneficio que percibe el público objetivo para poder lograr un cambio de comportamiento y aceptar el mensaje comunicacional. Sobre los objetivos organizacionales y comunicacionales, se alinean a los objetivos institucionales y la misión y visión de la ONG; a pesar de ello solo

${ }^{18}$ Página 8 del Marco Teórico 
centrándonos en este proceso, estarían nuevamente definidos por experiencias pasadas más no por el desarrollo de una matriz estratégica que permita organizar de manera eficiente y eficaz un plan de trabajo. En cuanto a los canales de comunicación, el contacto directo mediante talleres es una buena alternativa para lograr influir en el público, así mismo se debe reconocer el esfuerzo por buscar nuevas alternativas para facilitar la trasmisión de mensajes, sin embargo, el uso del internet no parece ser la herramienta más adecuada para llegar al público ${ }^{19}$. Se debe tener en cuenta que la programación de actividades de la ONG se ve amenazada por la disponibilidad de recursos asignados, ya que la institución es financiada por otras organizaciones internacionales, de las cuales depende. Finalmente, la medición y evaluación del proyecto es una actividad que recién se pondrá en marcha con el inicio de esta serie de actividades, ya que como se mencionó previamente, la institución no cuenta conestudios formales.

La recomendación es que se debe identificar específicamente cuales son los problemas que se quiere abordar y definir objetivos medibles que luego sirvan como indicadores para continuar con el proceso de la creación de estrategias, acciones clave, argumentos o discurso a usar y medios por el cual transmitir el o los mensajes. Asimismo, es importante identificar los actores clave, intereses de los mismos, intereses políticos, culturales, económicos que afecten el desarrollo del proyecto; establecer un clima de confianza y apertura que permita desarrollar el dialogo entre todos los actores; y principalmente tener en cuenta que la prevención es el factor fundamental para lograr el entendimiento y acuerdo de los implicados. No se puede dejar de lado la evaluación posterior a la aplicación y desarrollo del proyecto, ya que esto permitirá calcular el alcance y eficiencia de las acciones llevadas a cabo.

Un punto que aún queda pendiente, es que las muestras de líderes sociales en su mayoría eran jóvenes entre 18 y 25 años. Ante esto, se formula la pregunta si es que estos líderes son representativos de la población en general. Considero que aún faltan datos para llegar a una respuesta ya que en el trabajo no se estudió el total de los veintiséis líderes que asistirían al programa. Sin embargo, el universo de estudio en cuento a líderes sociales da respuesta al segundo objetivo específico, sobre cuáles son las expectativas de los líderes con respecto al proyecto, todos concordaron en que lo principal es aprender para

\footnotetext{
${ }^{19}$ Tomando en cuenta que en el Perú para el año 2015, el uso del internet en las zonas rurales solo era del 18\% del total. (GFK Perú, 2015).
} 
transmitir a su comunidad y/o organización y continuar gestionando el debate sobre la problemática local, además de impulsar proyectos que ayuden a la sociedad.

En conclusión, el principal problema que enfrenta Tarpurisunchis es la falta de estudios previos, fuentes de información estadística, planes estratégicos en el ámbito comunicacional y estudios posteriores que sustente con cifras los objetivos de los proyectos que plantean emprender. Si bien la organización conoce los espacios y al público, ya que han tenido una larga labor en la zona, no tienen datos que respalden estas hipótesis y ayuden a construir un plan estratégico de acción certero que pueda prever la respuesta del público objetivo y la recepción de los mensajes. Es por ello que algunos de sus productos comunicacionales, aunque sean novedosos, tienen una alta probabilidad de que no lleguen a ser recibidos por el público objetivo, un ejemplo de esto es la revista Llaqtanchispaq la cual es difundida por internet.

Por último, las preguntas más importantes son las siguientes: ¿El taller seguirá la línea que indica Tarpurisunchis y las instituciones aliadas? ¿Será consecuente con el modelo alternativo de desarrollo que se propone y se basará en la decisión de los pobladores? Y si es que son consecuentes con sus políticas de cuidado ambiental ¿influirán en la opinión del público objetivo con respecto a su opinión contradictoria de la minería a gran escala vs la artesanal? Sobre todo teniendo en cuenta que en Apurímac existirán fuertes antecedente de proyectos, en los que la mayoría de población estuvo de acuerdo con esta actividad hasta que se presentaron cambios e incumplimientos del actor principal, la empresa, que iniciaron los conflictos ${ }^{20}$.

Sin duda, estás preguntas solo se responderán viendo el contenido de los talleres de formación de líderes sociales. Por ahora, queda la certeza de que Apurímac es una zona

${ }^{20}$ Caso del proyecto minero Las Bambas, en el que el conflicto social por su alto impacto ha llevado a declarar el estado de emergencia en 6 regiones de Apurímac. En el 2010 la compañía suiza Xstrata Copper se convirtió en la dueña del yacimiento minero ubicado en la zona apurimeña, desde entonces, la relación entre la mina y las comunidades cercanas era buena y se contaba con la aprobación de la mayoría de la población. Sin embargo, en el 2014, Xstrata vendió el proyecto a la empresa china MMG, la cual realizó modificaciones en el estudio de impacto ambiental (EIA), que incluyó la cancelación de un minero ducto y la construcción de una planta de molibdeno. Estos cambios no fueron del agrado de varias comunidades y organizaciones de las zonas de impacto ya que aseguran que ponen en riesgo las zonas aledañas debido al transporte de minerales. Además, sostienen que la construcción de la planta podría afectar una de las fuentes de agua de la zona (Challhuahuacho), por lo que la licencia social ganada se tornó en contra del proyecto. Actualmente exigen que esta planta sea retirada y que el proyecto minero sea puesto a consulta previa. 
con un riesgo latente, una bomba de tiempo en cuanto al riesgo de presentar conflictos si es que no se empiezan las actividades de prevención y de interacción con la ciudadanía.

Desde esa perspectiva, la comunicación resulta estratégica, pues facilita los procesos de diálogo, encuentro y decisión entre los diversos actores. 


\section{REFERENCIAS}

Bernardo Toro, J., \& Rodríguez, M. (Setiembre de 2001). La comunicación y la movilización social en la construcción de bienes públicos. Recuperado el 18 de setiembre de 2016, de Banco Interamericano de Desarrollo (BID): http://services.iadb.org/wmsfiles/products/Publications/2220179.pdf

Bourdieu, P. (2001). Porder, derecho y clases sociales. Bilbao: Editorial Desclée de Brouwer S.A.

Cooperaccion. (1 de abril de 2015). cooperaccion.org.pe. Recuperado el 3 de Julio de 2015, de http://cooperaccion.org.pe/main/mapas/informe-deconcesiones/2015/540-septimo-informe-cartografico-sobre-concesionesmineras-en-el-peru-base-de-datos-abril-2015

Defensoría del Pueblo. (2013). www.defensoria.gob.pe. Obtenido de http://www.defensoria.gob.pe/temas.php?des=3

Defensoría del pueblo. (1 de Julio de 2016). http://www.defensoria.gob.pe/. Recuperado el 16 de Agosto de 2016, de Defensoría del pueblo: http://www.defensoria.gob.pe/conflictos-sociales/objetos/paginas/6/48reportemensual-conflictos-sociales-149-julio-2016.pdf

Defensorio del Pueblo. (1 de Junio de 2015). Ministerio del Ambiente. Recuperado el 11 de Agosto de 2015, de http://sinia.minam.gob.pe/documentos/reporte-mensualconflictos-sociales-ndeg-135-mayo-2015

Díaz-Albertini Figueras, J. (2010). Redes cercana: El capital social en Lima. Lima: Universidad de Lima. Fondo Editorial.

Dubois, A. (2006). Bantaba. Obtenido de Diccionario de Acción Humanitaria: http://www.dicc.hegoa.ehu.es/listar/mostrar/28

Eizagirre, M. (2006). Bantaba. Obtenido de http://www.dicc.hegoa.ehu.es/listar/mostrar/83

Galraith, J. (1983). La anatomía del poder. Barcelona: Plaza \& Janes.

GFK Perú. (2015). Uso de Internet en el Perú. Lima: GfK Perú.

Hammond Cisneros, M. S. (Setiembre de 2008). Diseño de estrategias de comunicación para la consolidación de un modelo de aprovechamiento sostenible de recursos naturales; Concesión Privada para la Conservación del río Queros, desarrollado 
por la Asociación para la consrvación de la Cuenca Amazónica. Proyecto

Profesional Teoricamente Fundamentado. Lima, Lima, Perú: Universidad de Lima.

Macassi Lavander, Huamani Ober, G, S., Alegría Galarreta, J., \& Rojas Alcalde, T.

(2012). Hacia una mejor gestión de los conflictos socioambientales en el Perú.

Lima, Lima, Perú: CIES.

Ministerio de Agricultura y Riego. (Febrero de 2009). http://minagri.gob.pe/.

Recuperado el 10 de Setiembre de 2016, de

http://minagri.gob.pe/portal/download/pdf/conocenos/transparencia/planes_estra tegicos_regionales/apurimac.pdf

Ministerio del Ambiente - MINAM. (2011). COMPENDIO DE LA LEGISLACIÓN

AMBIENTAL PERUANA. Lima: Ministerio del Ambiente -MINAM.

Niel, M. (2011). EL CONCEPTO DEL BUEN VIVIR. Madrid.

Orellana, R. (1999). Aproximaciones a un marco teórico para la comprensión y el manejo de conflictos socioambientales. En P. Ortiz, Comunidades y Conflictos Socioambientales: Experiencias y Desafíos en América Latina (pág. 101). Quito: Ediciones ABYA-YALA.

ProDiálogo. (14 de 01 de 2014). ProDiálogo, prevención y resolución de conflictos. Recuperado el 4 de 1 de 2017, de http://prodialogo.org.pe/

RedGE. (2012). Transiciones para salir del viejo desarrollo HAY ALTERNATIVAS AL EXTRACTIVISMO. Lima.

Rodríguez, C., Obregón, R., \& Vega, M. J. (2002). Estrategias de comunicación para el cambio social. Quito: Friedrich-Ebert-Stiftung.

Servaes, J. (2000). Comunicación para el desarrollo: tres paradigmas, dos modelos. TEMAS Y PROBLEMAS DE COMUNICACION, 10, 5-28.

Xavier, I. (1980). Development from below: notes for workers engaged. Ranchi: Xavier Institute for Social. 


\section{BIBLIOGRAFÍA}

Accion contra el hambre. (12 de Julio de 2014). Obtenido de

http://www.accioncontraelhambre.org/

Delen, B. (14 de 06 de 2014). Broederlijk Delen. Obtenido de http://www.broederlijkdelen.be/home-en

Educación sin fronteras. (8 de abril de 2014). Educación sin fronteras. Obtenido de http://www.educacionsinfronteras.org/es/

El Comercio. (27 de octubre de 2016). El Comercio. Recuperado el 22 de Diciembre de 2016, de http://elcomercio.pe/sociedad/apurimac/nueva-capital-mineraapurimac-enfrenta-enorme-reto-noticia-1942198

Grupo Propuesta Ciudadana. (2012). Foro de debate. Red participativa Perú. Foro XX. Lima: Grupo Propuesta Ciudadana.

Madre Coraje. (8 de abril de 2014). Madre Coraje. Obtenido de http://www.madrecoraje.org/

Malpartida, J. (2006). Experiencia del PER Apurímac. TAREA Revista de Educación y Cultura(64), 25-28.

Murguialday, C., Pérez, K., \& Eizagirre , M. (2006). Bantaba. Obtenido de http://www.dicc.hegoa.ehu.es/listar/mostrar/86

Oficina Nacional de Diálogo y Sostenibilidad. (s.f.). http://onds.pcm.gob.pe/.

Recuperado el 16 de agosto de 2016, de http://onds.pcm.gob.pe/el-estado-y-laconflictividad-social-en-el-peru-actual/

Rios, A. V. (2012). Enfoques teóricos en la comunicación para el desarrollo.

Perspectivas. Lima: USMP. 
ANEXOS 
ANEXO 1: RESUMEN DE PREGUNTAS DE

DIMENSIÓN ORGANIZACIONAL

\begin{tabular}{|c|c|c|c|c|c|c|c|c|c|c|c|c|c|c|c|c|}
\hline 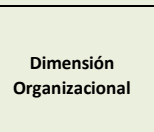 & 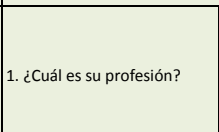 & 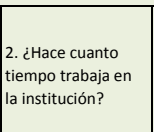 & 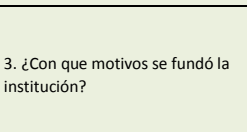 & 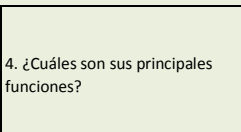 & 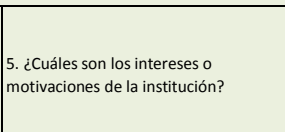 & 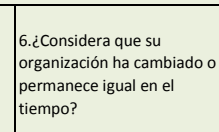 & 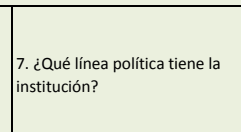 & 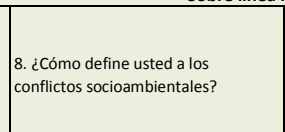 & 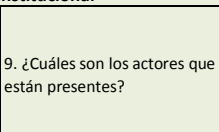 & 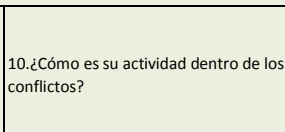 & 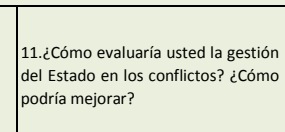 & 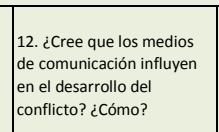 & 3 acuivers: & 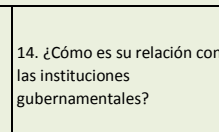 & 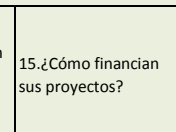 & 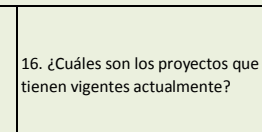 \\
\hline 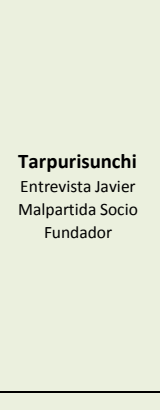 & Educador & 112 12005 & 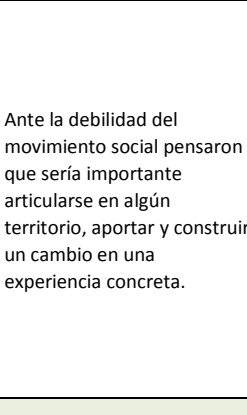 & 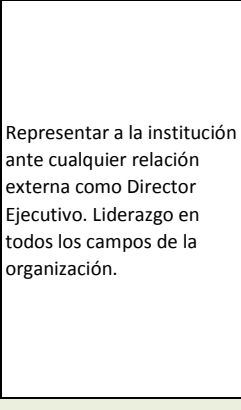 & 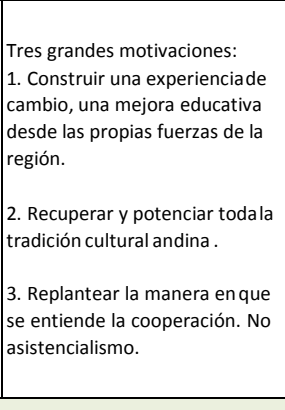 & 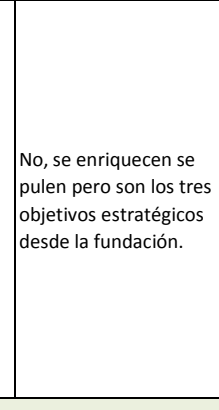 & 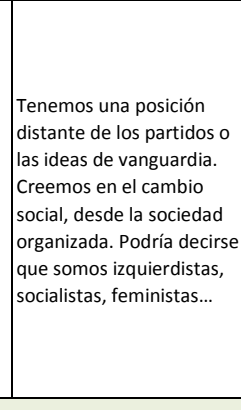 & 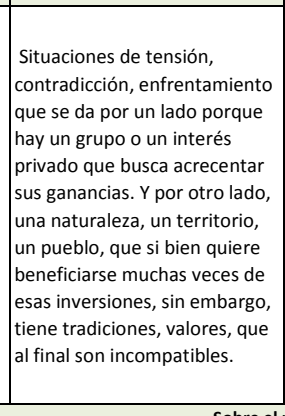 & 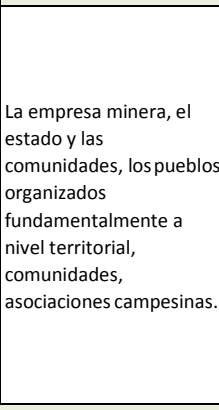 & 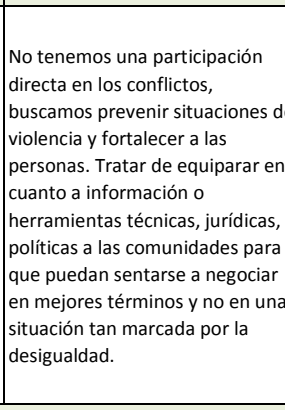 & 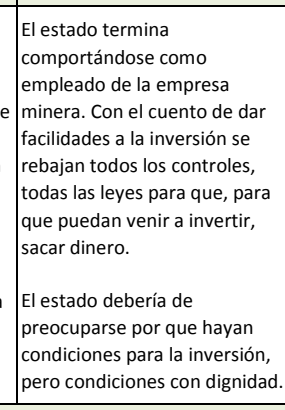 & 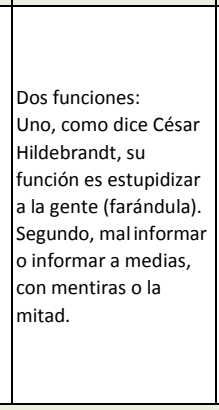 & 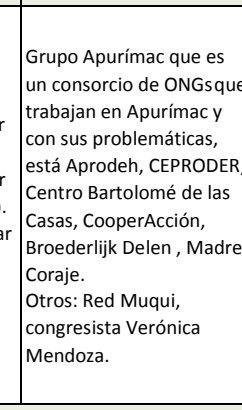 & 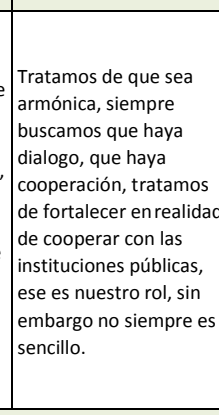 & 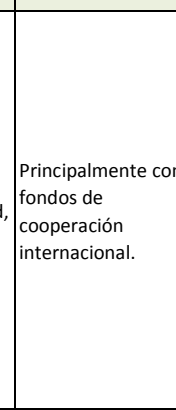 & 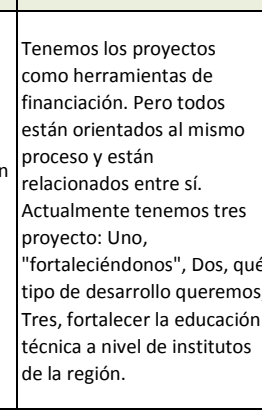 \\
\hline 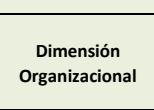 & 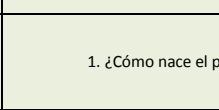 & rovecto? & 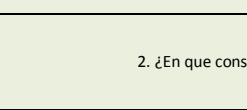 & 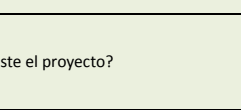 & 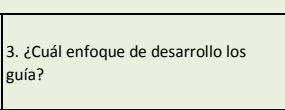 & 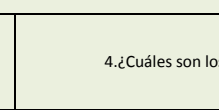 & 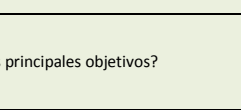 & 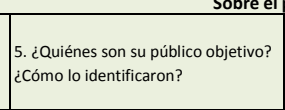 & 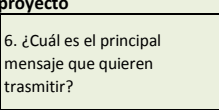 & 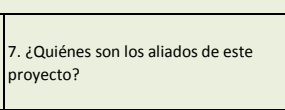 & 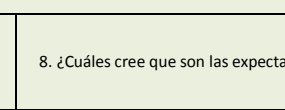 & 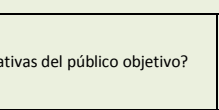 & 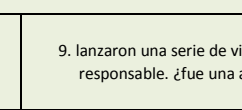 & 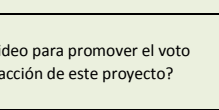 & 10. cualestie & 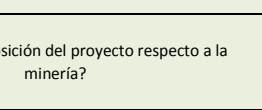 \\
\hline 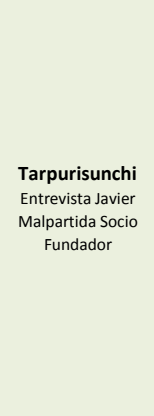 & 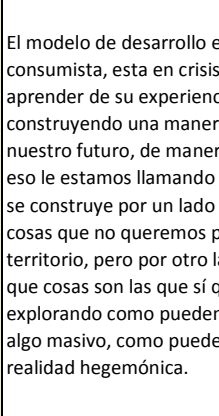 & 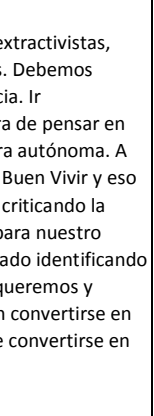 & 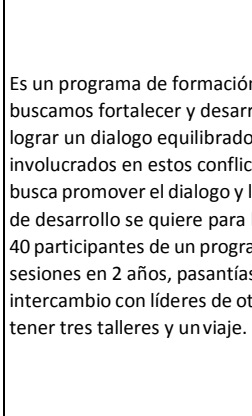 & 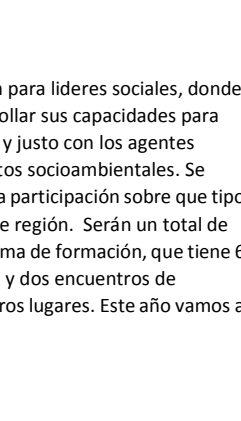 & 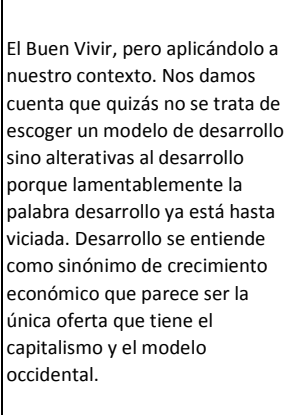 & 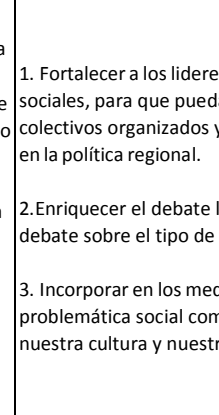 & 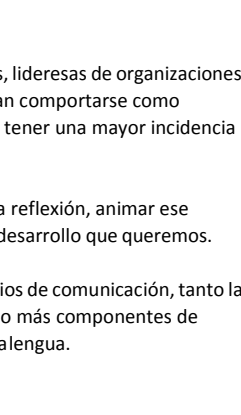 & 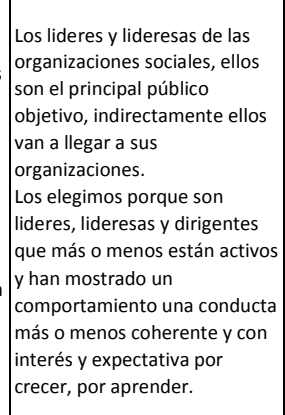 & 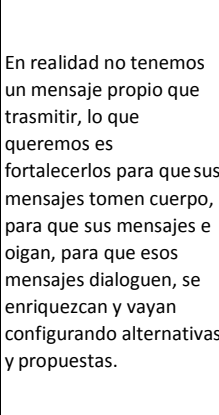 & El Grupo Apurimac & 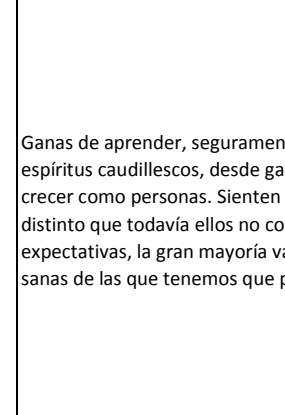 & 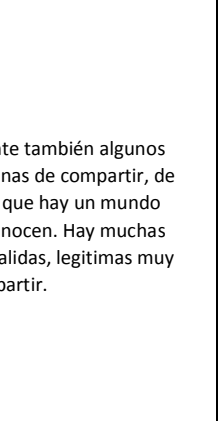 & 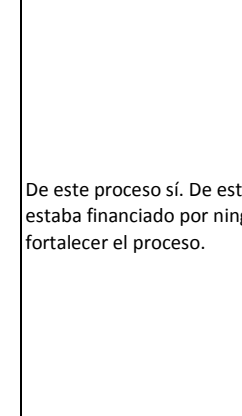 & 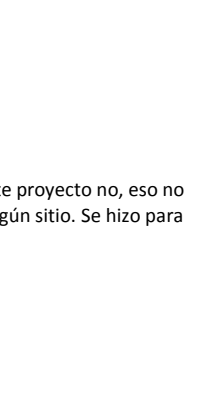 & 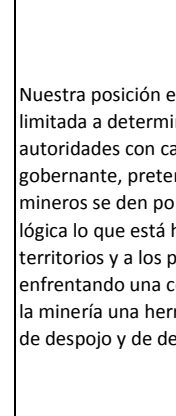 & 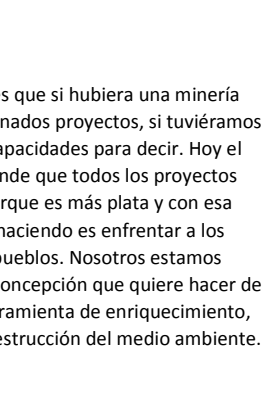 \\
\hline 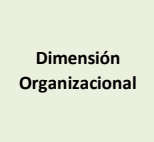 & 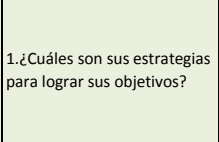 & & Alitarn? & 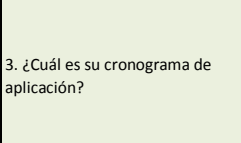 & 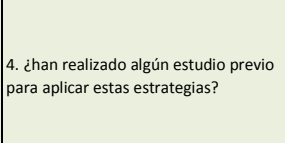 & 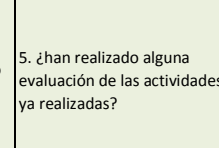 & 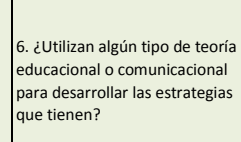 & 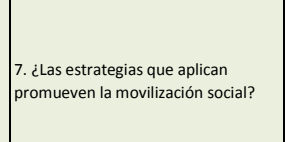 & 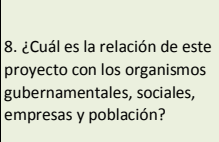 & & & & & & & \\
\hline 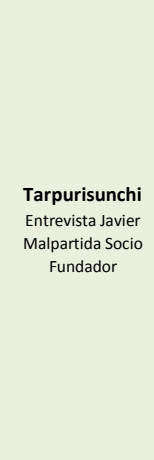 & 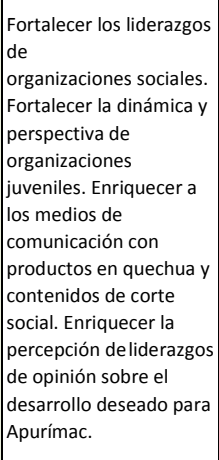 & 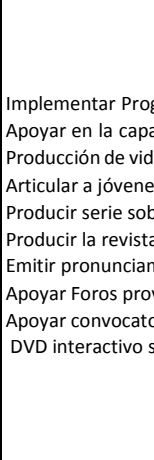 & 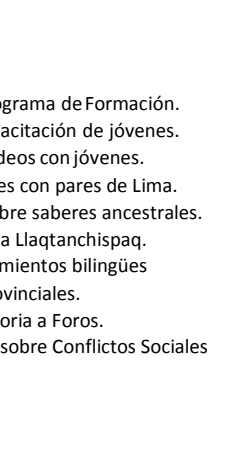 & Figurat 7 & 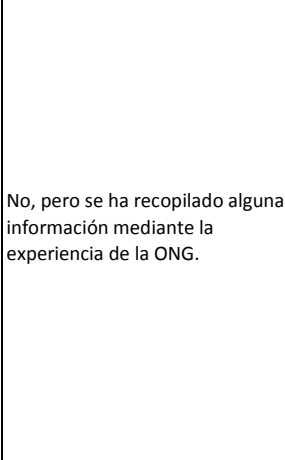 & No, todavia no. & 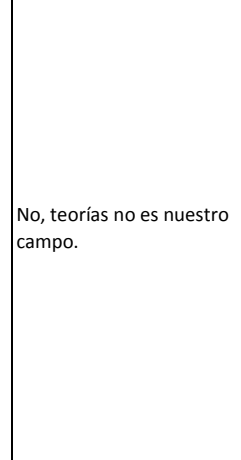 & 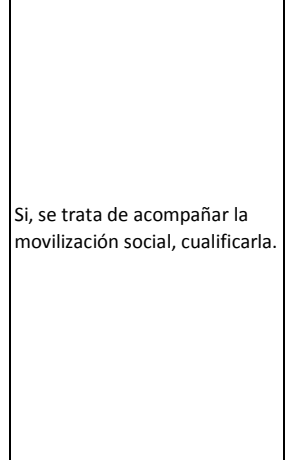 & 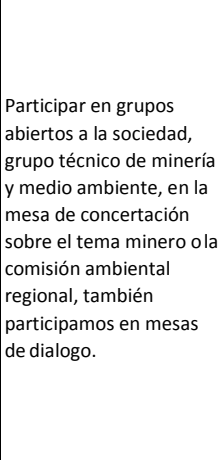 & & & & & & & \\
\hline
\end{tabular}




\section{ANEXO 2: GUÍA DE PREGUNTAS PARA DIMENSIÓN INSTITUCIONES ALIADAS}

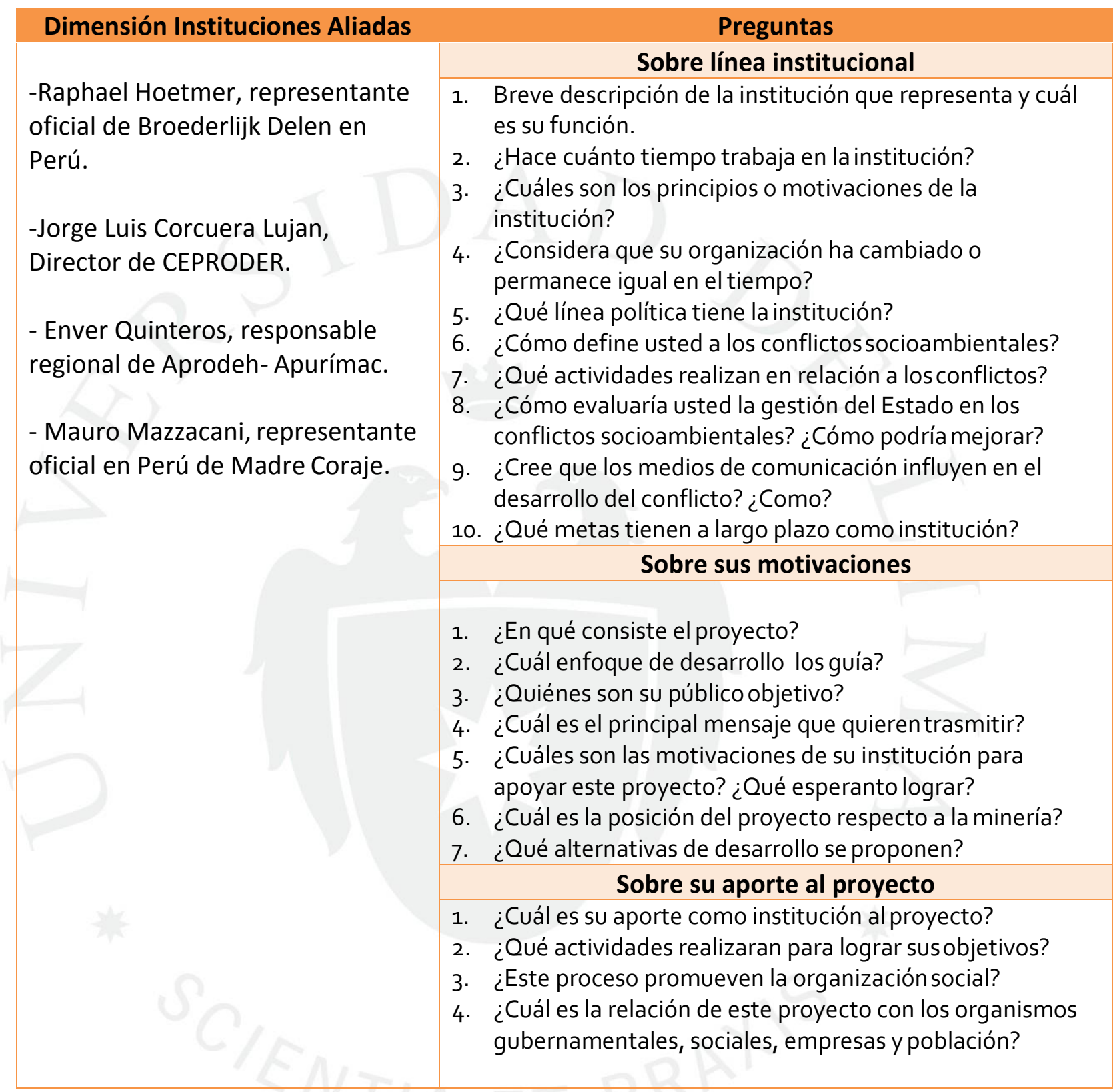




\section{ANEXO 3: TRANSCRIPCIÓN DE ENTREVISTA A RAPHAEL HOETMER, REPRESENTANTE EN PERÚ DE BROEDERLIJK DENLE.}

C: ¿Podrías darme una breve descripción de la institución que representas y cuál es la función que cumple?

R: Bueno, nosotros somos una organización de solidaridad internacional que nos consideramos parte de un movimiento global por el cambio, la justicia y la solidaridad, digamos como valores que deberían de dirigir las sociedades mundiales. De que además nos estamos enfrentando con problemáticas que son globales, que requieren de propuestas globales, por lo tanto trabajamos en nuestro país que es Bélgica, como también en diferentes países alrededor del mundo. Seis en África, seis en América Latina y Palestina. $Y$ bueno en el Perú tenemos un programa que este concentrado en Cusco y Apurímac. Tenemos unos quince proyectos entre, ellos esta lo de Tarpurisunchis. Nuestro trabajo consiste en dar seguimiento a los proyectos, hacer análisis del contexto para ver qué cosas apoyar o no. Pero también en organizar actividades colectivas, capacitaciones, etc. Con las distintas comparsas con quienes trabajamos.

C: ¿Hace cuánto tiempo trabajas en la institución?

R: Cuatro años.

C: ¿Me podrías decir cuáles son los principios o motivaciones de la institución?

R: Bueno, creo que algunos ya te los he mencionado ¿no? Que creemos que vivimos en un mundo donde el nivel de desigualdad e insostenibilidad y de injusticia que genera el modelo de desarrollo actual, nos debe llevar a plantear una trasformación. De cómo está organizado económicamente y políticamente nuestros países y el mundo en general. Entonces los principios que tenemos tienen que ver con eso, con la justicia social, la solidaridad. También un tema clave es que nosotros queremos, en los planes y las iniciativas que surgen desde debajo de las organizaciones y movimientos sociales, esto ¿no? Y bueno nuestro trabajo se dedica principalmente a colaborar con las poblaciones del campo porque en el mundo actual hay procesos de urbanización muy fuertes que lleva a que la gran mayoría de la población mundial ya vive en ciudades, mientras que en realidad también necesitamos mucho al campo, a la condición agrícola y queremos de que en ese sentido el trabajo de las comunidades y de las poblaciones rurales que hacen pequeña y mediana agricultura es fundamental y hay que apoyarlos.

C: ¿Ustedes tienen alguna línea u orientación política como institución? ¿Derecha, izquierda?

R: Bueno yo creo que los valores principios u horizontes que yo te he mencionado son más de izquierda que derecha. La organización de donde provengo surgió desde la teología de la liberación Belga, aunque no somos parte de la iglesia o el carácter católico que ahora es menos fuerte que antes, pero quizás más que describirlo políticamente es buscar los procesos de organización social de los pueblos. Creemos mucho en el derecho de los pueblos de crear y definir su propio destino y la obligación del estado de organizar los derechos de la población y de colaborar con esos procesos de construcción de formas de vida de los pueblos.

C: Pasando al tema de los conflictos sociambientales, ustedes ¿Cómo definen estos conflictos? ¿Por qué motivos creen que ocurren?

R: Bueno en mi opinión el término. Bueno pero es mi opinión, no tanto la de mi organización el termino de conflicto sociambiental no es un término adecuado porque es un término muy eufemístico que no expresa la profundidad de las disputas que se dan ahí. A que me refiero, a que los socioambiental nos hacen sentir que lo que hay en juego son temas sociales o ambientales relacionados a determinados actividades como la minería. 
Mientras que lo que realmente está en juego en estos conflictos es toda la forma de vida de la población. La minería transforma la cultura, las relaciones de género, las relaciones económicas, las relaciones políticas, las relaciones de poder, entonces lo que en realidad hay en estos conflictos son disputas territoriales, disputas de modos de vida que se expresan a través de los conflictos. $O$ sea un elemento que el termino de conflicto socioambiental no recoge bien es de que esos conflictos no son de hoy día, se escriben de largas historias de formas de negociación y de confrontación entre poblaciones locales y el estado peruano que buscan de alguna manera, renegociar el lugar que tienen esta poblaciones dentro de la sociedad peruana. No nos olvidemos que la sociedad peruana es una sociedad muy desigual muy excluyente también en lo cual las poblaciones indígenas y campesinas históricamente a través de distintos procesos han sido relegadas a esta categoría que Alan García una vez llamó, ciudadanos de segunda categoría. Entonces creemos que esas son disputas que tiene una larga historia que tratan del modo de vida y que son distintos en los distintos sitios. Tenemos algunos conflictos que podemos llamar conflictos de convivencia, donde las poblaciones no se oponen a la actividad minera pero si buscan negociar los términos bajo los cuales se puede o no se puede realizar. Que tienen que ver a menudo con temas de salud, temas del medio ambiente, del agua, del aporte al desarrollo local y de otro lado tenemos conflictos de resistencia o alternativas donde sí la población se opone a la actividad minera porque tiene otra propuesta de desarrollo de Buen Vivir, como vivir en su espacio local y ejemplos de esos son Islay, tambo Grande, Conga. Esos en realidad, esos conflictos son la minoría ¿no? En ese sentido no es tan cierto como a veces lo presenta el gobierno que en todo sitio la gente estaría tratando de impedir la actividad minera.

C: Ustedes como institución, ¿realizan alguna actividad para prevenir los conflictos?

R: Bueno nosotros no incidimos tanto en los escenarios de conflictos porque creemos que eso es responsabilidad del estado, pero si tratamos de apoyar procesos y políticas locales y regionales que deberían ayudar a que esos conflictos no se den. $O$ a que las poblaciones locales puedan ejercer sus derechos y supervisar mejor a la actividad extractiva en su territorio. Un ejemplo de ello es que trabajamos mucho en procesos de ordenamiento territorial que deberían servir para que las poblaciones y sus autoridades definan que tipo de actividades productivas económicas se realizan en que espacios de su territorio, entonces este tipo de procesos es fundamental para incidir donde sí y donde no realizar la actividad minera. Porque reitero que en el Perú se necesita minería como parte de su modelo económico, pero no puede ser la única actividad económica que se apoye. De otro lado una actividad que apoyamos mucho es todo el tema de vigilancia ambiental comunitaria que tiene que ver cuando ya se da la actividad minera. Es muy importante que las poblaciones tengan herramientas para saber si esta actividad está perjudicando al medio ambiente a la salud o a la calidad del agua y para eso esta propuesta de vigilancia ambiental es importante. $O$ sea son dos tipos de actividades que apoyamos que no directamente tienen que ver con los conflictos pero que podrían ayudar a que se encuentren formas institucionales y democráticas para canalizar los conflictos, para que no lleguen a expresarse de la forma como hemos visto y para que tampoco sean condicionados o reprimidos por el estado mismo.

C: ¿Cómo evaluarías la gestión del estado peruano en estos conflictos?

R: Bueno, ahí solo puedo dar mi opinión personal. Yo creo que el estado no está cumpliendo, adecuadamente su responsabilidad de ser un garante de derechos de las poblaciones. De que haya formas institucionales para decisiones sobre el territorio y de garantizar la regulación adecuada de la actividad minera que hace las poblaciones locales no sean demasiado perjudicadas por su actividad. Lo que quiero decir es que el estado peruano puede hacer más para no caer en conflictos. $Y$ más bien tener actividades colectivas que ayuden a definir donde sí y donde no realizar la actividad minera. Todo ello significa que el estado debería de asumir un rol más neutral, hoy en día parecer demasiado articulado los intereses de las empresas mineras.

C: En cuanto a medios de comunicación ¿Cómo crees que influyen en el conflicto? 
R: Bueno lamentablemente los medios de comunicación tienen grandes limitaciones en su función de informante de la sociedad, creo que muchos de los medios de comunicación también están muy articulados a ciertos intereses económicos, por lo tanto cubren de una u otra manera los conflictos. He creo que hay poco esfuerzo, hay excepciones, para entender lo que realmente piensa la gente que se está movilizando en torno a la actividad minera que les ha llevado a tomar esas decisiones. Entonces también hay un tratamiento que vienen reproduciendo a menú de que algunos somos más ciudadanos que otros.

C: ¿Qué metas tienen a largo plazo?

R: Bueno, yo creo que Apurímac se encuentra en un momento muy interesante pero muy crítico por su historia. En lo cual hay una disponibilidad de fondos muchos mayores que antes hay inversiones económicas de enorme escala que van a incidir en el territorio Apurimeño. Lo cual es un gran desafío a lo cual nosotros queremos aportar un poquito, porque somos una organización muy pequeña, tenemos muy pocos fondos en comparación con el estado con, los fondos sociales de las empresas. Pero queremos aportar a que Apurímac pueda desarrollarse desde su propia historia y cultura, desde una diversidad e actividades económicas importantes, incluyendo la agricultura. Y en lo cual sea la población Apurimeña que va definiendo el destino que quiere tomar ¿no? Entonces esperaríamos que después de todo este proceso Apurímac pueda surgir como una región más democrática, con una institucionalidad más sólida, con los derechos de las poblaciones más consolidados y con una confirmación, yo creo que sí, de su identidad histórica quechua. Apurímac es la región más quechua del país y más agrícola también del país. Entonces su busca que esta identidad no se tiene que dejarse de lado y se deben buscar formas como la expansión minera que se va a dar en esta región se realice en un cierto equilibrio con esas otras actividades.

C: Centrándonos en el proyecto de fortalecer capacidades en líderes sociales en un contexto de extractivismo, ¿me podrías explicar de qué trata el proyecto?

R: Bueno tiene distintas dimensiones, hay una dimensión más comunicativa que busca contribuir a que haya más debate público en Apurímac sobre la minería, sobre el modelo de desarrollo, sobre la identidad y la cultura. Hay otra parte que tiene más bien que ver con el fortalecimiento de capacidades de un conjunto de líderes de distintas provincias del país. Entonces básicamente consiste más en una escuela de líderes, en la cual los líderes que recibirán una capacitación de Tarpurisunchis, de otras instituciones. Más que todo se genera un espacio de encuentro de interaprendizaje entre dirigentes de las siete provincias de Apurímac. $Y$ eso les debería de ayudar para ejercer mejor su liderazgo, la gestión de sus organizaciones, etc.

C: ¿Se guían por algún enfoque de desarrollo?

R: Si bueno el enfoque final lo tiene que dar Tarpurisunchis ¿no?, pero la noción de Buen Vivir, no es un enfoque de desarrollo, es más un enfoque a la alternativa de desarrollo, pero tampoco es un enfoque totalmente acabado. Es más un lugar desde el cual podemos repensar como queremos vivir en nuestro territorio. Me explico, el desarrollo a menudo viene siendo una suerte de receta a ser aplicada en los territorios, una receta externa además que no toma en cuenta esas nociones de cultura, sueños, planes. Entonces hablar de buen vivir es hablar de la posibilidad de repensar como queremos vivir en el mundo actual, tomando en cuenta las ventajas y desventajas de la modernidad, de las distintas actividades económicas que promueve tomando en cuenta también nuestra historia, nuestra cultura y nuestros deseos de futuro, entonces si yo creo que el proceso de formación de líderes, toma en cuenta esta necesidad de crear nuestro propio horizonte de cómo queremos vivir bien. Para esto, el pensamiento indígena que tiene términos distintos Buen Vivir, Vida Digna, Vida Plena, dependiendo de su contexto. Es un camino de pensamiento que nos puede ayudar.

C: ¿Cuáles crees que son las expectativas de los líderes que participaran?

R: Yo creo que habrá distintos tipos de expectativas que dependen mucho de donde vienen los dirigentes y líderes. Yo creo que hay una parte de expectativas que tiene mucho 
que ver con el tema de la minería. Creo que la gente quiere saber cuáles son sus derechos, cuáles son sus opciones para negociar mejor en algunos casos para decir no, aunque eso es muy minoritario en el caso Apurimeño; entender lo que está pasando en sus territorios también, yo creo que eso es un parte. Otra parte seguramente también tiene que ver con el interés como termas los intereses sociales y políticos del país, porque además estamos en año electoral y la gente en Perú se mueve mucho en torno a la actividad electoral a menudo. Y que el acontecer tiene que ver con la gestión de las organizaciones, hoy en día las organizaciones en Apurímac se han debilitado mucho, entonces me imagino que también hay una expectativa por parte de la gente que participa en saber que herramientas hay para reconstruir sus organizaciones.

C: ¿Utilizan algún tipo de estrategia?

R: Sí claro, hay toda una estrategia pedagógica de temáticas a trabajar. También se trabajará seguro en un primer taller sobre las expectativas, pero esto en realidad es más la labor de Tarpurisunchis.

C: ¿Es una estrategia más pedagógica?

R: Yo creo que todo proceso siempre va a ser más pedagógico, lo pedagógico tiene que ver con la forma en que aprendemos. Entonces la estrategia general siempre va a ser una estrategia pedagógica, pero que seguramente tienen distintos tipos de herramientas como el intercambio, el tema de tener ciertos invitados para hablar de ciertos temas, la idea de generar inter aprendizaje entre distintos líderes.

C: ¿Cómo es la relación con los organismos gubernamentales o empresas del entorno?

R: Depende un poco de donde, no es lo mismo en cada sitio, pero sí en algunos sitios como Cotabambas algunas empresas no les gusta esos espacios de capacitación.

C: ¿En cuanto a lo gubernamental? ¿Municipios, gobiernos regionales, etc.?

R: Ahí también es distinto. En el caso del gobierno regional creo que aún está por ver qué posición va a tomar. El gobierno regional anterior no tenía una actitud muy positiva de estos espacios, pero creo que en gobiernos locales y provinciales hay mejores posibilidades.

\section{ANEXO 4: TRANSCRIPCIÓN DE ENTREVISTA A JORGE LUIS CORCUERA, DIRECTOR EJECUTIVO,}

\section{CEPRODER}

C: ¿Podría dar una breve descripción de la institución que representa?

J: Yo soy Jorge Corcuera Lujan, soy director de la ONG CEPRODER Apurímac. Que significa Centro de Promoción y Desarrollo Rural.

C: ¿Hace cuánto tiempo trabajas en la institución?

J: Desde 1994, me contrataron para el área de proyectos y ahora soy el director.

C: ¿A qué se dedica la institución?

J: Somos una ONG especializada en desde nuestro inicios en potenciar las actividades productivas de las comunidades, de los productores que viven en las comunidades, $y$ ligado a esta actividad la gestión del manejo ambiental.

C: ¿Cuáles son los principios o motivaciones de la institución? 
J: Bueno, el primero es un enfoque de desarrollo territorial. Es decir, tenemos toda una propuesta de desarrollo territorial pensando que vivimos en Apurímac, una región con montañas. Esta característica topográfica nos ha obligado a planificar estas acciones mirando este enfoque bien preciso respecto a la gestión del territorio, por un lado. Al hablar de la gestión del territorio implica otros enfoques, es hablar de la gestión de cuencas, del manejo de los recursos.

C: ¿Tienen alguna línea política que los guie?

$\mathrm{J}$ : Claro, nosotros tenemos claramente el tema la incidencia y el fortalecimiento de las capacidades. Bueno una política no partidaria, sino el principio del cuidado del medio ambiente principalmente en tecnologías limpias a favor del medio ambiente de que no degraden el contexto local y una política de total transparencia de educación horizontal de nuestras relaciones con la población.

C: ¿Cómo definen los conflictos socioambientales?

$\mathrm{J}$ : Lamentablemente, para nosotros es un desentendimiento de intereses entre la población y principalmente las autoridades. Nosotros vemos en las comunidades el conflicto de interés por el acceso a la tierra o el acceso al uso del agua, por las políticas de estado que en algunos momentos imponen políticas o normas desde el gobierno a favor de terceras personas.

\section{C: ¿Como institución que actividades realizan en la situación de conflictos?}

$\mathrm{J}$ : Bueno, nosotros al ser una institución ligada directamente a las actividades productivas y ambientales, nuestra línea es fortalecer capacidades de los productores locales, de líderes, de organizaciones comunales para que tengan mejor y mayores capacidades y alternativas frente a estos conflictos que se vienen. En ese sentido, nosotros hacemos claramente actividades ligadas $u$ orientadas a este tema. Por ejemplo: nosotros al aplicar la herramienta del ordenamiento territorial, ordenamos todo el territorio planificando sus zonas. Las comunidades tienen zonas de producción intensa, zona de pastoreo, zonas de manejo de humedales, zonas de recuperación natural, zonas de laimes, zonas de bosques... entonces, esta es una herramienta que nos permite la planificación, ocupar el territorio y evitar estrictamente los conflictos que hay entre familias, entre comunidades $y$ bueno proponer una posible alternativa de desarrollo que no se ve en cualquier comunidad de la sierra andina, del Perú o de Sudamérica. Eso es por un parte, lo otro que al fortalecer sus capacidades productivas miramos que los productores sean autosuficientes tanto en su alimentación como en su auto consumo, como también en generar ingresos. Al generar ingresos, se vuelven más autónomos, se diversifica sus demandas familiares y al ser autónomas ya no están migrando a buscar mano de obra a otros lugares, ya no están migrando o pensando en las actividades extractivas que en Apurímac es brutal en estos últimos tiempos. ya no están viniendo a buscar trabajo en las minas o también dedicarse a la actividad minera artesanal que si bien es muy atractivo pero que al tener al lado actividades productivas que les generan ingresos, que le permiten mejor vivir, entonces hacen mejor lo que toda la vida han hecho y enfrentan con buenos ojos otras alternativas al extractivismo.

C: ¿Cómo evaluarían la gestión del estado peruano con respecto a los conflictos sociambientales?

J: El estado peruano, primero es ineficiente. $Y$ segundo a pesar de la normatividad existente es una institución que trabaja a espaldas de su población. Está clarísimo que la política neoliberal del estado peruano favorece a los grandes empresarios. Ya sea a las empresas mineras, a otro tipo de empresas que generan inversión en el país, pero en Apurímac se ve que es a espaldas de la población, de la gran mayoría. ¿Por qué? Porque el estado así como concede, no tiene un sistema eficiente de control, de seguimiento y monitoreo de estas actividades, una entidad que esté permanentemente monitoreando los conflictos, etc. Yo pienso que la política del estado peruano está permitiendo que existan 
estos vacíos, o sea que a la par que concede territorios, concede a las empresas privadas privilegios, pues se olvidan de la otra parte de la población que también tiene derechos y se estén generando conflictos. $Y$ absolutamente nada hace, o sea tu no vez a un comisionado, a un institución del estado, ya sea nacional o regional, mediando, superando conflictos, etc., etc. Es por eso que creo que el estado peruano no se encarga de solucionar, más aun creo que existe un historial de represión, una cultura de la violencia y bueno eso es nítido y se ve claramente en nuestra región.

C: ¿Qué crees que podría hacer el estado para mejorar esta situación?

$\mathrm{J}$ : Yo pienso que, esto es triste decirlo, pero siempre estamos a la espera de que el estado siempre cambie, siempre tenga equipos eficientes, capacitados o que al menos tenga alguna institución que tenga esos alcances esa cobertura que haga eso. Pero, parece que fuese mucho pedir, cada año que pasa el gobierno regional es una ineficiencia total y se suele esperar lo mismo del estado. Se siente en estos últimos años que Apurímac es la última rueda del coche y creo que no tenemos una esperanza de que el estado pueda tener una labor más homogénea más inclusiva mirando estos temas.

C: Pasando al tema de medio ¿Crees que los medio de comunicación influyen en esto conflictos?

$\mathrm{J}$ : Claro, es totalmente cierto. Tu y yo sabemos que los medios de comunicación es el cuarto poder y claro que hay una influencia total, eso se ve en la prensa escrita, en la prensa televisiva a nivel del Perú, claro que sí influye. Y que también por los arreglos o la capacidad de pagar estos medios claro que influyen en las noticias en los conflictos, influyen en el tema mediático de estar azuzando a la población, mal informando muchas veces. Por eso estoy totalmente convencido que los medios si influyen en el desarrollo de este tipo de conflictos, ya sea a favor o quizá en contra también.

C: ¿Crees que hay un tratamiento correcto o incorrecto de este tipo de noticias?

J: Más incorrecto porque hay muy pocas instituciones que hacen capacitación o sensibilización respecto a cómo afrontar el conflicto, respecto a que normas están detrás de estos conflictos, como debe comportase una población, que pasos dar, que instituciones deberían ayudar a orientar a las poblaciones, etc. En realidad, hay un vacío en ese tema, porque podrían hacer eso, pero normalmente no se escucha, no se habla de eso.

C: ¿Qué metas tiene su institución a largo plazo?

J: Bueno nosotros desde hace un año hemos actualizado nuestro plan estratégico y para nosotros está clarísimo el aporte al desarrollo de la región en lo que hemos hecho todos estos años. Nuestra misión es promover modelos de desarrollo alternativos, ruralalternativos, en las comunidades de la región. Es decir, con lo poco que te he comentado, nosotros estamos trabajando modelos de desarrollo rural alternativos, ordenando el territorio, promoviendo actividades productivas, innovando, investigando y capacitando tecnologías ambientales agropecuarias ligadas a la zona andina. Esa es nuestra perspectiva, ahorita estamos construyendo un centro de innovación y tecnología única en la región andina del Perú y lo estamos haciendo en una comunidad que ha mostrado procesos de innovación muy interesante y pensamos que ese centro, a partir de ese centro se va irradiar la investigación, la participación al resto de productores de la región Apurímac y estamos pensando hacer diferentes pisos ecológicos en la parte alta para granos andinos, en la parte media para crianza de animales y quizás cultivos y en la parte baja para frutales. Vamos a tener tres centros de producción de centros de innovación y tecnología para que a la vez los productores puedan innovar, puedan adaptar, mirar, mejorar sus técnicas de producción y puedan normalmente comer bien productos de calidad y a la vez insertarse a los mercados locales y regionales. Eso es lo que va a hacer CEPRODER en el futuro y para nosotros ya está trazada esta meta, mejor dicho, ya estamos en camino. 
C: Ahora conversemos del proyecto para fortalecer a líderes sociales en contexto de extractivismo. ¿Podrías explicarme un poco más a cerca de este proyecto?

J: Nosotros, el Grupo Apurímac, hemos definido que nosotros solos no podemos, entonces tenemos que hacerlo a través de líderes sociales, organizaciones de base fuerte, capacitados que puedan equilibra los niveles de opinión de incidencia en la región. Entonces, al tener esta junta esta unión estamos empeñados en que este programa de formación de líderes, tenga ese sentido, esa orientación. Que sean líderes formados, no solamente para sentarse y escuchar las demandas, sino también para proponer, hacer llegar la opinión de la sociedad civil respecto a los procesos del contexto que se nos viene en el futuro, es vital. Solamente que a nivel institucional, tenemos un matiz respecto a otras instituciones. Nosotros hemos demostrado que en el proceso de los proyectos en CEPRODER que un líder se forma haciendo y practicando y revolucionando su comunidad del lugar donde viene. Un líder no solo se forma teóricamente asistiendo a talleres, este es un líder, para nosotros, formados a medias, en cambio, aquel líder hecho que produce la tierra, que ha demostrado que come bien, que tiene bien sus productos, ese es el líder que podríamos pensar. El perfil de un líder que podría invitar, liderar un cambio en la región. De esta forma, en el proceso del grupo Apurímac, nosotros estamos orientando a que esos líderes no solo sean de asistencia de talleres, que sean muy teóricos, que vayan a pasantías. De tras de ese líder tiene que haber una experiencia, una capacidad de cambio en su territorio en su comunidad. Este es el cello que le vamos a poner desde CEPRODER y también lo estamos compartiendo en el Grupo Apurímac.

C: ¿Cuál es el enfoque de desarrollo que los guía?

J: Como institución nuestro enfoque es clarísimo, es de manejo territorial. Como ya te he comentado, al estar viviendo en un sistema de montañas que son los andes para ir de un lugar otro tienes que subir y bajar montañas. Por consiguiente el enfoque que trabajamos es el de enfoque de desarrollo territorial. Dentro de este enfoque nos centramos en no solamente trabajar con una sola familia, sino con todas las familias. Pero, además de ese enfoque, también hay otros que animan nuestro trabajo. Es un enfoque de participación plena, de opinión de los pobladores que es sinónimo, de calidad de productos sanos, de buen vivir también. Un enfoque de derechos, donde todo lo que hacemos es por los derechos de un buen vivir, de acceder a servicios básicos, de un buen comer. Más 0 menos esos enfoques los estamos aplicando en nuestro trabajo.

C: ¿Quiénes son su público objetivo?

J: Principalmente líderes sociales, familias de las comunidades campesinas de la región Apurímac, incluye productores, mamás, jóvenes e hijos, prácticamente con todas las familias de la región andina.

C: ¿Cuál es el principal mensaje que quieren transmitir?

J: Bueno, una frase que podría definirlo sería el buen vivir, el buen comer, el buen producir. Nosotros, dentro de esta nueva mirada que le estamos dando al desarrollo es rescatar estos saberes locales, por lo tanto el buen vivir es el concepto más próximo que se acerca a todo lo que hacemos. Buscar y rescatar el buen vivir en estas poblaciones que para el estado prácticamente no existen y para mucha gente tampoco. Ya que ven como si esta población que está detrás de los cerros ni los conocen, ni los valoran y ni quieren saber de ellos.

C: ¿Por qué su institución apoya este proyecto? ¿Cuáles son sus motivaciones?

J: Es básico, tu cuando trabajas en este mundo de las ONGs de las instituciones privadas te animan aspectos más humanos y sociales que económicos y de otra índole. Entonces al iniciar el trabajo en CEPRODER, ubicamos e hicimos un mapeo, un diagnóstico de Apurímac. $Y$ entendimos que en Apurímac han tres provincias de mayor atención y concentración de proyectos públicos y privados por su naturaleza, estas son Abancay, por ser la capital, Andahuaylas por su peso poblacional juntos con Chincheros, son las 
tres provincias de mayor atención de cualquier programa del gobierno, de las instituciones públicas, privadas o etc. En estos lugares están los bancos, aeropuerto, instituciones públicas que se conocen. $Y$ el resto de las provincias están rezagadas, como olvidadas. Entonces, nosotros como institución decidimos trabajar en la provincia de Grau, porque era una provincia con esas condiciones, hace 20 años, de olvido y erosión de problemas sociales que nos animó a trabajar ahí. Además, mostrar en el tiempo procesos de desarrollo que reviertan estos fenómenos entonces eso es lo que estamos haciendo. Estos dos últimos años hemos decidido también tener un impacto mayor en la región, sin distraer la mirada obviamente. Entonces nos ha animado el olvido de todas las instituciones la post violencia política que se vivía en esa zona y nos ha animado también decir: como profesionales y como Apurimeño ¿Qué aportamos nosotros al desarrollo de Apurímac?

C: Entonces lo que ustedes buscan es capacitar y empoderar a la población mediante los líderes sociales y de familia.

J: Claro que sí. Ese es el objetivo, lideres con mayor capacidad, familias capacitas para gestionar, dirigir y que hagan una revolución productiva en su entorno.

C: ¿Cuáles cree que son las expectativas de su público objetivo?

J: Bueno la población ya nos conoce, eso es una gran fortaleza. Al saber que nosotros estamos trabajando en un lugar hay una expectativa de cambio. En estos tiempos, la expectativa ha cambiado un poco, es diferente trabajar en el 95, en el año 2000 que trabajar en el años 2011 - 2010 a trabajar ahora. Yo pienso que la población hace años, y también el estado peruano han tenido políticas de dar insumos, materiales, obras, etc. En estos tiempos no. La expectativa es de la con-participación es del con-financiamiento, es de las decisiones conjuntas, esa es la perspectiva que tiene la población, nos mira a nosotros como un aliado, como un equipo de técnicos que nos conocen, nos tenemos confianza y que con nosotros vamos a imprimir procesos de desarrollo únicos en la región.

C: ¿Cuál su posición con respecto a los proyectos de minería?

J: Bueno es un tema bien claro, difícil al inicio, pero que no podemos ir en contra de las políticas del estado. Las políticas de esta son ahora de apertura total a las empresas mineras, la región Apurímac no es la excepción. Apurímac en esto últimos años es "la niña bonita del estado peruano". Nosotros no somos una institución que trabaje en contra de esa corriente, la forma en que trabajamos es al costado de las comunidades para fortalecer esas capacidades que te he comentado, para actuar en estos conflictos. Tampoco somos anti mineros, lo que nosotros queremos es que si en un territorio existe una actividad minera pues entonces que la población tenga la capacidad de negociar. No un juego de casaquillas, no una serenata con la minera, que tenga la capacidad de negociar procesos de desarrollo de diez años, de quince años. Hemos hecho bastante reflexión sobre este tema.... (Se cortó la llamada)

C: Se cortó la comunicación, ¿Me podrías repetir lo último que me estabas diciendo por favor?

J: Te comentaba que nosotros no vamos en contra de la minería pero, si acompañamos procesos de alternativas a otro desarrollo. No somos antimineros, pero si nos gustaría que las actividades que se realicen cuiden el medio ambiente, que apliquen tecnologías que minimicen estos daños, que trabajan de forma coherente con el desarrollo de las comunidades. Yo creo que podrían trabajar con las comunidades para poder negociar esto modelos de desarrollo de los que estamos hablando. Que las poblaciones y comunidades puedan promover alternativas de desarrollo diferente a largo plazo y no solamente depende de lo que siempre hacen las empresas mineras en la región. Solamente se aparecen para regalar cosas en aniversarios, en torneos deportivos o traer artistas. Eso no es desarrollo.

C: ¿Qué alternativas al extractivismo se proponen? 
J: Primero, es promover y trabar la herramienta del ordenamiento territorial. Al trabajar esta herramienta, zonificas la propiedad y promueves tecnologías para recuperar el territorio. Trabajar la base productiva, la producción de productos locales, su inmersión al mercado. Darle valor a estas cadenas productivas que existe en todas las comunidades de nuestra región. Y cuidar por supuesto el medio ambiente. Hacer grandes proyectos de humedales, sembrar y cosechar agua, eso también importante. Cuidar, proteger estos humedales, de los lugares donde sale el agua, etc. Eso es lo que podríamos decir un modelo de desarrollo rural alternativo.

C: ¿Estas son las actividades que realizan para lograr sus estrategias?

J: Sí, además de la formación de líderes locales, lideres con ganas de aprender haciendo. Un líder que aporta al desarrollo no solamente de una formación en talleres, sino también en una formación práctica e inclusiva. Algo importante es la incidencia y la réplica de estos modelos de desarrollo en otros lugares y comunidades de la región Apurímac. Nuestra misión a mediano plazo es replicar en la región.

C: ¿De qué forma generan la participación y dialogo con la población?

J: Es una práctica nuestra que cualquiera de nuestras actividades tenga niveles de articulación con la población. A partir de eso nos animamos, a trabajar respetando sus actividades, tiempos y espacios. Nosotros no somos una institución que imponga, nosotros conversamos con ellos para tener una comunicación más horizontal y respetar sus procesos de autonomía, etc.

C: Las estrategias que utilizan ¿Promueven la organización social?

J: Claro que sí, todas les estrategias promueven la participación. La Minca es donde todos trabajan por un solo objetivo y el Ayni es a nivel familiar, trabajamos bajo estos principios.

C: ¿Hay alguna interacción de este proyecto con los organismos gubernamentales y privados como empresas?

J: Depende también de los estilos y los liderazgos locales. Pero siempre tratamos de articularnos con todos los organismos que apoyen estas propuestas. Los procesos que desarrollamos aportan a los objetivos de la región, buscamos trabajar con la gerencia de desarrollo de recursos naturales o también aporta a la gestión del agua. $O$ si trabajamos el tema del medio ambiente, aporta a la actividad forestal de Apurímac y así... Uno de los organismos claves son los municipios, los regidores electos en cada lugar. Ellos son las primeras autoridades con las que primero interactuamos y coordinamos

\section{ANEXO 5: TRANSCRIPCIÓN DE ENTREVISTA A ENVER QUINTEROS, RESPONSABLE REGIONAL DE APRODEH. APURÍMAC.}

C: Breve descripción de la institución que representa y cuál es su función.

E: Mi nombre en principio es Enver Quinteros, responsable regional de la asociación de Derechos Humanos Aprode, en Apurímac. La institución tiene 10 años en la región, casi 11 y estamos orientados a trabajar en torno a la promoción y defensa de los Derechos Humanos. En los primero $5-7$ años hemos estado trabajando en torno a la implementación de las recomendaciones de la comisión de la verdad y reconstrucción, eso tiene que ver con trabajar en torno en reparación penales de las víctimas de la violencia, el tema de justicia, es decir, la judicialización de casos de violación a derechos humanos, el tema de memoria para no olvidar lo que ha pasado y finalmente un tema de exigibilidad en torno a la búsqueda de desaparecidos. 
Después de esta primera etapa hemos estado orientados a trabajar en torno a la promoción en torno a otros derechos de sectores más vulnerables, por ejemplo a la población LGTB, campaña contra la discriminación y racismo, precisamente porque Apurímac está viviendo una coyuntura particular respecto a la llegada del extractivismo de la región y comenzamos a trabajar en torno a la defensa de promoción de derechos vinculadas a actividades extractivas.

\section{C: ¿Cuáles son los principios o motivaciones de la institución?}

E: Entendiendo que somos un país complejo, con características democráticas y autoritarias, ciertamente partimos inspirados en la ética de los Derechos Humanos, contribuir a la construcción de una sociedad, en la cual este clima de Derechos Humanos sea ejercida por todos y todas y cuando digo todos y todas me refiero a los sectores sociales, de género, generación entre otras, esa es la fuerza que nos motiva, y esto, cuando digo una sociedad democrática y autoritaria, entendiendo a su vez que tiene un conjunto de problemas estructurales que tienen que ver con distancias, discriminación, racismos, jerarquías.

C: ¿Considera que su organización ha cambiado o permanece igual en el tiempo?

E: Si bien los contextos cambian, nosotros también actualizamos que derechos promover y defender, esto no significa un abandono de temas anteriores, si bien la agenda BCR estuvo en auge después de que la comisión de la verdad entregara su informe, nosotros seguimos trabajando esta agenda en la región, aunque ciertamente con un menor énfasis, también por que se han logrado algunas cosas, quizá no como quisiéramos pero se han logrado avances en reparaciones, algo en busca de justicia, algo en tema de búsqueda desaparecidos, algo en tema de memoria; el avance en esta agenda no ha sido como hubiéramos querido, pero en todo caso en el tema de reparaciones si se ha avanzado, es decir si bien es una agenda entre el 2004 hasta el 2010 que tuvo cierta fuerza, y hoy la agenda extractiva es la que pesa, no significa que esa agenda la hayamos descuidado, si la seguimos trabajando pero con menor énfasis

C: ¿Qué línea política tiene la institución?

E: Nosotros partimos de la idea de que los Derechos Humanos, en realidad, si tienen un origen, consideramos que estos no tienen bandera ni de derecha ni de izquierda, pero también hay que reconocer que son los sectores de izquierda quienes la reivindican con mayor énfasis. Y si vale mi apreciación, el de derecha, centro tiene los mismos derechos que la gente que no piensa como ese sector, por eso nosotros postulamos por la universalidad de los Derechos, pero también precisamos que se nos asocia con sectores de izquierda y a nivel personal, muchos de nosotros tenemos esa motivaciones si se quiere pero eso no significa la negación de los Derecho del conjunto de peruanos y peruanas.

\section{C: ¿Cómo define usted a los conflictos socioambientales?}

E: Bueno, es una pregunta muy complicada, pero para nosotros sería el resultado a dos nivele: de causa estructurales y también de causas de momento de la coyuntura, es decir, en el caso de Apurímac, incluso la definición de los conflictos hay que repensarla bastante, a diferencia de Cajamarca, Arequipa donde hemos visto las noticias en los medios en el caso de conga que la conflictividad social reduce a la manifestación o desencuentro a dos grandes sectores, las comunidades campesinas contra las empresas transnacionales, ciertamente con el Estado ausente y no ausente dependiendo los contextos. En el caso de Apurímac es bastante distinto, la variable de la conflictividad mundial a estos dos actores se suman los propios conflictos que hay entre comunidades es decir intercomunal y también el aspecto intra comunal. Entonces siendo sincero considero que habría que repensar la definición de lo que significa la conflictividad social si le añades como hago mención a diferencia de Cajamarca y Arequipa, aquí los actores de las comunidades juegan un papel importante; no tendría una definición concreta, solo estoy manifestando la caracterización. 
C: ¿Cuáles son los principales actores que presentes?

E: Como te digo aquí no solo es Empresa contra comunidad, acá es en varias direcciones: empresa contra comunidad, comunidad contra comunidad. Dentro de las comunidades hay conflictos por que existe. Un fenómeno particular en Apurímac, es el tema del crecimiento de la Minería Artesanal Informal o como quieras llamarlo, es una variable muy Apurimeña, si bien sabemos que en Madre de Dios hay una minería Artesanal, incluso ilegal, aquí hay un fenómeno particular que se suma a eso que te mencionaba en cuanto a la rivalidad empresa comunidad.

\section{C: ¿Qué actividades realizan en relación a los conflictos? ¿Cuál es su nivel de participación?}

Ha sido un proceso gradual, en realidad nos estamos involucrando recientemente con este tema. Ha supuesto una deliberación interna para... como institución ver que capacidades tenemos para involucrarnos con este reto o desafío. Decíamos que en esta parte de Apurímac, de Abancay. Si bien hay no organismos gubernamentales (ONGs) no hay, más que Aprodeh la única institución que promueve la defensa y promoción de derechos humanos. Si se quiere, moralmente, había como una suerte exigencia social. No es que la gente nos exigiera, sino nosotros mismos teníamos así como que la necesidad de trabajar esos temas, porque si no ¿quién lo haría? Ese debate interno lo hemos tenido, entonces nos hemos impuesto la necesidad de revisar, informarnos sobre las experiencias nacionales, las internacionales y bajo este marco progresivamente hemos ido interviniendo ya... no directamente en conflictos sociales, aún. Porque como entenderás es un reto grande. Es decir, que yo sepa de los doscientos y tantos conflictos que la defensoría reporta mensualmente, apenas uno u otro ha tenido éxito a nivel de su resolución. La gran parte no ha sido resulta, están a nivel de latencia por lo menos. Entonces, que quería decirte con esto. En el caso de Apurímac precisamente por esa complejidad no es que participamos directamente en los conflictos, lo que si estamos haciendo es que en una zona en particular de Apurímac que se llama Aymaraes estamos trabajando en torno de la defensa de un grupo de comuneros, ciudadanos peruanos que han sido criminalizados, precisamente en su ejercicio de derecho de la protesta. En el 2013 una empresa minera, en este caso Southern Perú, estuvo según ellos manifiestan haciendo traslado de maquinaria pesada, ellos se opusieron y los buscaron en la comunidad los procesaron. Nosotros hemos entrado a hacer defensa legal de ellos porque sus derechos se han vulnerado. Ese es un primer campo, el segundo tiene que ver... ahí estamos con Tarpurisunchis y otros aliados del grupo Apurímac participando en un espacio mixto de concertación que se llama Grupo Técnico de Minería y Ambiente, este espacio está conformado por las empresas mineras, por el estado, por las ONGs y por las organizaciones sociales, es decir los cuatro actores involucrados estamos en ese espacio que tiene como función proponer políticas públicas en torno al tema ambiental. Entonces nosotros, desde el Grupo Apurímac, no estamos centrando básicamente en uno en la elaboración de un protocolo que permita ordenar como las distintas instituciones estatales, incluso la sociedad civil en su conjunto ver que responsabilidades cuales son las funciones en este caso básicamente del estado contienen para prevenir o involucrarse en los conflictos sociales. Entonces es un protocolo que permite ordenar estos roles tan confusos, poco claros que a pesar que esta normado, pero que están en el estado. Esta es nuestra puesta y desde ahí lo queremos es ojalá tener este protocolo que ayude por lo menos a prevenir en algo los conflictos que tenemos en Apurímac que por cierto son veintidós.

C: ¿Cómo evaluaría usted la gestión del Estado en los conflictos socioambientales? ¿Cómo podría mejorar?

E: Bueno el estado tiene, como me dijo alguien como mucha razón, tiene varios rostros. Una cosa es el estado central y otra el estado regional, incluso otra es el estado local, si bien tú los puedes ubicar con ese membrete a todos, sus características, sus concepciones y comportamientos son muy distintos. A nivel nacional creo que no variamos de la interpretación general respecto a este tema hay una miopía un sesgo de cómo entender estos conflictos sociales. Con esto que quiero decirte, que esta miopía 0 
sesgo pasa por no entender en el fondo que está pasando en la base de estos conflictos, sino se apela a este razonamiento simple de decir que hay un grupo de anti mineros, grupos organizando que están en contra de esto. $Y$ apropósito de esto, hay un conjunto de medidas, los denominados paquetazos ambientales que están a la orden del día para garantizar la reactivación de la economía a eso se suma la intención o un ánimo persecutorio a las instituciones que estamos abocados a estos temas. Te habrás enterado de que la AFI (Alliance for Financial Inclusión) ha definido una comisión para que en el sur andino entre comillas ver si las ONGs tienen sus papeles en regla, si sus recursos están siendo bien utilizados entre otras cosas... esa es la interpretación del estado central. A nivel del estado regional, nosotros entendemos que si bien hay una normativa frente a los conflictos con las grandes empresas que limita el papel de los gobiernos regionales, precisamente eso hace que los gobernadores regionales tengan un papel básicamente de espectador pese a los conflictos y aquí en el caso de Apurímac no es la excepción. Hemos tenido en enero un conflicto en Las Bambas en la cual el papel del presidente fue de espectador intentó hacer una que otra cosa pero sin mayor trascendencia, luego hubo un conflicto en Andahuaylas muy sonado, también ahí involucraba más que nada al estado central, no digo que el gobierno regional no haya hecho nada, ciertamente intentó hacer una que otra cosa, pero su papel está muy limitado por la normativa que hay, vemos entonces que en el gobierno regional no hay una estrategia ligada a la conflictividad social, ni en el actual gobierno ni en el anterior. $Y$ a nivel ya de la localidad, es decir, de las provincias o distritos allí también el comportamiento del estado es distinto, en un distrito es probables (dependiendo de las características del conflicto) de pueda alinear o con el gobierno regional o sus ciudadanos.

C: y en cuanto a los medios de comunicación ¿Cómo están influyendo en los conflictos?

E: A ver... difícil medirlo en el caso de Apurímac, es una muy bue pregunta, incluso habría que indagar un poco al respecto... A mí me parece que es un poco... polarizada. Como sabes la prensa nacional llega a todos lados y ha habido un discurso homogéneo muy vinculado a esta perspectiva que tiene el estado para abordar esta temática. Más bien desde las regiones hay como dos tendencias. Señalando que desde el grueso de personas que ejercen el periodismo en provincia y la mayoría no son profesionales de la comunicación ni mucho menos periodistas. La mayoría de ellos hace un trabajo poco profesional en este rol, yo diría que en la mayoría de los casos el tratamiento de esto temas son bastante sesgados o poco rigurosos. Pero si bien hay esto, hay un mínimo sector de los periodistas que si intentan abordar con un mayor cuidado y ciertamente con un enfoque distinto a la prensa nacional, un poco más crítica, un poco más desde la perspectiva regional.

\section{C: ¿Qué metas tienen a largo plazo como institución?}

E: Como deseo o ideal, es lo que te dije al principio. La posibilidad de que el enfoque, las perspectivas sobre derechos humanos este inserta en el conjunto de los ciudadanos y ciudadanas de la región, esto no pasa solo porque las autoridades toquen los temas de derechos humanos, menos cementos y más desarrollo de capacidades humanas. Sino que también la ciudadanía, debe conocer que es sujeta de derechos también es importante que se reconozca como sujeto de deberes y hay ahí una gran carencia que tenemos no solo aquí sino en el país como conjunto. Peor en todo caso, es eso. Que la ética de los derechos humanos contagie los diferentes sectores de la ciudad para trabajar en sociedad. Claro, por su puesto esa es la teoría, la realidad es bastante distinta...

C: Hay un gran trabajo todavía

E: Uff... enorme e interesante.

C: Pasemos ahora así a las preguntas sobre el proyecto de fortalecimiento de líderes... ¿Cuál enfoque de desarrollo los guía?

E: Tenemos al buen vivir como una idea, pero falta desarrollar su contenido. Un poco reconociendo lo que puede haber en Bolivia en Ecuador, si bien están como referencia 
como ideal, hay que desarrollar que significaría esto en Apurímac. Ya que se puede ver acá que la propia comunidad está abandonando el campo para hacer minería, entonces desde ese punto tenemos que pensar que contenido le das a este enfoque de buen vivir. Se tiene que aterrizar en la práctica, justo hemos estado conversando esto con el Grupo Apurímac, no solo ir con un discurso idealizador o más simpático, sino con una propuesta alternativa, eso es lo que tenemos que plantear bien.

\section{C: ¿Cuál es el principal mensaje que quieren trasmitir?}

E: Todo esto está pensado en torno a la posibilidad de trabajar modelos alternativos de desarrollo, es decir, nuestra lectura del extractivismo pasa en el caso de Apurímac es distinta en lo que viene sucediendo en otras regiones. Aquí aun cuando apareciera un anti minero radical, su discurso, me da la impresión y casi la certeza que ese discurso no pegaría en Apurímac. Por qué, porque aquí las comunidades, un porcentaje importante esta apostado por la minería artesanal. Supongamos que hay una empresa trasnacional, acá la gente estaría diciendo no la minería grande pero si a la minería artesanal. Acá es difícil, me parece, eso lo estamos discutiendo recién con el grupo, ese mensaje anti minero no tendría sentido aquí. Entonces lo que queremos transmitir es la posibilidad de pensar modelos alternativos de desarrollo. Ojala encontrar algún modelo agropecuario, ganadero, no sabemos aún, que puede construirse progresivamente en un modelo frente a la opción extractiva. A eso se suman otras variables como la posibilidad de construir región. Apurímac es tan particular que sus provincias son a veces muy enfrentadas una a la otra, Andahuaylas - Abancay por ejemplo, eso sería más o menos, el mensaje.

C: ¿Cuáles son las motivaciones de su institución para apoyar este proyecto? ¿Qué esperan lograr?

E: Como te comenté más temprano. En lo inmediato, desde el estado, es que estos tres niveles del estado reconozcan que no todo tiene que ver con economía, entonces la idea es que se reconozca que hay otros lados, de las capacidades, de derechos, de la recuperación del campo agrícola y desde la ciudadanía, por supuesto que tenemos que seguir trabajando la idea de que son sujeto de derecho pero también que tienen deberes y eso se suele olvidar. Aspiramos a que poder transformar nuestra ciudad, nuestra región, tal vez en una sociedad menos autoritaria, menos jerarquizada.

C: ¿Cuál es la posición del proyecto respecto a la minería?

J: Si compartimos la idea de que debe haber minería el tema es su gradualidad, lo que observamos desde el estado es una apuesta por el extractivismo de manera compulsiva, depredadora y eso si hace daño. Nosotros decimos no a esa compulsión que creo ya está dañando a Apurímac, frente a eso apostando por las poblaciones y pensar bien que ofrece la minería. Minería con responsabilidad pero también pensando en cómo ella puede ayudar a que otros ejes económicos, como la actividad agropecuaria, el turismo, puedan potenciarse, eso es más o menos lo que tenemos. Como te darás cuenta el tema extractivo de Apurímac, que empezó con el tema de concesiones, oculto a la población, y es precisamente en ese contexto que nos ubicamos en esta nueva coyuntura y buscar soluciones que nazcan desde la propia población.

C: ¿Cuáles son sus estrategias para lograr sus objetivos?

E: A ver, partiendo de un hecho concreto Apurímac ahora es la región que tiene 22 conflictos sociales, la que lidera, lamentablemente, a nivel país. Pero hay una variable adicional que junto a Ayacucho, Huancavelica, Huancayo fue la que fue más azotada por la violencia política. Porque te menciono esto, porque la violencia política no solo asesinado o desaparecido personas, ya sea por Sendero o las Fuerzas Armadas. Entre otras muchas cosas una de las consecuencias graves es que ha debilitado enormemente las organizaciones sociales y los liderazgos comunales y sociales que habian en Apurímac antes de la violencia, todo esto movimientos de liderazgos sociales, comunales, de la zona rural a lo largo de la violencia fueron desapareciendo debilitándose, luego con la dictadura de Fujimori aparecieron estos programas asistencialistas en los cuales solo 
se les enseño "a recibir pescado pero no a pescar" Entonces nos ubica en una región con liderazgos muy débiles, una variable en que las condiciones de estos líderes sociales de la región son distintas a otras regiones, por ejemplo con cusco donde hay un poco más de organización y fuerza. $Y$ es en el marco de ese escenario que hemos visto que, como estrategias más puntuales la identificación de las siete provincias en potenciales líderes, que podrían convertirse en actores no solo sociales, sino políticos de la región para mi esa es una principal estrategia que estaríamos planteando para este programa de formación.

C: ¿Qué actividades realizaran? ¿En qué consisten?

E: En principio hay un programa de formación, que será una suerte de escuela. Va a tener tres o cuatro módulos que van a durar tres, cuatro días cada una de ellas, en total suman unos doce días promedio, estos van a ser con intermedio de meses, el primero en agosto, luego en diciembre, el otro en febrero del próximo año. Por cada provincia hay una selección de liderazgos plural digámosle. Hemos identificado lideres jóvenes, mujeres, productores, una selección plural por provincia, ellos van a participar en el programa de formación, luego participaran en una pasantía que está por definirse el lugar, para pensar, conversar y ver las consecuencias o circunstancias del tema extractivista. Así mismo, está pensado una serie de foros en las siete provincias, con estas personas y otros actores para generar el dialogo. Finalmente un foro regional como epilogo, como final. Esa es la estrategia de formación y capacitación. Luego hay otra estrategia a nivel de campaña, ahí supone la idea de desarrollar una campaña sobre conflictos sociales, en la cual estamos trabajando un DVD interactivo todos los temas que te he mencionado, pero pensando cómo comunicar a la población. Esto va a estar acompañado visualmente de una representación teatral temática que va a visitar las siete provincias con el objetivo de sensibilizar a la gente sobre el tema extractivista, oportunidades y amenaza. Esas son las principales, por ahí una que otra más pequeña para reforzar, pero esas son las principales. Ah me olvidaba del tema de las sinergias, eso es importante mencionar, ya que dentro del Grupo Apurímac pese a las dificultades que hay, existe un importante esfuerzo por la unidad, por cooperar.

C: ¿Las estrategias que aplican promueven la organización social?

E: Esta es nuestra puesta, bajo este enfoque del contrapoder, es decir del poder de la ciudadanía, se pretende recuperar eso. Que los ciudadanos, ciudadanas, de la ciudad y del campo son los que al final tienen el poder, se ha perdido esa idea. Se entiende que el estado, los funcionarios, los políticos son los encargados y hay una suerte de asilamiento de la sociedad civil frente a esta agenda y eso es lo que creo que tenemos que recuperar y en esa perspectiva viene lo del programa de formación, pasantías, foros, etc. Con este grupo de liderazgos, nos proponemos eso, contribuir a la rearticulación del tejido social rural urbano y ojala también, que se hagan actores políticos en el mejor sentido de la palabra, si bien hay organizaciones ya formadas se debe proponer una agenda, por ejemplo hay muchas organizaciones de mujeres, pero que solo se centran en celebrar el 8 de marzo y está bien, pero no avanzas, se debería contar con agendas con perspectivas de la mujer, del enfoque de género pero en el marco del contexto que está viviendo la región.

C: ¿Cuál es la relación de este proyecto con los organismos gubernamentales, sociales, empresas y población?

E: Yo creo que el Grupo Apurímac, reconociendo que los derechos humanos no tienen bandera ideológica, no podemos negar el dialogo a ningún sector. Es decir, acá en Abancay encontramos algunas organizaciones no gubernamentales que "están a la otra orilla" no tenemos problema o discrepancia con ellas, tampoco con las empresas. De hecho en ese grupo técnico que te mencioné, la pluralidad de los actores permite el debate. Nosotros como Aprodeh somos secretarios técnicos de esa comisión, dialogamos con la empresa, con las organizaciones sociales, con ONGs. Otro tema, es que tampoco es que el espacio funcione de maravilla, las impresas participan irregularmente en ese espacio. Las organizaciones sociales, también participan irregularmente, el estado por el 
contrario su participación es regular pero yo lo veo más dos razones desconocimiento sustantivo si se quiere de lo que puede implicar este modelo extractivista y también lo veo por otra lado que la burocracia de los estados tienen muchas contradicciones. Finalmente las ONGs son las que más participan en este grupo técnico.

\title{
ANEXO 6: TRANSCRIPCIÓN DE ENTREVISTA A
}

\section{MAURO MAZZACANI, REPRESENTANTE EN PERÚ DE MADRE CORAJE.}

\author{
C: ¿Podría dar una breve presentación de la institución que representa?
}

M: Yo soy Mauro Mazzacani, soy responsable de los proyectos de desarrollo de Madre Coraje en el Perú. Madre coraje es una Eniecs significa una Organización No Gubernamental Extranjera que trabaja en el Perú ejecutando o financiando proyectos de desarrollo. Madre Coraje es del sur de España. Trabajamos principalmente en el Perú, ahora en los dos últimos años hemos entrado a África, Mozambique; y en el Perú trabajamos en dos regiones en específico, en Apurímac y en Huancavelica. En estas regiones por las razones de la pobreza, pobreza extrema, que hace de estas regiones las más afectadas del país, más o menos entre 15 y 18 años que estamos por acá. Hacemos proyectos en asocios con ONGs locales, somos parte del Grupo Apurímac, podemos decir que lo hemos impulsado en un comienzo, ha sido en comienzo un espacio de los socios de Madre Coraje para luego independizarse y devenir en un espacio más autónomo.

\section{C: ¿Cuánto tiempo tienes trabajando en la institución?}

M: Yo llegué al Perú en el año 2010 y estoy en Apurímac desde el 2011, primero como responsable regional y desde el 2012 como responsable país en el Perú.

C: ¿Cuáles son los principios o motivaciones de la institución?

M: Digamos que tenemos una misión que es de colaborar con los pueblos empobrecidos y en riesgo de exclusión del mundo. Empezó en el Perú Madre Coraje a raíz de una cita de su presidente, el presidente fundador de Madre Coraje que escogió al Perú como lugar de inicio. $Y$ con Perú nos relaciona una historia, como te digo, de ya casi 20 años, rica en relaciones humanas, en compromiso social. Madre Coraje tiene como principios la gratuidad, la reciprocidad, la solidaridad internacional y el perseguir la justicia social.

C: ¿han cambiado en el tiempo o permanecen iguales?

M: Las motivaciones permanecen iguales, porque las razones de fondo por las cuales trabajamos siguen siendo las mismas. Aunque en Perú hay bastantes avances en términos de crecimiento, no sé si decir en términos de desarrollo sobretodo relacionados a estas zonas del país ¿no? Pero aquí sigue habiendo necesidad de cooperación, entendida como cooperación entre los pueblos, no a nivel de naciones de países o de gobiernos sino a nivel justamente de gente que siente la injusticia social como un problema compartido y son las mismas razones que nos han impulsado ahora a trabajar en África, donde tienen otra gravedad, otro nivel y en donde hay mucho por trabajar.

C: ¿Tiene algún tipo de línea política?

Diría que sí, estamos construyendo nuestra línea política somos una asociación apartidaría. En este sentido la organización es muy estricta en no ligarse a ningún tipo de partido o movimiento político y mantenerse apartidarios. Pero yo creo que trabajar en movimiento sociales con la presencia en el territorio y posiciones netas y fuertes significa si mantener una line política.

C: ¿Cómo definirían los conflictos ambientales? 
M: Los definiría en principio por conflictos originados por un déficit democrático, por una falta de profundización de la democracia o por una falta del estado de derecho. Si en términos de una buena gobernanza hubiera la participación de toda la población en definir un modelo de desarrollo compartido o sino consensuado, no debería haber espacios para conflictos de este tipo. Del conflicto siempre puede nacer algo bueno, depende de cómo es manejado, puede deteriorarse, puede transformarse y llevar a una reorganización de la sociedad o del pensamiento o del modelo de desarrollo elegido.

C: ¿Cómo es su incidencia en los conflictos?

M: Nosotros como Madre Coraje, creemos que nuestro rol no es el de tener una incidencia directa. Por eso mismo trabajamos con organizaciones locales, aunque seamos internacionalistas seguimos siendo extranjeros $y$ al ser extranjeros $y$ meterse directamente a un conflicto a veces no favorece ni a la parte que tú quieres respaldar. Nosotros apoyamos la autonomía de los pueblos, de las organizaciones y en general la autonomía de la sociedad civil y en tomar sus decisiones. Nosotros estamos aquí para acompañar e impulsar procesos, pero teniendo bien en claro siempre cual es nuestro rol; de quedarnos no siempre más atrás, sino más bien al costado de las organizaciones.

C: ¿Cómo evalúas la gestión del estado peruano en los conflictos socioambientales?

M: Bueno, actualmente pésima claramente eso lo demuestra el número de muertos, el número de conflictos sociales y la degradación misma de estos conflictos ¿no? Con justamente el estado que asume posiciones que no son las que debería de tener en un estado de derecho. Como el uso inopinado de la violencia, no respetar los derechos de los manifestantes, sembrar armas, todo lo que se ha visto, la manipulación de los medios y la información hay una posición clara ahí que no va mucho por el lado de hablar con la población y de saber de lo que la población quiere y negociar. Sino negociar para que pase lo que ya está establecido, entonces no es una construcción democrática de consenso. Si no más bien intentar, primero por las buenas y luego por las malas de hacer pasar algo que para ellos sí o sí deben ir.

C: ¿Y los medios de comunicación?

M: eso es lo peor que he visto en el país. Claramente al servicio de poderes fuertes, que ni siquiera son el estado sino que son los poderes que justamente suelen tener más influencia en la mayoría de los países en un modelos liberar, las empresas transnacionales y las empresas más adineradas o más poder económico.

C: ¿Qué metas tienen a largo plazo?

M: En el Perú ya tenemos una meta a mediano plazo, más que a largo plazo, porque en el 2021 consideramos que terminará nuestra cooperación económica con el Perú. No nos iremos de aquí, estamos conversando con nuestro aliados para encontrar otras formas de seguir cooperando, pero la crisis de la cooperación internacional de un lado, el crecimiento del país del otro, el PBI y todo lo que sea; obliga a tomar decisiones respecto a la cooperación financiera, en ese sentido en el 2021 deberían de terminar nuestros proyectos, luego veremos si serán maduros los tiempos para hacerlo. Pero queremos que tanto los proyectos que son el medios, como los procesos que son los fines con los cual trabajamos, sean sostenibles a la hora de irnos entonces trabajamos para dar sostenibilidad a los procesos que impulsamos, que son de participación ciudadana, procesos de gobernabilidad, fortalecimiento democrático, superación de la pobreza, proyectos más netamente productivos, fortalecimiento de los derechos de las minorías como los grupos en riesgo de exclusión como pueden ser las mujeres, los pueblos indígenas originarios, el trabajo con las comunidades que están bien debilitadas en estos tiempo. Dar sostenibilidad a los procesos que trabajamos para q puedan seguir por si solos no vamos a resolver ningún tipo de problema. Estamos en un proceso de cientos de años y esperamos que la gente pueda lograrlo por si sola. 
C: ¿en qué consiste el proyecto?

Proyecto modelos de desarrollo, es un proyecto q estamos trabajando con el Grupo Apurímac pero más precisamente con Tarpurisunchis y con Aprodeh como ejecutores. EI proyecto tiene que ver con los modelos de desarrollo, es decir, definir los modelos de desarrollo endógeno y autónomo que se quiere, desde el pueblo de la región de Apurímac para el pueblo de Apurímac. Ahí hay varios componentes hay un tema q es patente en esta región es el tema de la debilidad de los liderazgos sociales. Tú decías el fortalecimiento de capacidades o el fortalecimiento de liderazgos tiene que ver justamente con dar las herramientas y los instrumentos a gente que se quiere involucrarse en la gobernanza de su región para poder seguir, vigilar, para poder crear consenso para poder hacer propuestas. Eso lo haces supliendo la base que falta, la base educativa que es el problema mayor de esta región como de otros lugares pobres. La gente quiere levantarse quiere responder, quiere participar pero no lo hace porque no ha sido acostumbra a hacerlo $o$ siente una inferioridad respecto a los conocimientos a la capacidad de desenvolverse, justamente a lo que podemos llamar inteligencia gubernamental, que se refiere a poder tener todos los conocimientos necesarios para poder opinar de forma atinada. Eso bloquea a la gente de opinar, participar, responder, para eso hay que trabajar temas de contexto, de autoestima, sobre temas de normatividad de reglamentación y sobre todo conversar mucho para que la gente pueda sacar su propia voz, su propia opinión que seguro que la tienen pero a veces no la pueden expresar. Entonces eso va desde el tema de fortalecimiento de capacidades. Luego, no solo los líderes sociales, los más pobres o los más excluidos, sino estamos frente a una sociedad apurimeña que es pasiva. Una sociedad que hasta en la clase media que vive en la zona urbana que tiene más accesos a la información le da igual, ha sido acostumbrada a que le de igual en su mayoría, entonces igual: fomentar el debate, mover las cosas, hacer que la gente piense y quizás se aleje un poco de la televisión de los modelos que le presenta la publicidad, el marketing... Eso y luego trabajar el tema de conflictividad, trabajarlo desde un acercamiento un enfoque de visibilizarían de los conflictos, primero. Hay conflictos que solo se visibilizan cuando sale el muerto, muere uno sale noticia; mueren dos ya se convierte en prioridad; mueren cinco y recién lo tenemos ahí todos los días en el noticiero. Hasta que no muera nadie parece que no hay un conflicto entre diferentes voluntades, diferentes miradas $y$ es en ese momento que hay que canalizarlo hacia algo positivo. Ahí se están trabajando varios mecanismos, hay un protocolo, campañas sobre el tema de conflictividad. Eso es más o menos lo que hace el proyecto y este proyecto es un proyecto medio atípico es lo que Ilamaríamos un meta proyecto, en el sentido que no se crea nada nuevo, es un proyecto que trabaja mediante procesos que tanto Tarpurisunchis como Aprodeh, Ceproder, Madre Coraje, ya venimos trabajando en nuestra cotidianeidad. A diario estamos en las reuniones en los espacios, haciendo la incidencia; con otros proyectos estamos fortaleciendo organizaciones, y este proyecto quiere sumarse para articular estos esfuerzos que quizás se pueden dispersar, dar un mínimo más de recursos, es un proyecto de tamaño pequeño para los que estamos acostumbrados a financiar y así fortalecer lo que ya estamos haciendo.

\section{C: ¿Qué enfoque de desarrollo los guía?}

M: mmm... Hablando de enfoques el enfoque de desarrollo humano, de derechos, el enfoque de género transversal considerando el enfoque de la mujer tanto aquí como en todo el mundo. El enfoque de desarrollo humano tiene que con la ampliación de las posibilidades de las personas, se conecta mucho con el enfoque de derecho, que tiene que ver con garantizar que a las personas tienen derechos, darle algo no que ellos necesitan, sino algo que ellos merecen, no me viene el sinónimo de derecho, pero es algo que esa gente no tenga. Derechos de primera, segunda y tercera generación, en este caso los estamos abarcando un poco todos, el derecho a tener un sustento, participación, a un medio ambiente saludable, el derecho a decidir sobre su propio desarrollo, como el caso de las poblaciones indígenas, cada uno debe de decidir cuál es su modelo, que cosa quiere para su territorio para su gente para su familia para sus futuras generaciones y que nadie venga a imponérselo desde más lejos.

El Buen Vivir, más que un enfoque es un concepto en construcción creo yo. Es muy difícil decir ahora que es el buen vivir, porque tú lo buscas en internet y encuentras trescientos 
documentos que te hablan sobre cosas diferentes. En principio si estamos de acuerdo y estamos metidos en colaborar en esa construcción de concepto, lo estamos haciendo en España. No se trata de un concepto universal, se trata de un concepto que está ligado a la tierra donde vives, a la cultura que tienes, a las raíces que te definen y a tu relación con la naturaleza, lo que puede ser Bien Vivir en España, por decir, trabajemos todos y que sean seis horas al día porque eso es suficiente y dediquemos el resto de nuestra vida a hacer otras cosas. Lo que puede ser aquí, Buen Vivir, un concepto muy distinto, estamos en eso pero no es algo que se tenga muy claro.

C: ¿Cuál es la posición del proyecto respecto a la minería?

M: la posición del proyecto con respecto de la minería es que buscamos que en la región haya una minería, primero socialmente aceptada, eso quiere decir que hay que negociar, si la sociedad acepta esa minería, muy bien. Si no la acepta, también y puede que no vaya la minería no. También se busca que haya una minería responsable con conciencia ambiental, debe acompañada de un sistema de gobernabilidad muy fuerte, en los gobiernos locales, provinciales, regionales; capaces de canalizar los fondos, los recursos que la minería puede devolver a la economía de la región e invertirlos de la mejor forma para el desarrollo de la región. No estamos hablando de pistas y veredas, sino de un proyecto de desarrollo claro para la región e impulsarlo a través de los recursos que lleguen. Sabiendo que la minería te dura 20 años, 30 años y luego se va. Entonces gobernamos para que la minería pueda hacer sus cosas o utilizamos a la minería para que el pueblo pueda llegar a la condición que quiere, esa es la disyuntiva.

\section{ANEXO 7: GUÍA DE PREGUNTAS PARA DIMENSIÓN}

\section{LÍDERES SOCIALES}

\section{Guía de preguntas para dimensión líderes sociales}

Dimensión líderes sociales

Seis líderes sociales

\section{Sobre su liderazgo y comunidad}

11. ¿Cuál es su nombre?

12. ¿Cuántos años tiene?

13. ¿Dónde vive?

14. ¿Cuál es su ocupación?

15. ¿Qué rol desempeña en la comunidad?

16. ¿De qué forma está organizada la comunidad/asociación?

17. ¿Qué labores cumple en este rol?

18. ¿Cómo toman las decisiones en su organización?

19. ¿Cuántas personas conforman su organización?

20. ¿Considera usted que su opinión es tomada en cuenta?

21. ¿Existe algún nivel de estatus o jerarquías entre los pobladores?

\section{Sobre relación con otros agentes}

8. ¿Cómo es la relación autoridades-población?

9. ¿Cómo percibe la relación entre el alcalde y los pobladores en general?

10. ¿Cómo percibe relación de su comunidad con otras comunidades?

11. ¿Qué medios de comunicación existen en la comunidad? 


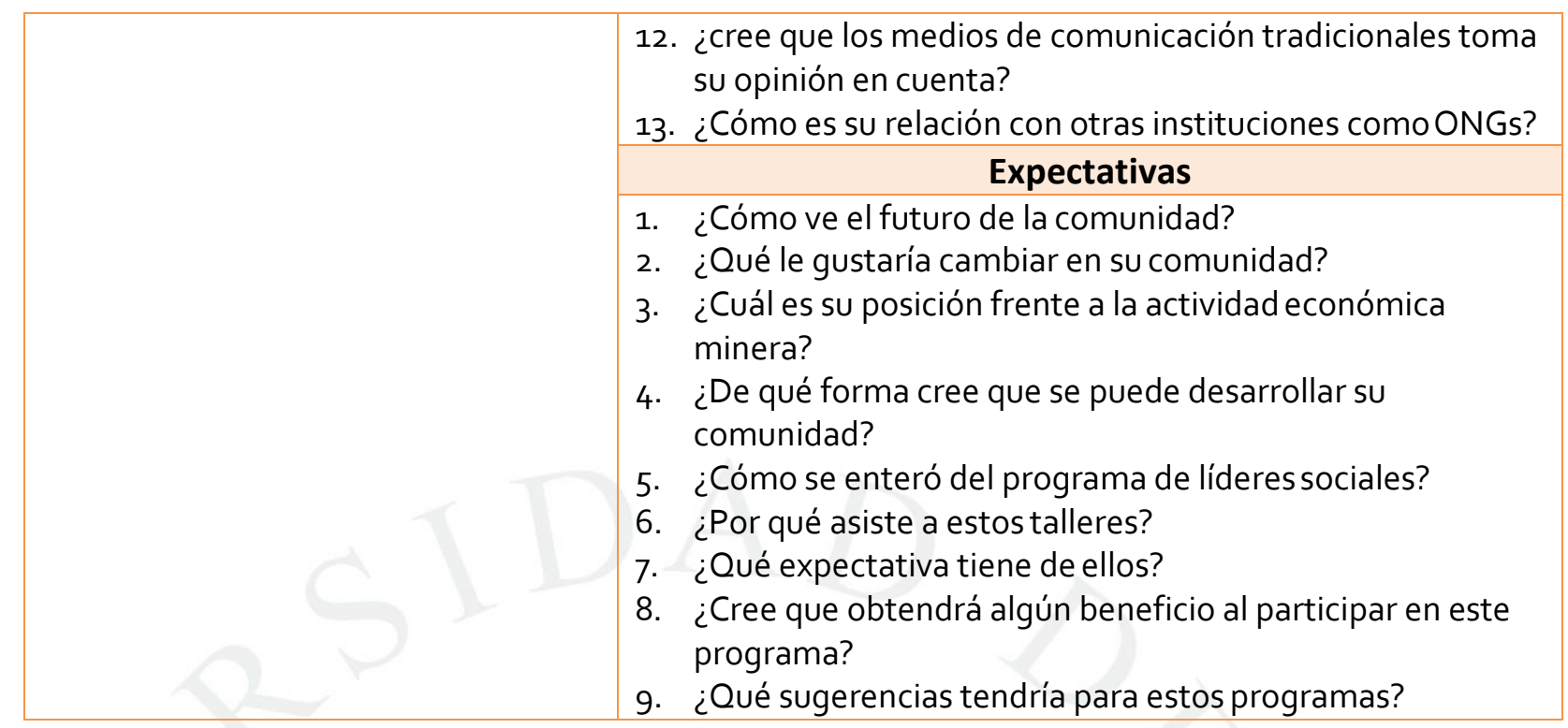

\section{ANEXO 7: SENTIDO DEL PROGRAMA Y METODOLOGÍA, ARCHIVO TARPURISUNCHIS}

\section{Sentido del Programa}

1.1. ¿Por qué es importante este programa?

El programa Atisunmi ha sido organizado para responder a la necesidad de formación y crecimiento planteada por líderes y lideresas sociales de las siete provincias de la región.

Es importante porque va a contribuir a fortalecer las capacidades de los liderazgos sociales existentes, así como a promover otros nuevos.

Además, en estos tiempos es especialmente necesario pues nuestra región vive momentos decisivos de cambio en todos los terrenos, que van a marcar la vida futura de cientos de miles de apurimeños.

En ese contexto, se espera que el programa contribuya a que las comunidades y organizaciones sociales se fortalezcan y participen de mejor manera en los próximos años, en las decisiones políticas que van a definir el rumbo económico, social, ambiental y cultural de nuestra región.

\section{2.- ¿A quiénes está dirigido?}

El programa está dirigido a líderes y lideresas sociales de toda la región. Busca una participación proporcional y equitativa, de liderazgos de diversos sectores sociales, debiendo participar personas de la ciudad y del campo; varones y mujeres; jóvenes y personas con mayor experiencia; de organizaciones tradicionales y de organizaciones que representan a nuevos sectores.

Se espera que I@s participantes reúnan los siguientes requisitos:

- Pertenecer a una organización social de su provincia.

- Ser dirigente intermedio o tener un liderazgo de base. 
- Saber leer y escribir.

- De preferencia, hablar el runasimi.

1.3.- ¿Qué vas a aprender?

El programa ha sido elaborado bajo el enfoque de competencias. Es decir, no solo va a tratar temas para que I@s participantes los aprendan, sino que va a buscar que al finalizar todos los módulos, I@s participantes sean más competentes y capaces.

Específicamente, se espera que al término de los 2 años de duración del programa I@s participantes van a poder:

- Alentar y orientar la construcción colectiva de un sueño de futuro que articule la modernidad con la tradición y saberes andinos.

- Animar y conducir acciones y procesos sociales que muestren formas de vida alternativas e incidan en decisiones políticas.

- Aprovechar la experiencia cotidiana y convertirla en aprendizaje permanente, tanto en el plano personal como organizacional.

- Incorporar en sus reflexiones y acciones cotidianas, los enfoques de derecho y de justicia. Tanto de justica de género, intercultural como ambiental.

En esa orientación, para que puedan desarrollarse o fortalecerse las capacidades arriba mencionadas, durante el desarrollo de los 2 años del programa van a trabajarse los siguientes módulos:

\begin{tabular}{|c|}
\hline $\begin{array}{l}\text { Módulo } \\
\qquad \frac{\text { Desarrollo v Buen Vivir }}{\text { ¿Qué futuro queremos? }} \\
\text { - Enfoques de Desarrollo. } \\
\text { - Política y Contrapoder. } \\
\text { - Buen Vivir. }\end{array}$ \\
\hline $\begin{array}{l}\text { Módulo } \\
\frac{\text { Aprendizaje Organizacional }}{\text { ¿Cómo seguimos creciendo? }} \\
\text { - Saberes y Aprendizaje. } \\
\text { - Enfoque Constructivista. } \\
\text { - InteligenciaEmocional. }\end{array}$ \\
\hline
\end{tabular}


aprovechamiento del tiempo. 
Habrá actividades presenciales, es decir, a las que tendremos que asistir personalmente, siendo estas las siguientes:

- Talleres Centralizados.- Serán 3 talleres al año, cada uno de 5 días, los mismos que se realizarán de manera itinerante en las diversas provincias de la región.

- Reuniones Provinciales.- Serán 3 reuniones al año, por grupos provinciales, para compartir y profundizar las lecturas encargadas en cada taller.

- Intercambio de Experiencias.- Será 1 reunión centralizada al año, en la que se concentrarán tod@s @@s participantes en la capital de la región para compartir saberes con liderazgos amigos. Igualmente, habrá otras actividades que no exigirán nuestra asistencia a algún lugar específico, y que podremos realizar en cualquier lugar y momento. Ellas son las siguientes:

- Lectura Personal.- Se entregarán 3 separatas al año, una en cada taller, con textos sobre los temas trabajados y preguntas para resolver luego en las reuniones de equipo provincial.

- Comunicación Virtual.- Cada participante deberá contar con un correo electrónico, de manera que por este medio se le haga llegar noticias actualizadas, documentos, videos o gráficos formativos.

\section{2.- ¿Cuál va a ser la metodología?}

La metodología que se usará en todas las actividades del Programa será vivencial y muy participativa, reconociendo y usando como punto de partida, la riqueza de saberes que tienen I@s propi@s participantes. De manera específica, la metodología del Programa buscará:

- Desarrollar Saberes Integrados.- Las competencias que se desea fortalecer, requieren de aprendizajes de distinto tipo que afecten el campo de los conceptos, los procedimientos y las actitudes. Ser competentes o capaces, significa saber, poder y querer hacer las cosas de mejor manera.

- Partir de la Experiencia de I@s Participantes.- Cada actividad formativa se iniciará usando y aprovechando los saberes existentes. Luego se pasara a alcanzar información para construir nuevos saberes, y finalmente se ejercitará y terminará de dar forma los nuevos conocimientos.

- Fortalecer el Aprendizaje Autónomo.- No se puede construir el cambio si nos limitamos a la repetición de enfoques, teorías o metodologías, por más valiosas que estas sean. No buscamos "transmitir" saberes indiscutibles, sino promover capacidades para pensar y recrear permanentemente el conocimiento existente.

- Motivar Aprendizajes para Transformar la Realidad.- Como en cualquier campo de la actividad humana, el conocimiento se convierte en un bien social, cuando afecta positivamente la vida de las personas. No pretendemos producir mejores conferencistas o eruditos. Queremos transformar desde la raíz la realidad regional.

\section{3.- ¿Qué recursos se van a usar?}

Para la realización del programa y de cada uno de sus módulos se usará una diversidad de recursos de apoyo.

Algunos de ellos se usarán en los talleres, otros en las reuniones provinciales, y otras más, en actividades no presenciales, vía comunicación virtual.

Se va a utilizar de manera combinada:

- Presentaciones virtuales. 
- Separatas

- Infografías.

- Videos.

- Documentos demostrativos.

Con ello, se alcanzará información clara, valiosa para la vida y acción social, así como útil para producir nueva información. 


\section{ÍNDICE DE FIGURAS}

Figura 1: Misión y Visión de la ONG Tarpurisunchis ................................................. 8

Figura 2: Ciclo de trabajo de las instituciones ................................................... 14

Figura 3: cuadro de actores más resaltantes en el ámbito de estudio ......................... 15

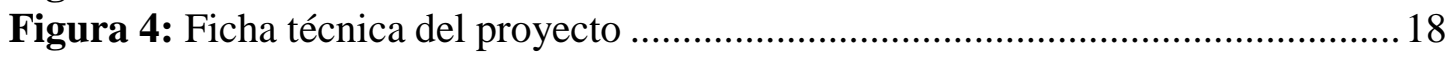

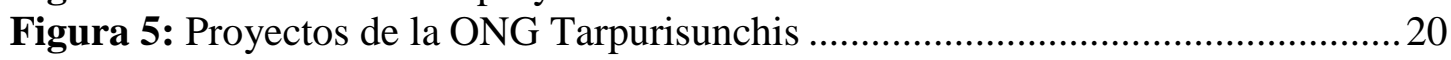

Figura 6: Ficha del desarrollo del programa, realizada por Tarpurisunchis ............... 21

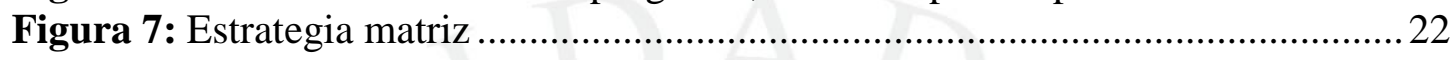

Figura 8: Línea de tiempo de desarrollo del programa .............................................2 23

Figura 9: Resumen de respuestas de las instituciones aliadas ................................. 26

Figura 10: Resumen de respuestas de los líderes sociales....................................28

Figura 11: Situación de las actividades económicas en Apurímac .............................31

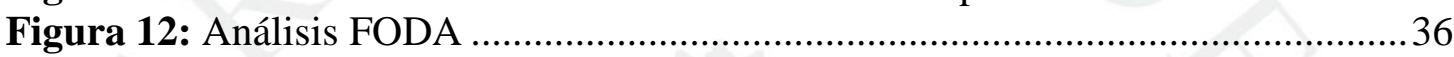

